\title{
Satellite Power System (SPS) State and Local Regulations as Applied to Satellite Power System Microwave Receiving Antenna Facilities
}

October 1978

U.S. Department of Energy

Office of Energy Research

Satellite Power System Project Office

Washington, D.C. 20545

Under Contract No. EG-77-C-01-4024

\section{DOE/NASA}

\section{SATELLITE POWER SYSTEM}

Concept Development and

Evaluation Program 
Ava1lable from:

National Technical Information Service (NTIS)

U.S. Department of Commerce

5285 Port Royal Road

Springfield, Virginia 22161

Price: Printed copy: $\$ 6.50$

Microfiche: $\$ 3.00$ 


\section{Satellite Power System (SPS) State and Local Regulations as Applied to Satellite Power System Microwave Receiving Antenna Facilities}

October 1978

Prepared by:

Allan D. Kotin

Allan D. Kotin Economic Consultants

Los Angeles, California 90024

for the

PRC Energy Analysis Company

McLean, Virginia 22102

Prepared for:

U.S. Department of Energy

Office of Energy Research

Satellite Power System Project Office

Washington, D.C. 20545

Under Contract No. EG-77-C-01-4024

\section{DOE/NASA}

SATELLITE POWER SYSTEM

Concept Development

and

Evaluation Program 


\section{NOTICE}

This report was prepared as an account of work sponsored by the United States Government. Neither the United States nor the United States Department of Energy, nor any of their employees, makes any warranty, express or implied, or assumes any legal liability or responsibility for the accuracy, completeness, or usefulness of any information, apparatus, product, or process disclosed, or represents that its use would not infringe privately owned rights. Reference herein to any specific commercial product, process, or service by trade name, mark, manufacturer, or otherwise, does not necessarily constitute or imply its endorsement, recommendation, or favoring by the United States Government or any agency thereof. The views and opinions of authors expressed herein do not necessarily state or reflect those of the United States Government or any agency thereof. 
This study reviews state and local regulation of power plant construction and operation as it may relate to solar power satellite receiving stations. These receiving antenna stations (rectennas) will each occupy a land area of 100-200 $\mathrm{km}^{2}$, and will receive microwave transmissions from the solar power satellite and convert them into electricity for transmission to the power grid. The long lead time associated with the SPS and the changing status of state and local regulation dictated emphasis on: (1) generic classification of the types of regulation; and (2) identification of "regulatory vectors" which affect rectenna facilities.

Following a brief summary of selected regulatory functions in 48 states, the report focuses on the four states of California, Colorado, Connecticut, and Florida. These four states all are identified by the Center for Policy Process as "be11wether" states and represent a useful cross-section in terms of size, location, and present regulatory framework. There is also a brief discussion of the extent to which analogues to U.S. state and local regulation exist in other countries.

A generic list of the types of regulation is developed and each type of regulation is classified by: (1) primary level of jurisdiction, e.g., state or local; and (2) estimated level of involvement with the SPS. Nine types of regulation are characterized by a presumabiy universal processing requirement for SPS. For most other types of regulation, SPS involvement is expected to be dependent on the particular location chosen. Federally pre-empted regulations, including microwave-related health regulations, are identified.

Among the regulatory vectors identified as having potential impact on the SPS are: centralization; resistance to new technology; increasing site size and remoteness; conflicts between land use and energy regulation; and increasing regionalization of planning without corresponding regulatory coordination.

If utilities are to be asked to commit to purchase SPS bulk power or finance construction in advance of the actual delivery of the power, both the rate regulators and the utilities will probably refuse without a federal guarantee of delivered SPS power cost.

The SPS may pose a major reliability problem because of the concentration of so much capacity in a single plant potentially subject to single-point failure. This may require significantly more instantaneous (spinning) reserves in a time of increasing regulatory resistance to funding apparently "excessive" reserves.

Reinforcement of ongoing parallel studies might be more cost-effective than further detailed independent study of the state and local regulations. The Berkeley Energy Facility Siting Study, ongoing studies by the Western Interstate Energy Board and the Southern Interstate Nuclear Board, and the current National Power Grid evaluation project should all be considered in this regard. Specific issues which appear to merit further SPS-focused research include: reliability and reserve requirements; prospects and prerequisites for regional regulation; and the need for federal energy cost guarantees as a condition of advance commitment. There is also a need for further integration of the existing research on state and local regulation with the ongoing research on SPS land use and siting. 
The author acknowledges the following people for their review of the first draft of this White Paper:

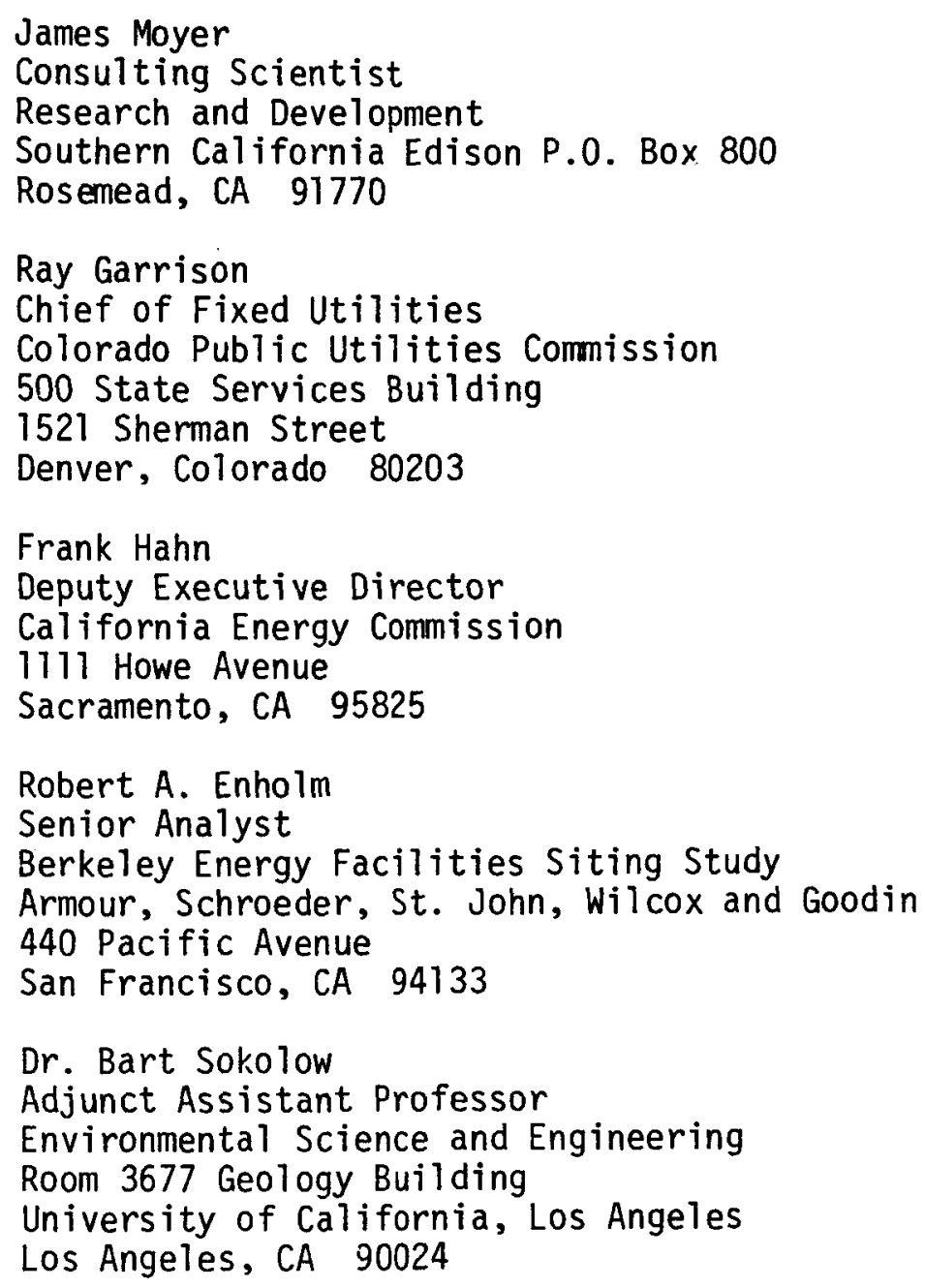




\section{ACKNOWLEDGEMENTS}

The extensive field research required for this report was conducted primarily by Sherri Cann, Economic Consultant, who also participated actively in the analysis and synthesis of key issues. Additional assistance on issues in rate regulation and power plant siting regulation in other countries was provided by Nancy Boxer of Economics Research Associates. The author would particularly like to thank the staff of the Berkeley Energy Facility Siting Study for their invaluable assistance in formulating an overview of key regulatory issues and also in providing the study team with key references to other ongoing study efforts. 


\begin{tabular}{|c|c|c|}
\hline & & Page \\
\hline I. & INTRODUCTION & 1 \\
\hline II. & $\begin{array}{l}\text { METHOD OF APPROACH AND LIMITATIONS } \\
\text { General Approach to Data Collection } \\
\text { Specific Data Collection Efforts in Four States } \\
\text { Need for an Indirect Approach to SPS Regulation }\end{array}$ & $\begin{array}{l}3 \\
3 \\
3 \\
4\end{array}$ \\
\hline III. & $\begin{array}{l}\text { EVOLUTION OF POWER PLANT REGULATION } \\
\text { Siting and Facility Need Regulation } \\
\text { Financial and Rate Regulation } \\
\text { Selected Regulatory Functions by State } \\
\text { Overview of Regulatory Process in Four States }\end{array}$ & $\begin{array}{r}7 \\
7 \\
8 \\
10 \\
15\end{array}$ \\
\hline & $\begin{array}{l}\text { CLASSES OF REGULATION } \\
\text { Classes of Regulation by Type } \\
\text { Apparent Applicability of Regulation to SPS } \\
\text { Regulations with Universal Processing Required } \\
\text { Regulations with Location-Dependent Involvement } \\
\text { Regulation Subject to Apparent Federal Preemption } \\
\text { Other Types of Regulation, Not Otherwise Classifiable }\end{array}$ & $\begin{array}{l}21 \\
21 \\
21 \\
26 \\
31 \\
33 \\
35\end{array}$ \\
\hline V. & $\begin{array}{l}\text { LIMITED APPLICABILITY OF PRESENT REGULATORY FRAMEWORK } \\
\text { Atypical Physical Parameters } \\
\text { Inadequacies of Existing Regulation with Respect to the SPS } \\
\text { Prospects for Further Federal Involvement }\end{array}$ & $\begin{array}{l}37 \\
37 \\
38 \\
38\end{array}$ \\
\hline & $\begin{array}{l}\text { KEY REGULATORY ISSUES IN THE REGULATION OF SPS } \\
\text { Siting and Facility Regulation } \\
\text { Financial and Rate Regulation } \\
\text { Reliability and Reserve } \\
\text { Regionalization of the Regulatory Process } \\
\text { Interaction with Federal National Power Grid Program }\end{array}$ & $\begin{array}{l}41 \\
41 \\
47 \\
48 \\
49 \\
51\end{array}$ \\
\hline VII. & $\begin{array}{l}\text { "SUB-NATIONAL" POWER PLANT REGULATION IN OTHER COUNTIES } \\
\text { Scope and Definition of Analysis } \\
\text { Preliminary General Findings } \\
\text { Regulatory Patterns in OECD Counties } \\
\text { Third World and Developing Nations }\end{array}$ & $\begin{array}{l}54 \\
54 \\
54 \\
55 \\
56\end{array}$ \\
\hline VIII. & $\begin{array}{l}\text { RECOMMENDATIONS FOR FURTHER STUDY } \\
\text { Limited Value of Further Independent Procedural Research } \\
\text { Reinforcement of Ongoing Studies } \\
\text { Need for Additional Issues or Vectors Research } \\
\text { Interface with Land Use and Siting Studies }\end{array}$ & $\begin{array}{l}57 \\
57 \\
57 \\
58 \\
58\end{array}$ \\
\hline
\end{tabular}




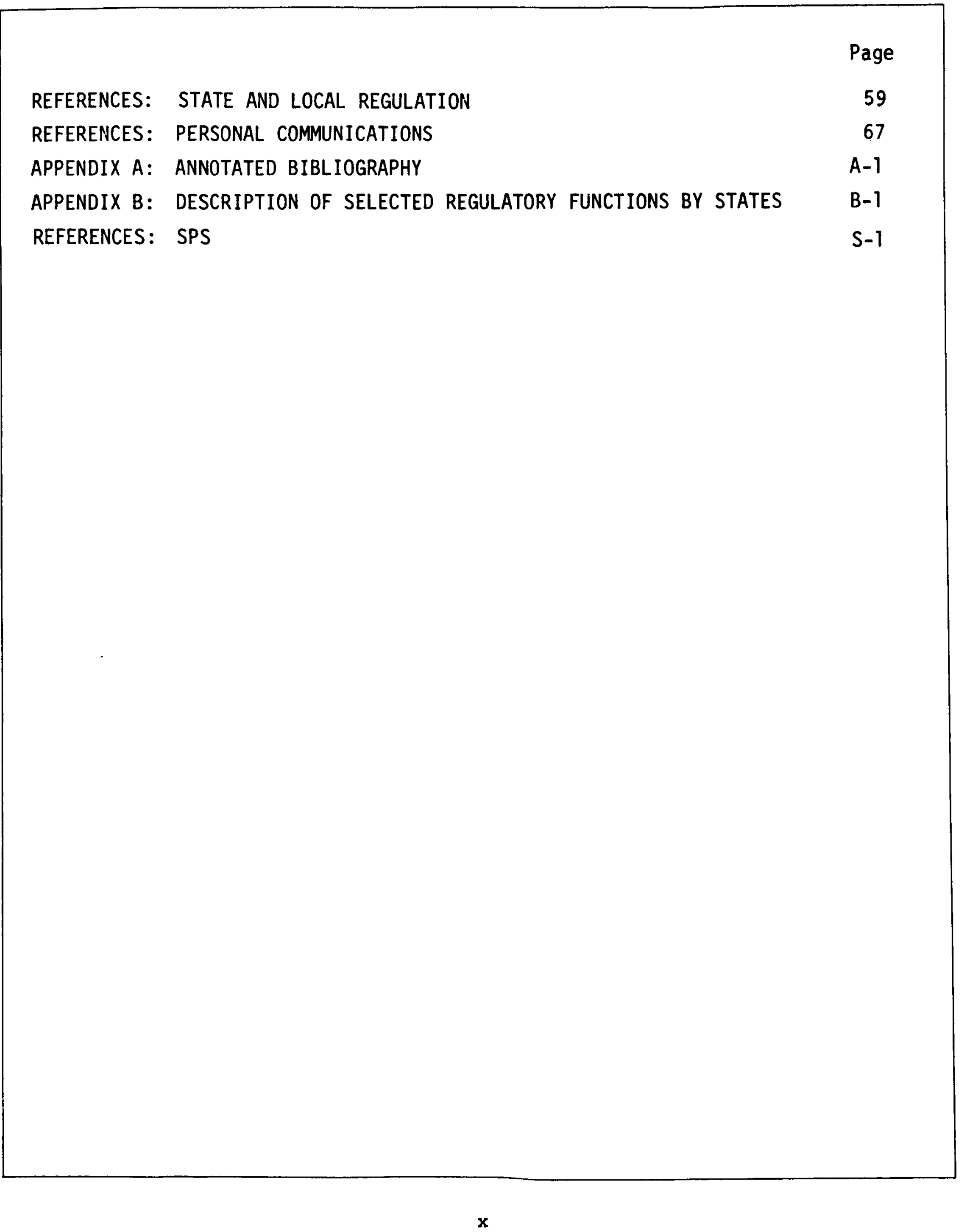




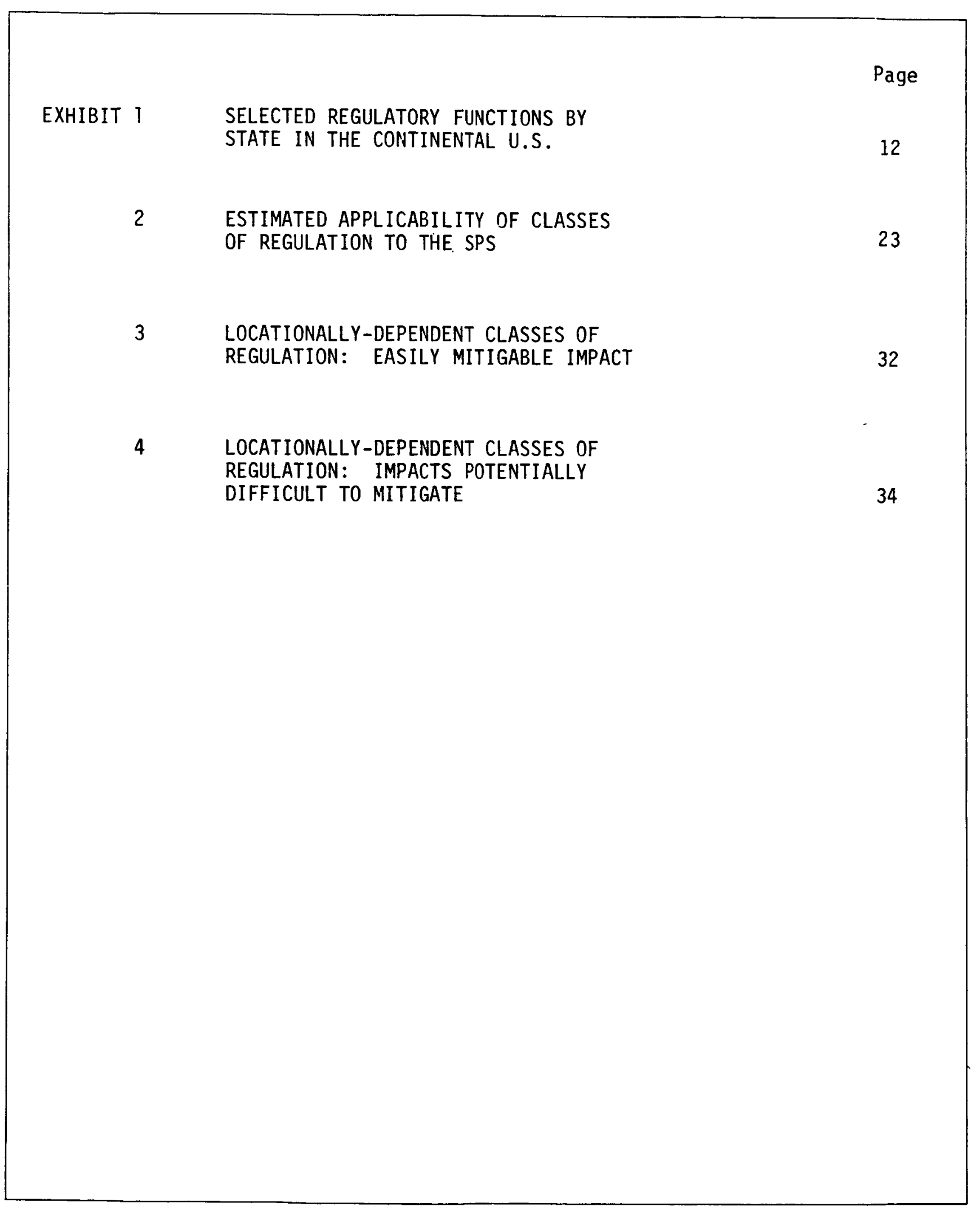




\section{INTRODUCTION}

The U.S. Department of Energy and the National Aeronautics and Space Administration are investigating a potential new source of energy called the Satellite Power System (SPS). The SPS concept involves placing a satellite equipped with large solar cell arrays in orbit around the earth. The energy collected by the satellite is converted to microwaves and beamed to a receiving station located on the ground. Both the satellite and the rectenna (receiving antenna) are on the order of one hundred square kilometers in size and the system is designed so that each rectenna will provide 5,000 megawatts (five gigawatts) to the utility grid. The total land area required by each rectenna facility, including provision for a microwave buffer zone, is estimated at approximately 50,000 acres or 200 square kilometers.

This study, which is being prepared for the Department of Energy under a subcontract to PRC Energy Analys is Company, is designed to determine what kinds of regulations should apply to rectenna facilities at the state, local and othercountry level ${ }^{1}$ in order that the SPS could operate and that the available power could be distributed to potential consumers.

The critical elements in the SPS rectenna description in relation to state and local regulations include:

1. its large capacity (five gigawatts per rectenna),

2. the unusually large land area needed $(50,000$ acres, including the buffer zone),

3. an initial operating date in the year 2000 ,

4. presumably remote non-urban locations due both to the large land area required and the potentially adverse microwave effect on radio reception in urban areas, and

5. the new and largely untested technology of the SPS which may still not be fully validated at the time of initial advance commitments by participating utilities.

The balance of this report is organized into six additional sections. Section II provides a description of the method of approach and certain critical limitations in the analysis. Section III provides a brief summary of the evolution of power plant regulation in the United States with a more detailed overview of the current regulatory process in four selected states. The classification of the types of state and local regulation is discussed in Section IV. Section $V$ deals with the limited applicability of present regulation to the SPS. The potential in the regulation of the SPS, examined in terms of issues rather than

TFederal regulations are the subject of another White Paper. 
as a reflection of present procedures, is the subject of Section VI.

A very brief treatment of power plant regulation in other countries is provided in Section VII and the report concludes with recommendations for further study (Section VIII).

There are also two appendices, the first of which is a brief annotated bibliography of recent and ongoing parallel studies of power plant siting and utility regulation. Appendix $B$ provides a detailed review of regulatory processing in several particularly sensitive areas for the four selected states. 


\section{METHOD OF APPROACH AND LIMITATIONS}

\section{GENERAL APPROACH TO DATA COLLECTION}

To some extent, the data collection effort was separated into two related but independent components. The first of these dealt with the extensive body of literature on facility siting and environmental regulations surrounding the establishment of new power plants in the United States. This is the area in which there has been the most recent development and in which regulatory processes are most rapidly evolving.

The second element in the data collection was a brief overview of the rate and financial regulation by the various state commissions.

In the initial study effort, specific attention was given to the identification and collection of various overall guides, handbooks and directories of siting and environmental regulations as they applied to power plants.

A critical element in both the data collection and subsequent analysis involved identification, review and personal discussion with the authors of other ongoing "overview" studies of the siting and regulatory process. Three sources in particular were found to be of unusual value in this regard. These included an ongoing study of critical issues in power plant sitings by the Lawrence Berkeley Laboratories and the Earl Warren Law Institute of the University of California (the Berkeley Energy Facility Siting Study, or BEFS Study; see Appendix $A$ and References 77 and 79). Staff members for this study were an invaluable source of information. In many respects this research represents an important over lapping of the current study effort al though it more explicitly focuses on current technology and coal-fired power plants.

Other important ongoing parallel efforts were identified with the Southern Interstate Nuclear Board (SINB) (81), the Western Interstate Nuclear Board (now known as the Western Interstate Energy Board) (89), and the National Academy of Public Administration (66). These and other relevant works are described in summary form in the annotated bibliography (Appendix A).

\section{SPECIFIC DATA COLLECTION EFFORTS IN FOUR STATES}

Because the variation in state regulation is so broad, it was clearly outside the scope of this study to attempt to analyze power plant siting, financial regulation and environmental regulation in a 1148 conterminous United States. Instead, an effort was made to identify several states which were particularly representative of patterns in energy and power plant siting relation. The four states selected were California, Colorado, Connecticut, and Florida.

These have been identified as "bellwether" states by The Center for Policy Process in their publication known as the "Trend Report" (25). Their analysis of 
public policy changes indicates that many aspects of national life, notably including regulatory processing, often occur first in one of these four states and later spread to others.

These four represent a useful cross-section of regulation processing and geographical constraints. California and Florida are apparent leaders in energy regulation with some of the most highly evolved siting and environmental rules. The four as a group represent a very diverse set of regulatory approaches. Furthermore, the four states represent a wide variation in land area and in population, as well as widely different levels of population growth and industrial expansion. Three of the four are coastal states and hence face the problems associated with coastal zone management.

There were extensive personal communications with regulatory personnel in each state. These are summarized in a second set of references identified as Personal Communications, also in Exhibit B. The comments and interpretations contained in this report reflect a synthesis of the various inputs received from a wide range of individuals and are not always specifically sourced to one person.

\section{NEED FOR AN INDIRECT APPROACH TO SPS REGULATION}

The viability of the SPS concept is still in its initial stages of evaluation. Should the Department of Energy decide to proceed with SPS, it will be many years before the technology is adequately defined and the specifications and operating characteristics of the system can be stated in any but the most general and speculative terms. Consequently, any attempt to directly analyze the applicability of present regulations to the SPS would be a largely empty exercise. Notwithstanding these obvious objection, it is useful to review some of the problems encountered in data collection and in inviting sources to speculate as to the potential regulatory problems that the system would encounter.

First of all there is a very limited knowledge of the SPS and a wide range of misconceptions. Such familiarity as regulatory staff members have with the concept sometimes leads them to emphasize the large and "monstrous" scale of the project, the dangers of microwave radiation, and the speculative "Buck Rogers" character of the system.

The problems of 1 imited knowledge and apparent misconceptions were further exacerbated by a semantic problem revolving around the word "solar". In initial attempts at data collection, the consultant identified the SPS project as the subject for his inquiry and was frequently referred to the "solar energy" department within the state agency. These entities were primarily concerned with decentralized applications of solar energy for water and space heating. As a result, they were not only unable to help with respect to the power plant regulation issues but often voiced strong objections to the SPS concept because of the high degree of centralization it seemed to represent. This semantic problem was later resolved by referring to the project only as a power plant at the initial stage of inquiry. 
The result of these observations was to create a focus in this study on two more generalized approaches to the problems of state and local regulations:

1. The classifications of types of regulations with special emphasis on "potential applicability to the SPS", and

2. the identification of generic issues or "vectors" in the regulatory process which might bear significantly on the SPS. Among the issues considered as regulatory vectors that could impact the SPS were centralization, attitudes towards new technology, problems with large physical sites, jurisdictional conflicts, issues of remoteness of load centers, etc. 


\section{SITING AND FACILITY NEED REGULATION}

Traditionally, decisions to site power plants have been governed by a combination of the corporate interests and obligations of the utility companies, tempered in varying degrees by the utility regulators and other permitting agencies. What resulted was a collection of requirements for various governmental approvals (for various aspects of the siting process) -- a collage of spinoffs from the planning, constructing and operating generation facilities.

The utility companies assumed the responsibility for forecasting need, planning, siting, constructing, distributing and transmitting electrical power. The utility regulators (generally Public Utility Commissions, or PUC's) were created around the turn of the century for approving rate schedules, equipment acquisition, financing, overseeing the quality of service, and the integrity of the utility corporate operations.

Before the beginning of this decade, the process by which a power plant was "created" was segmented and informal, but it generally worked. Utility companies projected their needs, located a site, figured out the financing and then went to state agencies for approval. However, since the late 1960's a number of factors have complicated this process:

1. The electrical blackouts in the northeast raised questions of the reliability of power supply on a regional basis (47).

2. The 1973 Arab 0il embargo heightened the realization that the nation's energy survival could depend on lessening its dependence on insecure sources of supply and caused a shift in emphasis from oil to alternative sources of energy (47).

3. Federal legislation such as the National Environmental Policy Act of 1969 (NEPA) and the Coastal Zone Management Act amendments, and the Air and Water Quality legislation created federal standards for the evaluation of impacts relating to construction of most major energy projects.

4. The rising cost of labor and of energy fuels has resulted in the utility rate regulators taking a much more critical look at applications for new generating facilities.

5. The desire to protect the environment and provide low-cost electricity has resulted in programs (both mandated and voluntary) for locating cheap, clean, renewable or undepletable sources of fuel.

A great deal of study and analysis of the existing regulatory maze has concluded that no single answer or framework, or legislation for handling the process has arisen. In states which have attempted to form an agency to issue a single permit, interagency conflicts, jurisdictional overlapping, and, in some cases, jealousies, have arisen. Further, the federal nature of some necessary 
approvals (such as those for air and water quality) and the technical expertise required by the state or local agency normally empowered with the jurisdiction cast some doubt on the efficacy of attempting to pre-empt that leve 1 of review and approval.

In some states such as Colorado, the process works best where there is no statewide legislation to cover the siting process. In other cases the law does little to affect the informal, but functional, relationships which already existed. In other states the underlying question of "who has the final authority" have yet to be answered simply because current situations do not require a resolution $(47,64,66)$.

The lead time for building generating capacity is now approaching a decade. State authorities recognize that it is important to assure not only that enough electrical capacity is built, but also that the new plants meet the tests of economy, environmental protection and national security $(64)$. In attempting to respond to all of these pressures and avoid federal involvement, 27 states have enacted energy facility siting legislation in the past eight years. Some attempted to create a single agency where the utility could apply for "one stop shopping". Other states have created agencies or empowered existing ones with the mandate to act as permit assistants. Some have merely attempted to reduce the red tape (79).

The number of siting decisions has decreased in recent years. Thus, siting decision making within a given state tends to be more of an individual, ad hoc process than a highly institutionalized routinized system. The projected size of new plants and the presumed economies of scale in large plants would seem to suggest that siting decisions will, in most states, continue to be infrequent.

\section{FINANCIAL AND RATE REGULATION}

Historically, rate regulation of electrical utilities was an arcane but not particularly controversial process by which elaborate formulas involving rate base, taxation and rates of return were incorporated into the financial regulatory framework. Actually, through the late 1960's, the cost of delivered electricity did not rise particularly (and arguably, actually declined in terms of constant dollars).

The combination of the energy shortages of the early 1970's and the growing environmental regulation of public utilities has created certain important changes in this as in siting procedures. A detailed consideration of the ratemaking process is not warranted since the massive financing needed for the SPS will require new institutions and regulations. Two aspects of current rate regulation would, however, appear to relate indirectly to SPS.

First of all, the traditional pattern of rate regulation in the context of new facility construction was that the utilities issued securities to build their new plants. The cost of the new plants was not included in the rate base until 
those plants became operational. At that time, the utility went before the regulatory body and petitioned to include in its rate base the capital costs, together with accrued interest on the funds borrowed for construction. As long as the time frame between the commitment and completion of a new plant was fairly short and completion was fairly certain, this process created no particular problem. More recently, the longer time frames and the substantially greater uncertainty associated with environmental processing have interfered with this process. Utilities now are faced with the need to seek rate relief before completion and, in some cases, for projects which are never completed.

The lead times are so long and the construction expenditures so large that there is increasing evidence that the private sector may not be able to supply the necessary funds without additional assurance of the utilities' ability to repay. Without some ability to pass on these costs to the ratepayers prior to completion, the utilities may be unable to provide the necessary assurance $(6,61)$.

In addition, there have been substantial construction funds or other "front end monies" advanced for new power plants which became unrecoverable because -

the plant is not actually built, e.g., Kaparowitz. This also has led the utilities to seek some sort of relief.

The incorporation of some portion of construction work in progress (CWIP) into the rate base is a critical issue for utilities. This problem is worsened by the decline in values of utilities stock and their increasing difficulties in raising financing in the private sector. Without profitability, their equity and debt issues are less attractive (61).

A second and very critical issue is the question of uncertainty of power costs. Rapid increase in fossil fuel costs in the 1970's has given rise to a strong movement for fuel adjustment clauses in rate regulation. This is to say that the utilities should be able to pass on, without the necessity of an extended rate hearing, those direct increases in fuel costs that are exacted by suppliers of crude oil, coal, etc. This has been resisted by the regulatory authorities who feel that their interest is to protect the consumer.

The fuel adjustment clause concept is not necessarily directly related to the SPS, but is indirectly relevant insofar as there is and will continue to be some residual issue of uncertainty with respect to the actual cost of SPS power until several rectennae are in operation.

Key Emerging Issues

The key issues in utility rate regulation that may bear indirectly on the SPS are:

1. CWIP, i.e., the willingness of regulatory authorities to incorporate within the rate base funds for construction work in progress or other "front end" monies. 
2. Willingness or ability of the regulators to deal with uncertainty as to fuel costs or, more generically, potential increases in delivered power costs due to third-party action.

3. The exacerbation of both these problems by the combination of rapidly rising capital needs on the part of the utility industry and diminished profitability and reduced access to capital monies.

Interaction with Site and Facility Regulation

The rate-making process and the attempts at redefinition of the rate base are to a very large extent a reflection of the increased problems with power plant construction and siting. Site selection and approval appears to be a major source of much of the delay and uncertainty. Consequently, much of the focus of this analysis has been on power plant siting regulation. Delay is: in turn, the source of sbustantial increase in cost and uncertainty. Siting regulation is one of several factors which lead to dimunition of the selffinancing capabilities of utilities and substantial increasing upward pressure on rates.

\section{SELECTED REGULATORY FUNCTIONS BY STATE}

In this investigation, detailed analysis of regulation was confined to the four selected states for the reasons given above. Nevertheless, a limited attempt was made to review the more critical regulatory functions for all 48 coterminous United States. For purposes of this analys is, several regulatory functions and/or entities (summarized in Exhibit 1) were selected as being particularly relevant to consideration of the SPS. This summary addresses the following issues:

1. Whether the Public Utilities Commission (PUC) will require certificate for generating plants and/or transmission lines;

2. the existence of a state power sitirig 1aw;

3. whether the coordination (if any) of the siting process involves a one-step or two-step permit process;

4. some evaluation of the extent to which the PUC certification authority is shared with other agencies and/or is contingent on environmental approvals; and

5. the degree to which the rate-setting authorities of the PUC are employed to set interchange rates, determine rate adjustment clauses, and to allow inclusion of construction work in progress (CWIP) or interest for funds used in construction in the rate base.

For the classification of power facility siting laws, the primary references were the Southern Interstate Nuclear Board (81) and the Berkeley Electrical 
Facility Siting Study (79). These two references, particularly the BEFS Study reference, are the most recent comprehensive treatments of this subject. For all other reaulatory functions, the source was the 1976 Annual Report of the National Association of Regulatory Utility Commissioners (NARUC) (67). This last is to some decree obsolete, reflecting conditions at the end of 1976 . The next NARUC annual report should become available later this year and could provide the basis for some updating of this material.

Any attempt at ceneral classification of the 48 states into simple "yes-orno" catecories is subject to a number of nualifications. These are indicated by the numerous footnotes to Exhibit 1.

Of the 48 states, 27 have laws or regulations dealing explicitly with electrical power plant siting. Within this group, most (2l states) also represent that they have one-stop permitting processes. As discussed subsequently in this report, these one-stop processes are, in many instances, more illusory than real.

Public utility commissions cenerally, but not universally, require a Certificate of Public Convenience and ".ecessity (CPCN) before they will authorize a utility to build a new generation plant or major new transmission lines. This authority is claimed in 26 states with respect to reneration plants and in 28 states with respect to transmission lines. In most states, the mandate to issue a CPCN is not necessarily the only measure of the power of the PUCs. Through their power to set rates, they can effectively limit new power plant or transmission line construction even in the absence of an explicit certification process.

There is an increasing tendency for PUCS to share their certification authority with other agencies, such as energy or environmental agencies, or other statewide planning and control entities. As of the end of 1976, there were 25 states in which this authority was shared. At the same time, 10 of the states specifically made PUC certification contingent on a positive recommendation by an environmental agency. This small number of states in which the codes specifically provide for contingent certification may substantially understate the impact of environmental regulation. Often environmental agencies can effectively block power plant construction through statutory authority granted under other laws.

Certain state PUCs have authority to regulate interchange rates (see sixth column of Exhibit 1), i.e., rates between their constituent utilities and also between those utilities and those of other states. This column is included primarily for information purposes and to indicate that only a few such states have this authority.

In most states, the laws and/or regulations governing the PUC provide for periodic rate adjustment. This adjustment may be either automatic ("auto" on Exhibit 1) or periodic. The automatic rate adjustment clauses in state regulations seem to apply almost exclusively to externally imposed costs outside the control of the utility, notably taxes. Most frequently, this type 


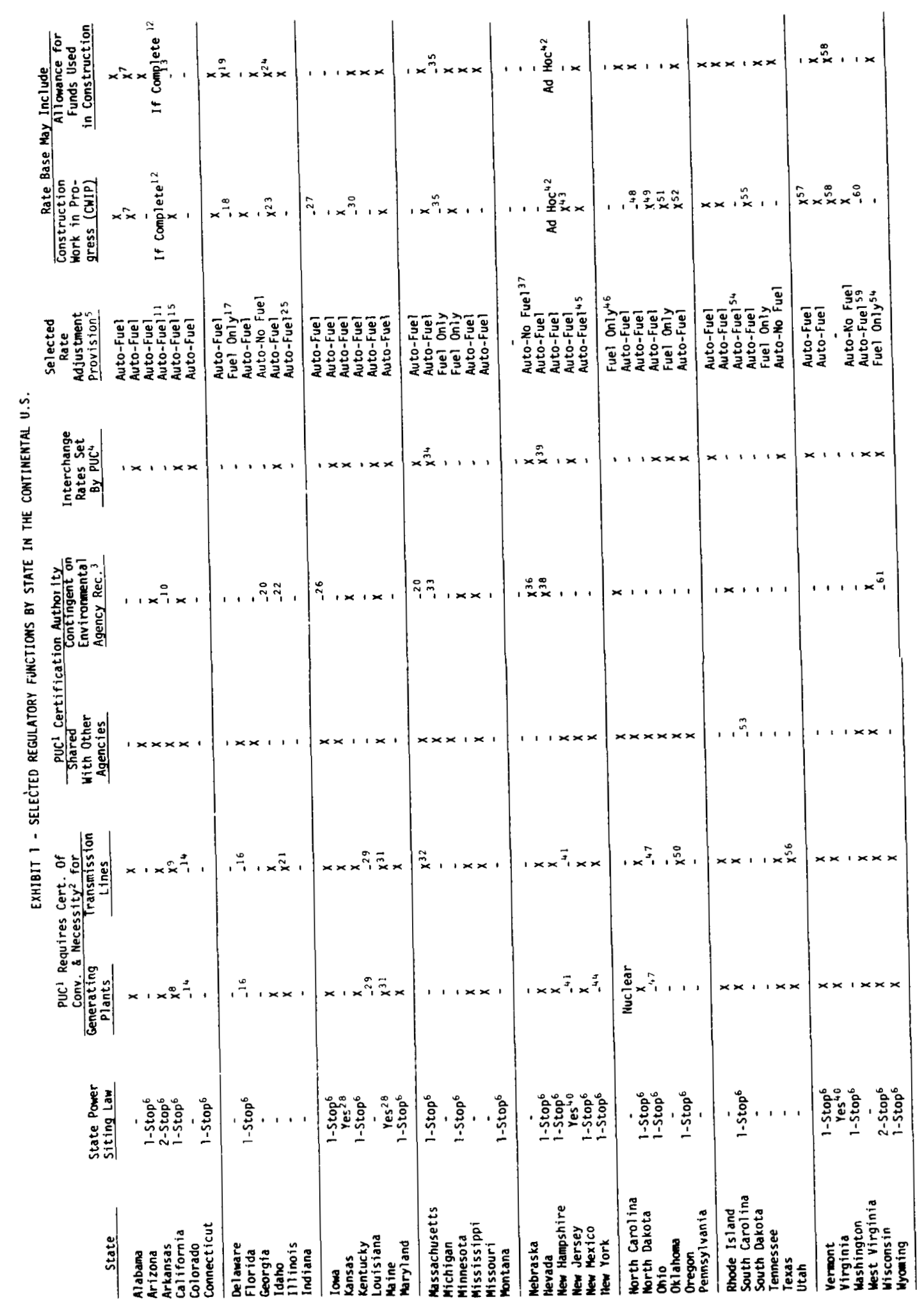




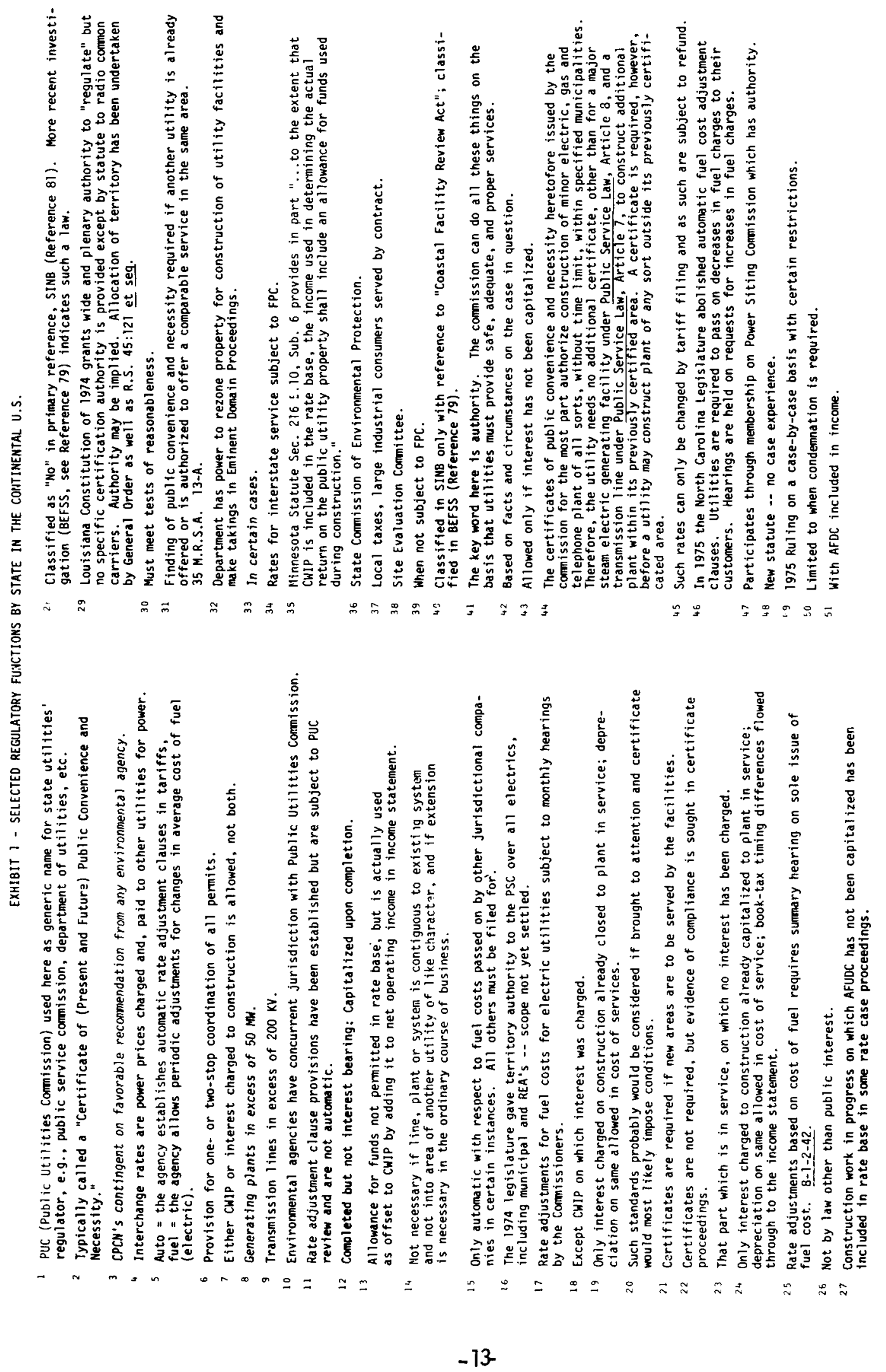




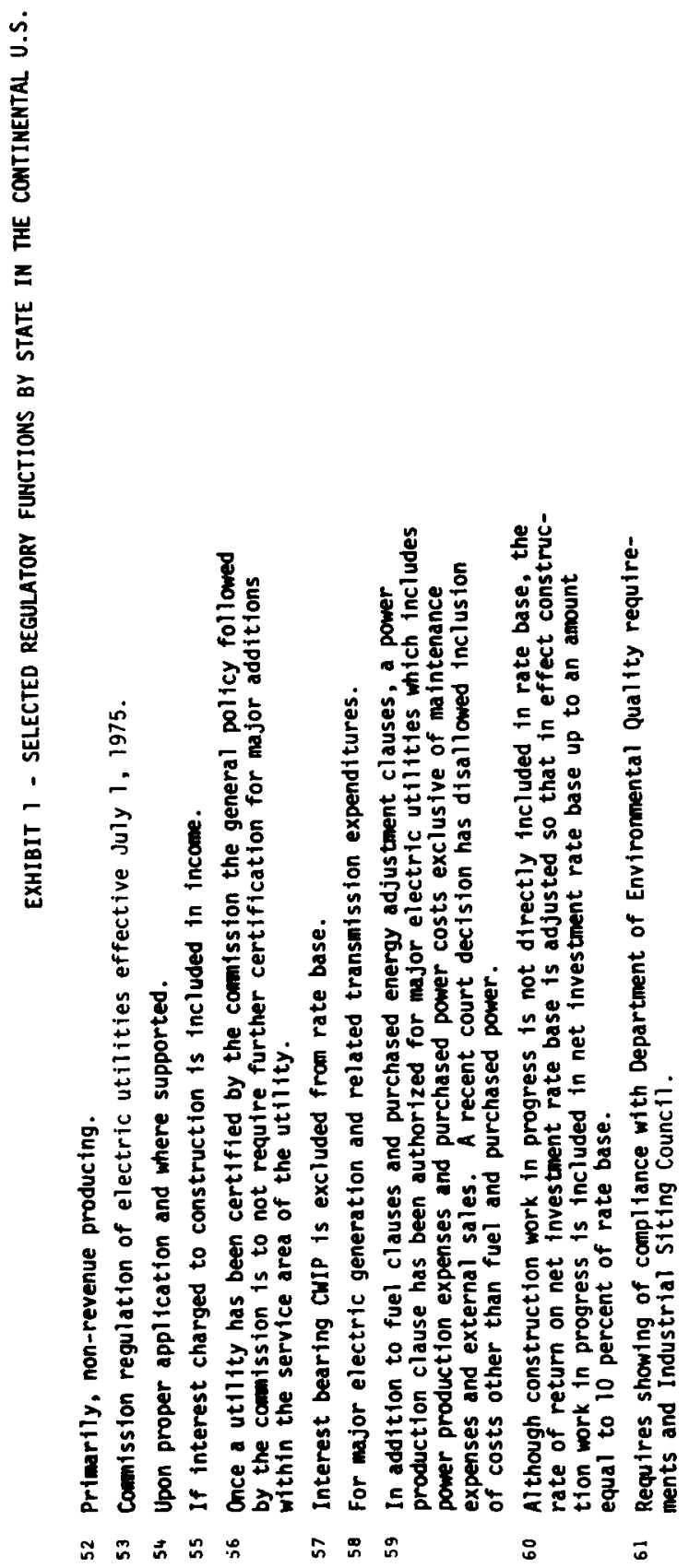

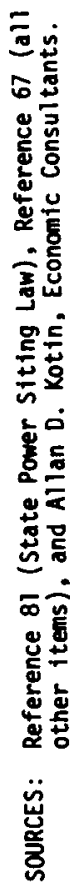


of escalation is available only for the imposition of local property taxes.

Many of the states also have fuel adjustment clauses which may be, but are not ordinarily, automatic. These clauses allow utilities to pass the

increased cost of fuel on to their ratepayers without full benefit of a new rate hearing. California has one of the most generous of the fuel adjustment clauses since it does not apply merely to direct fuel costs (e.g., oil and natural gas) but also to increases paid for bulk power purchased from other utilities.

Approximately half of the states have some form of provision for including construction work in progress (CWIP) or an allowance in the rate base for the interest cost of funds used in construction. As can be seen from the large number of footnotes in Exhibit 1, in most cases this is not an automatic or blanket provision but is carefully conditional on "completed" status of "reasonableness" of the charge. Careful perusal of the footnotes indicates that there is at least some presumption (characteristic of most utilities) that CWIP should not be in the rate base. In contrast to this, there appears to be a general presumption that there should be an allowance for interest on funds used in construction.

\section{OVERVIEW OF REGULATORY PROCESS IN FOUR STATES}

Below is a brief description of the current procedure being employed in the four belliwether states.

\section{California}

The California legislature passed the Warren-Alquist Act (AB 1575) in 1975, placing the primary responsibility for thermal power plant site and facility approval in the then newly-created California Energy Resources Conservation and Development Commission (later called the California Energy Commission). It was felt that by centralizing the process, several important concerns could be better handled in a more organized manner.

Pursuant to the Harren-Alquist Act, a certificate from the CEC is issued in lieu of any permit, certificate or similar document required by any state, local or regional agency (or federal agency to the extent permitted by federal law). However, permits issued by the local Air Pollution Management District and Regional Water Quality Control Board cannot be preempted by the CEC and must be acquired prior to certification by that Commission.

Although the Energy Commission has sole authority to certify all sites and related facilities, other federal, state and local agencies are required to take part in the evaluation process and make recommendations to the Commission. The siting procedure consists of two stages: the Notice of Intention (NOI), and the Application for Certification (AFC) for any proposed power plant of $100 \mathrm{MW}$ or more. 
The NOI is required by law to include data for at least three alternative sites (only one site is required for geothermal projects). One of the three sites must be located inland. The data in the NOI are evaluated to determine (a) whether the electrical energy to be produced is needed in accordance with the Commission's demand forecast, and (b) whether construction and operation of a facility at the proposed sites would endanger public health and safety, or adversely affect environmental quality. At the end of the 18-month review process (or nine for a geothermal NOI), a decision is made either to disapprove the NOI or to approve one or more of the sites as eligible for further consideration.

Upon certification of the eliaibility of a site, the utility is eligible to submit an Application for Certification (AFC) which again initiates an 18month sequence of events. The emphasis in the AFC phase analysis is on sitespecific facility design, including the preparation of an Environmental Impact Report. Under the California Environmental Quality Act (CEQA) the CEC is the lead agency for purposes of complying with the Environmental Impact Report procedures.

Regarding the timing of NOI and AFC, it is theoretically possible for the utility to complete the siting process within 36 months. As of midyear 1978, no project had completed this process, pending litigation testing the limits of the Commission's authority.

As part of a utility's application to build an energy facility, an adjustment in the rate is usually involved. The Public Utilities Commission has regulatory authority over all aspects of rate adjustments. The PUC issues the final construction permit, i.e., a Certificate of Public Convenience and Necessity, but oniy after final certification from the California Energy Commission (CEC) has been obtained (84).

\section{Colorado}

Colorado does not have an energy facility siting law. Instead, a number of state agencies, as well as local political units, exercise the authority to grant a variety of permits for the establishment of energy facilities. The state entities are the Public Utilities Commission, the Air Pollution Control Commission (located within the Department of Health), the State Engineer's Office, and the Ground Water Commission (located within the Department of Natural Resources), and state District Courts in which Water Judges exercise jurisdiction over water matters.

Each of these entities exercises some partial control over the permitting process. For example, the Public Utilities Commission must grant a certificate of public convenience and necessity before any public utility can construct a new facility or any extension of an existing facility (90). Although the PUC places the burden of proof on the utility, it does exercise its authority by questioning forecasting methods used by the applicant to prove need. The PUC hearings provide the arena for other issues, such as zoning, to be settled 
(28). Boards of County Commissioners may exercise authority regarding energy facility siting due to their authority with respect to zoning, solid waste disposal, and subdivision development.

Local governments, municipalities and counties are empowered, after public hearing, to designate specific areas and activities of state interest which are defined by statute to include major facilities of a public utility and the siting thereof. Such local governments may grant or deny permits for developments in designated areas or for activities of state interest subject to general review by the Colorado Land Use Commission. State district courts are empowered to review the granting of such permits.

As long as new energy facilities can be sited without undue delay, it seems unlikely that energy facility siting legislation will be forthcoming in Colorado. The threat of federal preemption may change this outlook.

It should be noted that a 1,000 megawatt coal-fired plant, to be located in Morgan County and called the Pawnee Plant, has recently passed through state and local government processing, after some delay at the county level. The issue of zoning has been settled and in August of 1978 the project was approved by the PUC $(28,90)$.

\section{Connecticut}

Connecticut enacted a Public Utility Environmental Standards Act in 1971. The Act, amended in the ensuing years for clarification, covers electric transmission, generation and fuel transmission facilities, associated equipment, and other plants which may have a substantial adverse environmental effect.

The Act establishes a "Power Facility Evaluation Council" consisting of the Commissioner of Environmental Protection (or his designee); the Chairman of the Public Utilities Commission (or his designee); one designee of the Speaker of the House; one desinnee of the President Pro Tempore of the Senate; five members of the public, to be appointed by the Governor, at least two of whom shall be experienced in the field of ecology, and not more than one of whom shall have any affiliation, past or present, with any utility. The Chairman is appointed by the Governor.

The Connecticut statute envisions two major functions for the Council. One is the licensing process; the other is the reviewing of long-range bulk power supply plans of the State and the interconnected utility system for adequate, reliable and economic service. The Act provides that prior to the acquisition of any real property, exercise of eminent domain, or commencement of construction of a facility that may have a substantial environmental effect, a party must procure a "certificate of environmental compatibility and public need" for a facility or modification thereof. An applicant for a certificate must file such information as the Council may require concerning information on costs; routing; detailed description of facilities; identification of other governmental agencies that have reviewed the proposed route; reasons why the facility is necessary; effects of the 
facility on the environment, on ecology and on scenic, recreational, and historic sites; justification for overhead rather than underground facilities in the case of transmission facilities; safety and reliability information.

The Public Utility Environmental Standards Act states that "environmental quality standards and criteria for construction and operation of facilities for the furnishing of public utility services (should be) at least as stringent as the federal...standards".

Connecticut has a very low level of activity due to its predisposition on regional power pools which have planned facilities until the year 1986. One application has been processed since the Council was established in 1972 and none is expected "for 12 years," according to a Council staffer (81).

Even though the Council is a one-stop agency for issuing State power plant construction licenses, other permits for air and water quality must be approved by the appropriate state agency before the license is awarded.

\section{Florida}

The Florida Environmental Reorganization Act of 1975 created the Environmental Regulation Commission and designated the Department of Environmental Regulation as the state agency with one-stop authority for power plant siting certification. The Governor and his cabinet act as the final authority on the application, approving or denying the issuance of a certificate. The Department of Environmental Regulation establishes air and water quality and other environmental standards and issues the site certification prior to construction and operation of the plant.

Each utility submits an annual 10-year site plan to the Division of State Planning, showing the utilities' forecasted power generating needs and the general location of the proposed power plant. The Division reviews the plan and may suggest alternatives to it. Findings of the Division are given to the Department of Environmental Regulation for its consideration at any subsequent site certification proceedings. The Public Service Commission (Florida's utility regulating authority) also prepares a report and recommendations for the Dept. of Environmental Regulation as to the present and future needs for electrical generating capacity in the area to be served by the proposed plant. This is done when an application for site certification is filed by a utility.

When an application for site certification is reviewed by the Department of Environmental Regulation, the Division of State Planning updates its preliminary study based on utility 10-year plans and gives its recommendations to the Department. After a public hearing and data collection process is completed, the Department presents the hearing examiner's findings and recommendations to the Governor and Cabinet for a final decision. 
Florida's law apparently does not attempt to override local authority in the manner of a true one-stop process. However, local authorities are not left completely autonomous. An independent hearing officer from the state holds a hearing in the county where the facility is proposed. While the hearing officer is empowered to interpret and apply the local statutes, he is not free to override local regulations on behalf of the state. This potential local-state conflict has not been a key feature of the Florida siting process to date, since thus far there hasn't been serious controversy about power plant conformance with local land use regulation.

These features are combined with the unusual fact that the Florida cabinet is directly elected by popular vote. In other words, the final permitting body is composed of popularly elected officials each of whom has run on his own platform (79). 


\section{CLASSES OF REGULATION}

\section{CLASSIFICATION OF REGULATION BY TYPE}

The siting and operation of power plants is regulated at several different levels. Excluding the federal regulations, dealt with in another White Paper, there are three often overlapping levels of jurisdiction: state, regional, and local. In this context "local" applies to County and City governments and, in the northeastern U.S., to villages and towns as well.

Specifically excluded from this analysis are those agencies which function purely as coordinating entities, having no substantive responsibilities, but having instead the charter to assure that other agencies work effectively together.

The classification used in this analysis is drawn primarily from the studies of the four selected states. The regulations have been classified by their regulatory function or purpose and not by the names of the agencies or the level of jurisdiction. In many cases, different functions are performed by the same agency in one state while they are performed by separate agencies in other states.

\section{APPARENT APPLICABILITY OF REGULATION TO SPS}

Depending on the location or particular circumstances of a specific site, it is conceivable that all of the listed forms of regulations identified in this study could be applied to SPS rectenna installations at some time. It is important to distinguish those that will necessarily be involved with any SPS facility, independent of locational considerations. It is equally important (particularly in reference to the independent but related effort to identify potential sites and land use requirements) to specify those forms of regulations with which the SPS might be involved, depending on location.

All the major classes of regulation are listed in Exhibit 2 and classified in turn according to the consultant's estimate of their applicability to the SPS. The applicability categories used are:

1. universal processing required (all types of SPS sites would be subject to these);

2. Tocation-dependent involvement: easily mitigable;

3. location-dependent involvement: difficult to mitigate; and

4. Tocation-dependent involvement: politically vulnerable.

In addition, Exhibit 2 also identifies two other categories of applicability. One is presumed federal pre-emption. The remaining category covers several types of regulation for which none of the foregoing classifications is particularly appropriate. 
The three-way categorization of location-dependent regulation is, to some extent, arbitrary. The distinction between "easily mitigatible" and "difficult to mitigate" is based on the author's experience and a limited review of energyfacility environmental literature. Most of those regulations categorized as "easy to mitigate" appear to be susceptible to mitigation through redesign or additional expenditures which do not materially change the project economics. The category designated as "politically vuinerable" applies to two classes of regulation dealing with land ownership in which "mitigation" in the traditional sense is often impossible and the difficulties associated with obtaining required approvals more often than not depend on the political sensitivity of the project as a whole.

The 34 types of regulations listed in Exhibit 2 could well represent a much larger number of agencies in any given state. In many instances, the same regulatory function is exerted at the state and ?ocal level. In some cases there is also a regional level of regulation, particularly in the case of air and water quality regulation.

Nine classes of regulations, appear to require universal processing: It is almost impossible to envision that a rectenna could be built without undergoing each of these types of regulatory processes either for formal approval or for a waiver of consideration, e.g., in the case of air quality. These nine critical types of regulations are:

1. Site selection and approval to construct

2. Energy policies (need for facility)

3. Rate regulation

4. Land use planning
5. Coastal zone management

6. Air quality control

7. Water quality control

8. Fire protection

9. Building permits-plan inspection.

The remaining types of regulation are location dependent. They include:

11 types of regulation that address impacts which have generally proved easy to mitigate for large projects,

4 types of regulation which address impacts which are potentially difficult to mitigate,

3 types of regulations, subject to Federal preemption,

2 types of regulations that are especially politically sensitive, and

5 types of regulations not otherwise classifiable.

The 34 classes of regulation are listed in Exhibit 2 by level of involvement. In those instances where the nature of regulation is not self-evident from its description, key issues are noted. 
APPLICABILITY TO SPS Class of Regulation

UNIVERSAL PROCESSING REQUIREMENT

Electric Utility Pricing Regulation (Rate Regulation)

Energy Policies (Need for Facilities)

Generating Facilities (Site Selection and Final Approval to Construct)

Land Use Planning

Air Quality Control

Water Quality Control

Coastal Zone Management

Building Permit/Plan

Approva 1

Local

State \& Local

State \& Local

State \& Local

Railroad Regulation State

Local
State \&

Regional

State \& Local

Regional
Solid Waste Management

LOCATION-DEPENDENT -
EASILY MITIGATABLE

Traffic Control

Fire Protection

Highways

$\frac{\text { ClaSS of Regulation }}{\text { UNIVERSAL PROCESSING REQUIRE- }}$
$\frac{\text { MENT }}{\text { Electric Utility Pricing }}$
Regulation (Rate Regulation)
Energy Policies (Need for
Facilities)
Generating Facilities (Site
Selection and Final Approval
to Construct)
Land Use Planning
Air Quality Control
Water Quality Control
Coastal Zone Management

Key Issues, Comments
No precedent for SPS scale; need coordination of land use and energy planning.

Presumably not a major SPS problem.

Presumably not a major SPS problem.

Classified as "Universal Processing Requirement" because: (1) it will apply to all off-shore sites; (2) it is an especially comprehensive form of regulation; (3) it has been invoked to "override" even the highest state regulatory bodies; and (4) its recent federal mandate has created considerable controversy.

Vehicle by which local fire, health and police interest enforced as well as building codes.

May be sensitive during construction.

May be sensitive during construction. 
EXHIBIT 2 - ESTIMATED APPLICABILITY OF CLASSES OF REGULATION TO THE SPS (Continued)

\section{APPLICABILITY TO SPS \\ Class of Regulation \\ LOCATION-DEPENDENT - \\ EASILY MITIGATABLE (cont 'd.)}

Flood Control

Wastewater Treatment

Health Care

LOCATION-DEPENDENT -

MITIGATION DIFFICULT ${ }^{1}$

Forest Protection (and

other areas of biological

significance or vegetative sensitivity)

Wildlife Protection

Parks and Recreation

Protection of Archaeological, Historical \& Culturally

Significant sites

LOCATION-DEPENDENT -

POLITICALLY VULNERABLE

Administration of Sale or

Lease of State-Owned Lands

Protection of Indian Land

State

Industrial Health and

Safety

Public Health and Safety

Aeronautical Control and

Planning
State \& Local

State \& Local

State \& Local

State \& Local

State

State \& Local Key issue is microwaves

Key Issues, Comments

Depends on extent of grading and water flow disruption.

Possible temporary overload on local facilities during construction.

Primarily a siting exclusion criterion.

Dimensions of problem unknown pending outcome of microwave research.

Primarily a siting exclusion criterion.

Primarily a siting exclusion criterion.

Not readily "mitigatable" in traditional sense: potential problem if project is controversial.

Not readily "mitigatable" in traditional sense: potential problem if project is controversial.

State \& Local Key issue is microwaves.

RFI (radio frequency interference) is a critical potential problem. 
EXHIBIT 2 - ESTIMATED APPLICABILITY OF CLASSES OF REGULATION TO THE SPS (Continued)

APPLICABILITY TO SPS Class of Regulation

OTHER

Electric Transmission Lines

Disaster Preparedness

Geological, Seismic \& Soils Concerns

Public Health

Right of Way Consideration
Jurisdictional Level (s)

Key Issues, Comments
Shared State/ Federal

State \& Local

State \& Local

Local

State \& Local
Changing technology and institutional relationship.

Scope of problem unknown: depends on actual and perceived microwave risk.

May be sensitive during construction.

Possible special procedure for detecting microwave health effects.

May be sensitive during construction; otherwise related to transmission.

1 Al1 "location dependent" classes of regulation are potentially difficult to mitigate and highly political sensitive depending on the specific circumstances. The categorization use here is a very general attempt to reflect "average" levels of problems based on the consultant's experience.

Source: Allan D. Kotin Economic Consultants 
REGULATIONS WITH UNIVERSAL PROCESSING REQUIRED

The following is a rather general discussion of the types of regulations which will require universal processing and a brief summary of their applicability to the SPS rectenna facility. A description of how each type of regulation is currently handled in the four bellwether states can be found in Appendix B.

\section{Site Selection and Approval to Construct Generating Facilities}

Each state seems to handle this question differently. (A review of the siting legislation for the four bellwether states can be found in the overview discussion presented in Section III). Selected aspects of this type of regulation are presented for all 48 states in Exhibit 1 . There seems to be no legislation which, by its own definition, would apply directly to the SPS.

Most siting legisiation requires air and water quality standards be met and specifically addresses those issues as part of the overall approval. Permits must be obtained separately from the appropriate agencies.

Siting SPS rectennas may pose a problem in states expressing a desire for decentralized power plant siting and smaller-sized facilities (as distinguished from larger, more centralized facilities). Also a strongly developed land use plan with no provision for larger energy developments could pose problems for the rectenna siting. The size of the rectenna seems to distinguish the SPS from other projects falling under the jurisdiction of energy siting legislation. Additional planning for centralized terrestrial solar plants, requiring large land areas, could, however, provide a useful precedent.

Although air and water quality permits are usually required from the appropriate agencies as part of the siting process, no problem is foreseen in obtaining these operational permits. Approval for construction, however, could become a stumbling block in a state where the SPS concept has not gained acceptance.

\section{Need for Facility}

Determining the need for a new power plant is an exercise in regulation in which state agencies have not been involved until recently. Regulatory agencies have assumed that generally electric power companies would propose new facilities only when the demand was perceived. In addition, agency determination of need has not heretofore seemed as critical because construction could be accomplished without concomitant increases in rates to customers. However, the growing size and complexity of energy installations and the rising construction cost per kilowatt often require an increase in costs to the consumer. Hence, the "need" for a proposed facility is no longer an issue that can be assumed to have little direct effect on consumer costs. 
There is no single reliable mechanism today to produce a credible assessment of future demand. Different regions of the country are experiencing different growth rates in electricity, as well as total energy consumption. The effect of conservation on load growth is difficult if not impossible to project without established national conservation goals. To complicate matters further, electricity projections are now considerably lower than historical growth rates and estimates of previous analyses.

With the rise in the cost of 0 il and labor, state-level agencies have (1) begun to develop methodologies for evaluating the utilities' forecasting and/or (2) begun imposing their own assessment methodologies on the utilities. Because this area of regulation is new, the jurisdictional lines between state agencies such as PUCs and Energy Commissions are still being drawn with respect to approving the need for a facility.

Energy planners are now generally attempting to look at least 10 years in advance and are planning facilities in the .5 to $1 \mathrm{GW}$ range. If the SPS capacity is to be $5 \mathrm{GW}$, planners must begin incorporating the potential use of such a large plant into their thinking at least 15 years before expected construction.

\section{Electrical Utility Regulation (Rate Approval)}

State-level rate regulator agencies assess the appropriateness of the public utilities' rate level and service. Utilities are usually regulated on a cost-plus basis. An inquiry is conducted into the expected costs and timing of a new facility in order to insure that utility estimates represent the true and allowable expenses of construction. When the inquiry is finished, a Certificate of Public Convenience and Necessity is issued by the PUC to the applicant utility. The Certificate has traditionally meant an authorization for the financing through rate adjustment, not site selection nor approval of need for the project.

Recently, however, in questioning the need for excess reserve capacity or the number of transmission lines required at a new facility, the PUCS have been exercising their regulatory powers in a larger area. Because the cost of construction has become a concern to the rate regulators, they have begun to disallow specific aspects of requests for Certificate of Convenience, thereby entering the realm of construction approval.

It is difficult to anticipate the probable reaction of utility rate regulators to requests for financing assistance for the SPS. First, there is the issue of pre-financing --e.g., allowing CWIP (payment for Construction Work in Progress) in the rate base, guaranteeing purchase of electricity prior to construction, or allowing interest on construction financing into the rate base before completion. Second, there is the problem of regulatory response mechanisms to regional pooling of finances and generating capacity. These issues are covered in Section VI, Financial and Rate Regulation. 


\section{Land (Ise and Zoning (A11 levels)}

Conformance with land use plans and zoning designations is generally a consideration at the local or county level. Statewide land use plans (along with associated maps) are usually a compilation of local plans, serving the purpose of centralizing information and, in some cases, planning efforts.

The proposed National Land Use Policy Act (which was tabled during the early 1970s) would have forced states to establish elaborate planning procedures to coordinate such planning functions air and water quality control. In 1974, with the passage of the Housina and Community Development Act, the federal government required that by 1977 each state receiving certain HUD grants must engage in land use planning. The individual states' responses to such federal pressure to coordinate land use planning continue to vary.

The enormous 1 and requirements for SPS rectennas will pose the most difficult problems relative to the land use and zoning question. In most states, it is unlikely that all of a proposed piece of land will have the same use or zoning designation. It also seems unlikely that an energy land-use designation will be reserved for large, remote, unpopulated areas. Therefore, regulatory approval in the area of land use/zoning may be difficult to obtain for a given rectenna site unless land use planning has been coordinated at the state or regional level. Furthermore, the real issue of whether a state can actually pre-empt zoning and land use jurisdiction from local jurisdiction has not been litigated at the federal ?evel.

A further discussion of the applicability of land use planning to the SPS can be found in Section VI of this report under "Siting and Land Use Policies".

\section{Coastal Zone Management}

In 1972, recognizing that conflicts over use of coastal lands and waters had reached a crisis point, Congress passed the Coastal Zone Management Act (CZMA). The Act provided funds for state programs, identified federal goals and outlined a format for state coastal zone management.

Each coastal state must develop a plan for approval by the Federal Government. It was not mandated that the states form a separate commission with permitting power. California, in response to the 1972 Coastal Initiative, formed the coastal commission which shares final authority with the California Energy Commission in the issuance of construction permits for energy projects within the designated coastal zone $(84,132)$. The commission is actively aimed at protecting the coastline from further physical degradation and may also be able to exclude certain areas within its jurisdiction from power plant construction. Neither Florida nor Connecticut has an approved Coastal Zone Management plan as yet.

If a state program qualifies, most federal agencies conducting activities or issuing permits in the coastal zone must defer to the state program. Air and water pollution contiol laws are not, however, subordinated to the coastal program. 
Given the size of the rectenna site and the generally narrow "coastal zone" areas, coastal zone management should not be a frequent problem for land-based SPS sites. SPS sea sites would, however, clearly involve coastal zone regulation.

It is also too early to tell whether the majority of Coastal Zone Management Plans will involve explicit permitting procedures. If they become vehicles for approving development through permit approval, they could represent another level of jurisdictional authority for offshore sites.

\section{Air Quality}

In the 1950s and 1960s, the federal government provided money to the states and admonished them to clean their air. However, little action was taken until Congress amended in 1970 the federal Clean Air Act of 1963. These Amendments imposed direct federal sanctions upon air polluters, ordered the EPA to establish acceptable levels of specific pollutants, and required that states submit qualifying air quality plans to the EPA. The states have generally complied and have developed planning documents, evaluation methodologies, and enforcement techniques through the issuance of permits (78). Largely as a result of federal mandate, all four "bellwether" states have detailed procedures for obtaining air quality control permits. Applicants must usualiy contact the cognizant air quality control agency before proceeding very far into the permitting process.

Research indicates that the federally preemptive nature of air quality standards has generally kept issuance of necessary permits within the control of the state or regional agency responsible for air quality rather than the "onestop agency," if such exists (79). If a specific air quality issue develops relative to the SPS, the promulgation of appropriate regulations may well occur at the federal level in direct response to the need. Special problems in air quality regulation may exist in states with more stringent standards than required by federal law, e.g., California, and on sites involving federal land. SPS air quality impacts appear, however, to be minimal in any case.

\section{Water Quality}

With the passage of the 1972 amendments to the Federal Water Pollution Control Act (FWPCA, PI 92-500), the Federal Government placed the responsibility for water pollution control on EPA and the individual states. The stated goal is to achieve water quality that will support fishing and recreational uses by 1983 and eliminate pollution in the nation's waterways by 1985 . The Act prohibited discharges of effluent into the water without a permit and established the National Pollution Discharge Elimination System (NPDES) to set standards and issue permits. States may administer NPDES by passing appropriate laws and establishing satisfactory administrative procedures. Public law 92-500 further defined discharge standards required for permiting. 
Initial research on SPS indicates potential for leaching effects of water running off of "billboards" (Large angled rectenna panels) and warns or the effect of chemicals on groundwater. Early environmental evaluation also reports that construction of the rectenna "can damage the terrain in such a manner as to increase water run-off during storms and thus decrease the 10cal water supply reauired for plant and animal life." This latter effect is temporary and all possible mitigative measures are assumed.

No long-term effects are expected to hinder granting of water quality permits given the following assumptions: water in streams running through the buffer zone will not be affected by increases in air temperature; water requirements for construction can be trucked to the site if necessary; sanitary facilities can be provided by mobile units; no wells need be drilled; any increase in temperature (air or gound) will not measurably affect aquifer evaporation rate; and permanent water supply requirements will be negligible.

The issue of water deliveries and water quality is often one of the dominant constraints in energy facility siting. However, both scarcity and pollution, which are limiting factors for most other methods of generating electricity, are expected to be easily mitigable or to pose no problems with the SPS rectenna.

\section{Fire Protection}

The original concern in keeping Fire Protection as a category of generic regulation was the permitting authority the Fire Marshal in California was assumed to have over construction activities in areas of high fire hazard. However, a phone conversation with a representative of the State Fire Marshal's office revealed that there do not appear to be any state-leve? procedural or permitting obstacles relating to the SPS rectenna. Jurisdictional authority for fire protection is generally at the local level. The Department of Forestry has control over state lands and the Fire Marshal's office has de facto jurisdiction over unincorporated areas.

No potential cause for concern was uncovered which could not be mitigated by such actions as brush ciearing at the site or grading twice the usual width along the access route. It was agreed that if the project proponent were to take reasonable precautions, there would be no reason for the SPS to be stopped or delayed on the grounds of fire related concerns.

\section{Building Permits and Plant Inspection}

Except for certain very limited exemptions, all local jurisdictions must issue building permits after inspecting the final building plans for all major projects. 11 though some state and federally owned projects are exempted, major power plantfacilities constructed by investor-owned utilities are typically not exempt. 
The building permit process is very important to local jurisdictions for several reasons. Not only does it permit them to enforce their local building code, but it is also the vehicle through which local fire, police, and health officials enforce local regulations within their jurisdictions. Building permit fees can also be an important source of local revenue, particularly in large projects, since often these revenues are among the major compensations for the significantly increased expenses.

Most states now have uniform building codes which they encourage but do not always require local jurisdictions to adopt. For certain highly sensitive projects, however, the states have partially superimposed their own restrictions on local building codes. Typically, such pre-emptions occur in the area of hazardous materials, other projects potentially dangerous to health, or projects which clearly cross local jurisdictional lines.

Consequently, building permit and plan inspection regulations of the construction of rectenna sites are likely to be characterized by a mixed jurisdiction. Presumably, much of the actual inspection will be performed at a local level possibly with additional state and even Federal inspectors.

Notwithstanding the very local nature of building permits, there is some degree of uniformity in certain types of constructions. Since most local building departments have relatively little familiarity and experience in dealing with major power plants, they typically retain consultants and/or use manuals or standards published for the entire industry. These consultants and manuals often. impose a basic uniformity on the actual standards applied to specialized projects.

\section{REGULATIONS WITH LOCATION-DEPENDENT INVOLVEMENT}

Theoretically, the SPS could become involved with any form of regulation as a function of a specific location and the sensitivity of that location. There is some value, however, in differentiating rather generally between three types of regulations with which there is potential involvement:

1. regulations addressed to impacts which are easily mitigable

2. those concerned with impacts more difficult to miticate, and

3. those which are considered politically vulnerable.

Many of the location-dependent forms of regulation are concerned with impacts which could be fairly easily mitigated, especially to the extent that they appiy largely to construction rather than to operation. These more easily mitigatible aspects of regulation are listed in Exhibit 3 . For example, the construction of an SPS facility in a remote area with a limited or highly sensitive water supply might create a real problem with respect to waste water treatment or sewerage. Given the scale of the SPS, this could well present an additional expense for a temporarily installed package treatment plant or conceivably 
Class of Regulation

PRIMARILY STATE LEVEL

Traffic Control

Highways

Raiiroads

LOCAL OR STATE AND LOCAL LEVEL

Public Safety Protection

Fire Protection

Public Works

Flood Control and Drainage

Solid Waste Disposal

Highways/Transportation

Water Delivery Systems

Heal th Care
Special Features or Assumptions

Permit may be necessary to move specialized/oversized machinery from one site to another. Otherwise congestion could be mitigated by paying for street lights or extra police to to direct traffic.

Utility lines will almost certainly cross highways.

Assume rail spur will be necessary, are there any conflicts between preselection criteria for potential sites and policies of railroads (or regulators of railroads)?

Any problems will probably be covered in the application for the building permit (for flood control as part of the National Flood Insurance Act). Any problems with drainage could either be mitigated or will come up in water quality.

Some time spent quizzing transportation people or looking at EIR's will tell if there's anything here that isn't mitigable.

Assume it's either mitigable or will be handled at the state level.

Minimal impact.

SOURCE: Allan D. Kotin, Economic Consultants. 
even a "trucked in" water supply. Similarly, problems with traffic planning and rail routes which could be created by the highly intense construction activity again are subject to mitigation through better planning or additional spending on traffic control, temporary road improvement, etc. Regulations in this classification are listed in Exhibit 3 .

There is another, smaller, set of locationally-dependent regulatory involvement addressing problems which might be much more difficult to mitigate. These revolve primarily around protection of special recreation, wildlife, or forest areas as well as archeological, historical and cultural sites. To some extent, these forms of regulation delineate exclusion criteria in the siting process. These are listed in Exhibit 4.

It is possible, for example, in the case of certain types of historical sites to mitigate by actually removing the building to be preserved, or by delaying construction long enough to permit thorough retrieval of archaeological artifacts. Adverse interaction of SPS rectenna site with a forested area or wildlife habitat is not yet known and depends on the outcome of ongoing research with respect to both microwave and heat effects of the rectenna sites.

In the course of the present research, two types of regulation were identified as location-dependent and explicitly "politically vulnerable", use of state owned land or Indian land. In some respects, any form of regulation represents a point of political vulnerability, to the extent that there is a significant and/or vociferous body of public opinion opposed to a project. These two areas of regulation are categorized as "politically vulnerable" primarily because they do not address any explicit physical environmental impact but can often represent a politically sensitive issue in the site approval process.

\section{REGULATION SUBJECT TO APPARENT FEDERAL PREEMPTION}

Three types of regulation exerted at the state and local level were identified as likely to be preempted by the federal government:

1. industrial health and safety,

2. public health and safety, and

3. aeronautical control and planning.

The chief issue with respect to health and safety concerns acceptable levels of exposure to microwave radiation. Research reveals that while the states do have elaborate occupational and public health standards, they do not exert any explicitly independent regulation with respect to microwave radiation. 
EXHIBIT 4 - LOCATIONALLY-DEPENDENT CLASSES OF REGULATION: POTENTIALLY DIFFICULT TO MITIGATE

Forest Protection (and other areas of biological significance or vegetative sensitivity)

Wildlife Protection

Parks and Recreation (including

regional and county)

Protection of Archaeological, Historical, and Culturaliy

Significant Sites
Location dependent, but because of land requirements, the likelihood of being in or near an area being protected is relatively high. Could be unmitigable depending on mandate of agency. (Will vary from state to state). Also the transmission lines could cross protected lands.

Location dependent. See above. Location dependent. See above.

Assume all protection is by policy not legal mandate - need to see what provisions there are in the law to override policy (i.e., if they found something sensitive but was in provision of state law to override for energy related projects).

SOURCE: Allan D. Kotin, Economic Consultants. 
The current standards applied in all the state governments contacted are those established by the federal government, and there is no evidence at this point that any state is considering more stringent regulations.

The extensive microwave transmissions associated with the SPS also pose significant problems for aeronautical control and planning. Preliminary indications are that there may be substantial sources of radio frequency interference created by SPS microwave transmissions, extending over potentially large areas. While the states do exert some regulation over air traffic lanes and airport procedures which might be affected by the SPS, aeronautical radio communications are already jointly controlled by the FCC and the FAA. Presumably. any further requirement constraints imposed by the SPS would also be developed and administered at the federal level.

OTHER TYPES OF REGULATION, NOT OTHERWISE CLASSIFIABLE

States normally regulate the location, rights of way, and other parameters of intrastate electrical transmission lines. Detailed consideration of the regulatory problems posed by the SPS in this regard requires further refinement of the ongoing siting and land use efforts. The transmission of 5 gigawatts of baseload power from a single site presents potential distribution problems whatever the method of generation, since all existing power plants are considerably smaller. Several aspects of the problem of large-scale power distribution are currently the subject of intensive investigation unrelated to the SPS. Consequently, any attempt. to project the regulatory environment for SPS operations in this regard would involve forecasting the changes in both transmission technology and institutional relationships that will occur over the next twenty years. Among the issues under study which will affect this aspect of regulation are; use of higher voltage transmission lines, regional reliability planning, and a national power grid. Except for the question of scale, there are at present no other known transmission line siting problems peculiar to SPS facilities.

Interstate transmission lines come under the jurisdiction of both the states and the federal Department of Energy. In many, if not a11, cases, rectennas will be serving more than one state, and therefore both state and federal regulation may be involved. The regu?ation of interstate power transmission is already a critical regulatory issue and effective institutional arrangements should evolve independentiy of the SPS before it becomes operational. There is also the real possibility of federal preemption at least with respect to the SPS.

In summary, the regulation of transmission as it may effect the SPS is in part dependent on technological change and in part on the resolution of the general issue of regional power regulation.

States typically have Disaster Preparedness offices designed to evaluate and, where necessary, impose requirements on large, potentialiy hazardous projects. At the moment, it appears that SPS would not represent any particular hazard even though many existing power plants do. On the other hand, there is extensive -- albeit possibly unfounded -- concern about inadvertent redirection of the microwave transmission which might involve Disaster Preparedness offices. 
Speculation on this issue is clearly outside the scope of this anaiysis, given the extensive research now underway with respect to adverse microwave radiation impact and the degree of targeting reliability in the SPS.

Considerations of seismicity and soils conditions are more appropriately incorporated in the initial site selection process than in subsequent regulatory processing. Except in clearly ineligible areas of known high risk, these concerns may be less relevant to SPS rectennas than to other types of power plants. Unlike nuclear power plants which are particularly sensitive to seismic hazards, or other facilities subject to explosion, the SPS would appear to be relatively insensitive. There is, of course, the potential problem of interruption of services by virtue of broken transmission 1 ines; but the SPS would generally appear to present less of a problem with respect to geological or seismic conditions than virtually any form of existing power plant.

One possible effect in this area that warrants some mention is the potential for ground water heating or chemical leaching. Both of these problems have been noted in passing in some of the descriptive literature for the SPS. There has been no formal determination of the seriousness of these problems.

Obviously, if an aquifer is quite near the surface under a rectenna site there is a potential for adverse effects from ground heating or chemical leaching from the surface of the rectenna. Since no useful estimates of this impact are available, detailed investigation of this type of regulation should be deferred, pending the outcome of other studies and/or the selection of potential sites where such a condition applies.

Right-of-way considerations are also regulated by the state and could interact with SPS construction and operation in several ways. New roads and/or rail lines might be required for construction and, of course, there are the transmission rights-of-way as well. At this time, there would seem to be no considerations that significantly differentiate the SPS rights-of-way from other power plant facilities or create any particular problem as to transmission rights-of-ways. Other rights-of-ways, i.e., rail and road, would be required only briefly during the construction period, at any level where they would represent particularly adverse or extensive impacts. 


\section{LIMITED APPLICABILITY OF PRESENT REGULATORY FRAMEWORK}

There emerged from the research two general considerations which suggest that the current state and local regulatory framework is inadequate to deal with the SPS. On one hand, there are several characteristics of the SPS which are unique and widely divergent from existing and prospective power plants. There are also several aspects of the present regulatory framework which appear inadequate to handle current processing requirements and would clearly be inadequate to handle the particular problems of the SPS.

\section{ATYPICAL PHYSICAL PARAMETERS}

Perhaps the most notable feature of the SPS in terms of provoking surprise or bewilderment on the part of existing regulators is the size of the site. No single power plant, even a multi-unit power facility, requires more than a small fraction of the land area needed for the rectenna. Power plants are often only 100-500 acres in size, and even the largest multi-unit coal-fired plants require only a few thousand acres including extensive buffer zones. This contrasts sharply with the 40,000 to 50,000 acres needed for the SPS. The whole question of the integration of energy planning and land use planning is thus particularly critical.

Perhaps the only analog to the SPS is the energy center or energy park concept. In this concept, several individually large baseload generating units, either nuclear or coal-fired, would be assembled in a single place. Estimates of land required for such regional energy parks range up to 63,000 acres (252 sq. $\mathrm{km}$.). This energy park concept has never been formally proposed. Although it has been studied for several years, the sole public reactions during tentative exploratory hearings in Pennsylvania and New Jersey were overwhelmingly negative.

The large capacity of the SPS is also another atypical feature. There are at this time no existing single-unit generating facilities which would approach five-gigawatt capacity. Typical sizes for new or planned units are in the neighborhood of 1 to 1.5 gigawatts $(1,500$ megawatts). Multi-unit facilities frequently run between two and three gigawatts and at least one such multiunitfacility has been proposed with more than five gigawatt capacity (the San Joaquin Nuclear Plan, for the Los Angeles Department of Water and Power). In these cases however, as in the case of the proposed energy park, the individual generating units are much smaller than five gigawatts. The use of several units rather than a single generating unit to produce an equivalent output tends to improve reliability and reduce reserve requirements.

Much of the existina regulation of power plant siting and operation deals with air and water quality and other environmental controls. One of the unique features of the SPS is that it has no apparent adverse impact on either air quality or water quality. Therefore, SPS rectennas may pose few problems in these two traditionally sensitive areas of regulation.

The large capital requirements associated with SPS also distinguish it from other power plants. Ignoring totally the cost of the satellite, space transportation, and power transmission from orbit, there is still an estimated cost 
of approximately $\$ 2.5$ billion for each rectenna site. This compares with total maximum costs in the neighborhood of $\$ 1-2$ billion for large multi-unit plants, now under consideration.

\section{INADEQUACIES OF EXISTING REGULATION WITH RESPECT TO THE SPS}

As noted in the Section VI, Key Issues, the need for regional coordination of power plant regulation is already emerging as formal power pools and other power sharing arrangements evolve.

Perhaps one of the most salient features of state and local regulations is the fact that they evolve or develop in response to need; this is particularly true of physical regulation. For example, prior to the emergence of air or water quality problems, no regulations were created. These regulations have developed in response to the need for them manifested partly by public outcry in individual states and partly by the passage of federal legislation mandating concern over these problems. As yet there has been no need for a body of regulations dealing with the specific problems created by the SPS.

It may be argued that existing regulatory frameworks are inadequate to deal even with existing power plant siting and facility regulation. Evidences of this are the increased delays in the approval process, and the very limited success of attempts at one-stop shopping designed to reduce the complexity and time of processing. There is extensive jurisdictional conflict among various agencies even at the state level, and further conflict between federal and state agencies.

\section{PROSPECTS FOR FURTHER FEDERAL INVOLVEMENT}

Another element which makes current regulatory processes inapplicable to the SPS and inadequate to deal with it is the prospect and, arguably the necessity, for further federal involvement in energy facility regulation. This research suggests the need and potential for federally mandated state coordination of 1 and use and energy planning $(66,77,81)$. The prospects for voluntary coordination of these two previously unrelated functions do not seem to be particularly encouraging. It may well be, as in the case of water and air quality, that a federal mandate requiring such coordination as a condition of approval or funding may be the necessary catalyst to effect this critical objective.

The situation with respect to the funding and sponsorship of new power-generation technology is also very unclear. The key issue here is governmental support for initial construction of generating facilities, other than small prototype facilities, which because of new and uncertain technology, cannot yet be fully privately financed. At the moment, the states are taking little if any role. in this type of funding support. Apparently, many state regulators, faced with increasing fiscal constraint, hope that the federal government will support whatever the utilities do not fund themselves. 
When federal government makes this commitment, it should increase confidence in new technology for power generation on the part of both utilities and their regulators. Without such a federal comitment, fiscal conservatism and technological uncertainty will combine to reinforce tendencies towards reluctance and risk-avoidance in dealing with radical new power generation technologies. This reluctance currently inhibits even general speculation on the SPS at all levels of state and local regulation. If not resolved in the early phases of SPS development, it could also pose a serious obstacle to the regulatory planning needed to accommodate the SPS. 
VI. KEY REGULATORY ISSUES IN THE REGULATION OF SPS

SITING AND FACILITY REGULATION

\section{Centralization}

There is evidence of a trend toward the construction of relatively few, but extremely large, facilities sited in locations remote from load centers. In many parts of the country, this apparent trend runs directly counter to stated regulatory policies promoting decentralization. Prior unchecked growth on the part of utilities, processing and technological economies of scale and increasingly regional power distribution have all contributed to centralization.

Part of the explanation lies in the history of unchecked growth on the part of the utilities. Large, investor-owned facilities have generally dominated and have tended to increase in size, generally unchecked by regulatory restrictions. For many years both the PUCS and the electric utilities have apparently assumed that the future power plants will be bigger than existing ones (132). Historically, utilities were able to justify increases in plant size by taking advantage of economies of scale and continuing to provide low-cost electricity.

Another factor in the economies of scale is related to the cost of providing the infrastructures associated with conventional power plants. In order to comply with air and water quality standards, more and more water has been necessary. Once a water supply has been located and/or developed there is a natural tendency to place additional units near that source. Similarly, if construction of the first unit required a new rail line or highway, it seems natural to build additional units at the same location to avoid the risk of duplicating the same cost and effort elsewhere.

Technological innovations in the construction of electrical generating facilities, together with the ability to buy certain parts of the plant "off the shelf" have also tended to continue the trend toward large centralized installations.

The processing maze which has sprung up around environmental controls and quality-of-life concerns has resulted in an attitude characterized by the saying that "We might as well be hung for a sheep as a lamb," or that (because of the difficulties involved) it is logical to ask for "more" with each application $(134,132)$.

Some of the state siting legislation seems to have informal "bias" toward centralization which develops from the process application itself. There is a natural break in the permitting process for electrical generating plants: approval of the location and approval of the facility. The location involves zoning, purchase of the land, air and water quality considerations, water deliveries, and other infrastructure. The approval for the facility usually involves safety aspects of construction, pollution abatement, and operating procedures (132). 
Because so many of the difficult questions are resolved in the site selection process, it seems logical for a utility to plan for additional units at the same site and thereby avoid having to deal with the issues at another location when another unit is needed (132).

Among the bellwether states, Florida has a bias toward centralization in that it encourages requesting approval for ultimate capacity when applying for site certification (132). In California, by dividing the process into the Notice of Intention (NOI) and Application for Certification (AFC) phases, the same sort of thing is encouraged (135). Connecticut's planned facilities are in units of 1,000 MW with two or three in the same location (115).

Although there seems to be a lot of research in developing alternative and cheaper methods of producing electricity, nothing has been developed that can provide sufficient capacity to justify a utility's pursuing it. Further, alternative sources of electricity have not yet proven to be as economical.

The regulatory institutions as they are established are not appropriate for implementing "appropriate technology" solutions to energy problems (132). Highly individualized methods of providing energy (individual solar water heaters, solar collectors for providing electricity, etc.) are not a customary part of the planning of the participants in the process (PUCS, Energy Offices and the utilities themselves).

Limitations on local and even regional resources required for power plants, e.g., water and land, tend to drive the siting of large aggregations of plants towards areas where these resources are available and are most easily assembled. Such areas are often distant from projected load centers (66).

There are, however, indications of trends toward decentralization of energy facilities, but these appear to be more in the area of policy than implementation. For example, as more municipalities take on private utility functions in order to enjoy the greatest degree of jurisdictional flexibility and authority, the units built will tend to be smaller.

State Energy Policy offices are often more concerned with energy conservation than in planning generating facilities (66). Many states' policies now favor decentralization as a means of avoiding large sources of pollution and as a method of solving the question of reliability $(66,13)$. The trend in reliability is that the smaller the average unit size, the more reliable the total system (115). Furthermore, the growth in the size of facilities has made the negative effects more visible and therefore to many, more objectionable.

The policy of smaller, decentralized electrical generating facilities is also consistent with the general trend in policies toward "developing alternative energy sources." There is, however, no indication that any attempt is being made to implement these policies in an economical and rational way. And finally, Public Utility Commissions in some states are beginning to think that large, centralized facilities are undesirable (134). 
Perhaps the most difficult and frustrating problem facing state energy planners is the need to prepare long-range plans in the absence of an articulated national energy policy. Choices made at the Federal level could help sharpen the current indecisive state-level approach toward developing new technolagies. Perhaps because of the reactive, rather than creative, nature of many state agencies, conservation and alternative-energy programs often seem to make slow headway; Federal leadership could accelerate such efforts.

Federal decisions, or indecision, affecting oil imports, balance of trade in the area of agriculture, weapons, etc., and natural gas deregulation are examples of the uncertain Federal atmosphere (47). Lack of Federal assistance toward the developing technologies is another area of concern.

Utilities are likely to plan the development of energy facilities in directions where the regulatory environment is favorable -- yet another indication that a coordinated policy is desirable. Due to the increasing financial controls by the PUCs, .a utility's natural response toward energy planning is to ask what proposal has the best chance of implementation.

After the recent experiences with nuclear generating facilities, it is unlikely that the utilities will enter new areas without assurances that the ir investments will come to fruition (79).

\section{New Technology}

There are two aspects of the current environment which tend to affect the development of viable alternative methods of generating electricity. The first issue is the limited availability of funds to implement new technologies and second is the extent to which the existing regulatory framework is favorable or hostile to that technology. 1

Another disincentive toward the development of new technology for alternate energy sources is the question of reliability. If an electric utility were to develop a new source of electric generation, its reliability would initially be in question until a body of experience in operation and maintenance had been accumulated. In order to assure that sufficient power will be available to the customers, the utility might have to provide additional reserve capacity using more conventional technologies. Rate regulators are just beginning to enter the arena of limiting reserve capacity, and it is too early to tell how they will react to a single facility of the size of a rectenna.

1

These issues have been covered in greater detail in Section V (Limited Applicability of Present Regulatory Framework). 


\section{Site Size}

The trend toward larger land requirements for energy facilities is well documented $(77,79)$, and is implicit in the trend toward centralization mentioned above. However, the land requirements for the SPS rectenna are far beyond anything currentiy under consideration, and only the energy parks are comparable (approximately 63,000 acres or $262 \mathrm{sq} . \mathrm{km}$ ). Accumulating sufficient land for these parks does not appear to have been considered a major problem by either the researchers or the reviewers of the concept. Recommendations for coordinated land use and energy planning seem to have been the most consistent response to the issue.

\section{Remoteness}

As aisun.. in the section on centralization, there is a concurrent trend

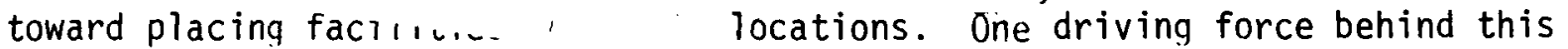
trend is the need to comply with alr quality standards. Obtaining approval for new source pollution permits is certainly easier in areas remote from urban centers. Further, as power pools develop. they are in a position to choose sites from a larger land base so that the placina of actual generation plants will tend to be further from the customer if an unpopulated state is a member of the pool. Interstate pools may also develop in order to take advantage of one state's (e.g., Wyoming's) willingness to permit generating facilities (132).

The response of the electric utility rate requlators to interstate power pools is only beginning to emerge. The states appear to be increasing their jurisdiction over utility combanies. The California Public Utilities Commission, for example, has recently ruled that California-based utilities must obtain PUC approval and demonstrate need before building plants out of state. California's utilities, however, are responding to a growing trend toward planning out-ofstate projects because of the moratorium on nuclear plants in California and because of strict air and water pollution requirements (25).

The Texas Public Utility Commission also maintains that it has the right to control out-of-state construction by its utilities. The El Paso Electric Company has filed an appeal with the district court over a Texas PUC ruling in Arizona. The Company's argument is that the PUC has no jurisdiction in that state. The concept that a state can affect a utility company's practices in another state has far-reaching implications, especially in regard to the SPS (25).

Siting and Land Use Policies

The relationship between land use planning and the construction of an energy facility is a critical one. Local control of land and its uses is a fundamental aspect of the state's rights issue, and beyond that, of the rights of local jurisdictions to decide the development of their own neighborhoods. Unless coordinated planning occurs whereby large areas are set aside for potential rectenna uses far in advance of actual project implementation, some bitter, time consuming and expensive battles could ensue. 
The following quote is from the literature on energy parks:

Calls for more and better planning are commonplace among the plethora of studies competing for attention on governmental bureaucracies.... The kinds of institutional problems posed by siting of energy facilities, whether dispersed (energy) centers, nuclear or nonnuclear, are forcing a recognition of the need for a better meshing together of the planning efforts of the several levels of government (66).

As a key element of the land use planning process, power plant siting activities have become a means to an end. States have realized that the location of energy facilities may well determine where people live, the site of recreational facilities and industrial complexes, as well as trade-offs involved when land is committed to a specific purpose for many years (81).

As the size of our electrical generating system grows in the United States, conflict over the same land increases proportionately. In fact, as one report suggests, "the occasions increase more than proportionately, for the land uses underlying (the) conflicting priorities are also growing, making the claims on land suitable for multiple uses more serious from all sides" (79).

The Berkeley Energy Facility Siting (BEFS) Study categorizes approaches to land use question on a state-by-state basis. The methods range from a case-by-case approach to site banking. The latter is the most specific type of advanced planning that can occur between a utility, a licensing agency and the public. In its idealized form, the decision process would be comprehensive and would begin well in advance of construction. A number of sites would be proposed by the utility, considered, and approved by all cognizant agencies. When the utility needs a new plant, it takes a location "off the shelf," with the assurance that the site-related licensing and permitting difficulties have already been resolved (79).

The State of Maryland legislation mandates an extensive research program for continuing site evaluation and related environmental and land use considerations. Using tax monies, the state purchased some land in advance of any requests by utilities for siting approval, conducted the appropriate research and designated the site as suitable for energy development. When a utility applied to the state for an energy facility, Maryland designated the approved location as the company's site, more or less as a fait accompli. Unfortunately, the utility was unhappy with the lack of involvement, both in the choice of location and in the price negotiations. Further, it was not convinced that 1itigation could be avoided by this method of siting energy facilities $(79,77)$.

A similar situation occurred in Florida. The utilities in that state are now reluctant to name specific pieces of land in their Ten Year Site plans because they fear resulting land speculation and rising prices (79). 
Therefore, although proper zoning and/or land use designation is encouraged in the literature on energy facilities siting, a practicable procedure has yet to be developed $(77,79)$. SPS conformance with land use planning will obviously vary. On parcels of state or federally-owned land conformance is unlikely to be a problem unless the state itself opposes the rectenna. If it can be proven that the SPS is compatible with agricultural uses, and if the state encourages variances by the local municipalities, there should be no major difficulty. However, if the land requirements are so large that small, privately-owned parcels become involved and the public attitude toward microwaves has not changed, difficulties could arise.

\section{Jurisdictional Conflicts}

There are two levels of potential conflicts between jurisdictions in regard to the licensing of an SPS rectenna facility.

First of all, there may be problems within a state resulting from the lack of clarity with which each of the functional classes of regulations is mandated to specific agencies or departments. If application were made, today, for

approval of a rectenna site, it might prove difficult to discover the cognizant agencies. Further, if exact applicability of siting legislation or construction approval were pursued, it would probably be found that no existing legislation applies to the placement or construction of a rectenna. These problems are reviewed at length in several of the references $(3,12,47,64,66,79,81,89$, $103,123)$.

The second source of potential jurisdictional conflict is the lack of framework for regulatory response at the interstate level. As regional power pools and associations develop, there must be a parallel set of regulatory agencies to deal with them. The following are two of the conclusions which resulted from the various studies on the energy park concept which seem to sum up both the problem and a possible response:

Among the array of institutional problems that would have to be solved in order to implement the energy park concept, the issue of multi-level government organization that would have to be developed appears to be the most difficult. The need for regional structures involving federal initiatives and support and major state involvement is strongly indicated.

The NAPA (National Academy of Public Administrators) Panel noted that at the present stage of investigation into the broad range of institutional considerations, opportunities for potential benefits realizable through the energy park concept appear to outweigh the potential disadvantages by a substantial margin (64). 
FINANCIAL AND RATE REGULATION

An extended and detailed consideration of the rate-making process as it will apply to the SPS is not warranted at this time. The huge capital commitments and high degree of technological uncertainty regarding the system clearly demand that new financial-ownership-management structures be evolved before its development and operation. These new structures, or scenarios, will necessarily involve an entirely new type of interaction with state financial regulation of utilities. It may even be, for example, that the systems will be largely exempt from such regulation, as a consequence of federal ownership or specific statutory exemption on the part of the U.S. Congress. Whatever its managementownership structure, however, it is quite probable that the SPS will function as a purveyor of bulk power. The present electrical utilities and/or consortia made up of such utilities would be the buyers of such power. The following very brief analys is of rate regulation has been based on the assumption that the utilities would in fact be buying the power and perhaps providing all or part of the ground facilities.

The potential interaction of the state--through its existing rate regulatory process--and the electrical utilities could have three significant characteristics. These are:

1. The involvement of regulatory authorities in authorizing the purchasing utilities to make commitments for substantial capacity from the SPS operating entity, well in advance of the operational phase of the system.

2. The willingness of the regulatory authorities to permit, and/or incorporate in the rate base, those front-ended expenditures that might be required of the utilities to develop appropriate land facilities in anticipation of SPS-delivered power.

3. The possibility of utilities being asked to pay for a "place in line" and, in some form, to contribute to a consortium or other entity that would operate the land facilities of SPS power. (It is assumed that regulators would be asked to recognize this cost as part of the rate base.)

With respect to all three issues, the probable response of most state regulatory authorities would be overwhelmingly negative at the present time. There is a high degree of resistance to inclusion of CWIP as part of the rate base (as noted in Section III, Exhibit 1 and discussion). The lead time for the SPS may well be even longer than the lead time for current power plants, so that the question of such allowances becomes even more important. 
The problem is significantly exacerbated by the fact that it will be critical for the sponsor entity of the SPS to get commitments from purchasina utilities well in advance of actual operation of the SPS. Without such commitments, it might well be that utilities would proceed to develop their alternative sources of power, which would then become redundant and/or competitive, and would further reduce the profitability of utilities.

In conversation with the staff of an economic regulatory administration of the Department of Energy, certain observations were made with respect to these issues. Most important among these was the fact that state regulation of utilities may be generally characterized by risk, avoidance, an unwillingness to depart from established precedents, and resistance to encouraging utilities to speculate on new technology $(139,140)$. The implication of this attitude for SPS is that regulatory confirmation for bulk power purchases in the future (and/or contribution of front end capital) would not be forthcoming without firm guarantees that the power would be delivered on time at a fixed cost.

It would appear that the only source of such guarantees is the Federal government. In the absence of such guarantees, advance commitment to SPS power would be virtually impossible to obtain, either from the utilities or from those regulating them, prior to full-scale operation and demonstration of the SPS. It may be that the proposed time frame for an operational SPS is inappropriate specifically for this reason. The Federal government must therefore be in a position not only to sponsor the research and development, but also to effectively guarantee the delivered cost of the power. Any scenario which involves major long-term planning on the part of a regulated utility, predicated on the availability of SPS power, must incorporate the present and prospective framework of regulation. It must also be based on a firm cost and not on an adjustment clause permitting increases to be passed on to ratepayers.

\section{RELIABILITY AND RESERVE}

The issue of reliability has heretofore been largely the concern of the utilities; only recently have regulatory agencies become involved. In order to assure adequate electrical supply in the event of a local power failure, the utilities have historically built reserve capacity. The amount of excess capacity has traditionally been unquestioned, since it has ordinarily been provided without undue increases in cost to the ratepayers.

The utilities have had ample reason for maintaining a high degree of reliability through redundant capacity. Higher physical plant costs included in the rate base yield higher total returns to the utility, since the regulated return is based in part on a percentage of the rate base. Further, public aoodwill is a natural concern of the utilities, who thus have an added incentive to keep power supply intact. Moreover, if a blackout can be traced to some neglect on the part of the utility, financial liablity might be charged. One final incentive is that utility personnel are generally engineers, who take pride in developing and maintaining a system that is operational (132). 
However, utility regulators began to probe the question of reliability after the 1965 blackout in the U.S. northeast (and subsequent stoppages). The PUCs are now realizing that large amounts of money invested in a system do not guarantee its reliability.

Improvements in forecasting techniques are likely to result in lower projections of demand for the next decade or two. Although the PUCs are not currentiy performing their own loss-of-load probability calculations, they are encouraging utility companies to rely more heavily on such non-capital intensive methods of providing reliability as increased utilization of load management techniques and greater dependence on equipment reliability (66).

Because base load power supplies have become generally more reliable, and because marginal increases in reliability are very expensive, the regulators have been disallowing what they considered excesses in plant design. Extra transmission lines, and even additional generating units, have sometimes been specifically disallowed in approving requests for Certificate of Public Convenience; the utility, in turn, is not likely to build something not recoverable in its rate base. This control of excess capacity could bring the PUCs into the forefront of siting and construction design regulation, should they choose to exercise it.

Two elements in the area of reliability relate directly to the SPS. First, the formation of power pools allows the individual electric companies to share reserve capacity and yet maintain a high degree of reliability. The development of such pools augurs well for SPS, since a single utility, and possibly even a single state, would not be able to afford or utilize a $5 \mathrm{GW}$ rectenna.

Secondly, the larger the system to which the rectenna is added, the smaller its percentage of total capacity. If the rectenna facility stops operating, it is necessary to pick up that capacity somewhere else immediately. The current rule of thumb is that a utility system must have "spinning reserve" equal to the two largest facilities on line at any moment (132). Thus the larger the facility, the more spinning reserve must be available.

\section{REGIONALIZATION OF THE REGULATORY PROCESS}

Planning considerations mentioned here refer to planning at a regional level within a state but beyond the boundaries of any single utility, and to planning and organizing utilities on a supra-state basis. In any event, it seems apparent that pianning for electrical generation is more successful on a cooperative, regional basis.

The following are some of the advantages of a regional approach to planning: 
1. Changes in the technology of electrical generation, transmission, and distribution have resulted in the expansion of the electric utility industry to the point where service areas determined by corporate interests may supersede the political jurisdictions and geographic boundaries of state and local governments $(66)$.

2. Utility companies have been having difficulty making plans for new plants in some states, such as California, because of regulatory-legislative barriers to certain types of power (nuclear) and strict air pollution and water quality standards (25). As it is easier to build plants in some states than in others, utility companies will tend to combine forces and build on a regional basis.

3. The availability of land in areas where air and water concerns are minimal tends to force utility companies to plan facilities according to those parameters rather than by proximity to the customers.

4. The trends toward centralization also promote the regionalization of power generation. Utilities in one or more states can pool their resources by building a large facility in a remote area, thus reaping the benefits outlined in the section on Centralization.

5. The existing regional organizations, NEPOOL, NYPOOL and PJM (New England Power Pool, New York Power Pool and Pennsylvania, New Jersey and Maryland Power Pool, respectively), have had considerable success in organizing and performing the functions of a single utility. These formal power pools exert day-to-day control on load balancing, as well as providing coordination of planning, reserves, siting and financing of new facilities.

The National Academy of Public Administration reports that:

Pursuant to the FPC recomendations, regional Electric Reliability Councils (ERC's) were formed in conjunction with a National Electric Reliability Council (NERC) representing about 95\% of the nation's load capacity. Under the aegis of the NERC, and in response to an FPC Order requesting annually updated data in twelve categories, the ERC's submit data regarding planned capacity additions unit retirements, construction programs, etc. These data are then aggregated by the FPC and made available for planning purposes; but it should be stressed that the utility associations are voluntary in nature, that compliance with the FPC is necessarily discretionary, and that no comparable government planning structure exists. In fact, in 
recent years the Southern Governor's Conference has created a

Southern Interstate Nuclear Board for the purpose of acting as an independent regional advisory body for energy development, and the Western Governor's Conference has followed with the creation of a similar Western Interstate Nuclear Board; but the New

England Regional Commission (created under Title $V$ of the Public Works and Economic Development Act of 1965) states more directly, that "At the present time there is no regional government counterpart to NEPOOL (New England Power Pool) with authority to provide for public review of the NEPLAN forecast (66).

Notably absent from the increasing trend toward regionalization is any formal or informal structure for coordinating the regulatory responses of the invclved states. Two possibie sources for formal regulatory coordination are (1) voluntary, interstate agreements, and (2) federally-mandated regional planning. Each would require explicit delineation of rights and obligations of of the participating state regulatory agencies. Awareness of the need for such coordination is reinforced through a review of the Energy Center literature and in conversations with knowledgeable informants. At the same time, these sources reveal considerable skepticism about the success of any voluntary efforts $(47,66,128,139)$.

In 1975, under a U.S. Nuclear Regulatory Commission contract, the Southern Interstate Nuclear Board (SINB) conducted a study of the feasibility and applicability of a regional approach to power plant siting. The study, "The Objectives and Institutional Mechanisms of a Regional Approach to Nuclear Power Plant Siting," established the validity of a regional siting concept and produced a detailed procedure for regional-interstate site review. Study of the implementation of this procedure was suggested in the SINB report "Power Plant Siting in the United States." It is not known whether the results have been published as of this writing.

This current trend toward regionalization of energy facilities, while possibly creating new dimensions in the area of regulation, is likely to promote the frameworks necessary for developing the SPS rectennas. There appears to be a growing recognition of the advantages in some system of providing bulk power (generating plants and transmission lines) under the aegis of large, regional organizations. Only through regional management is it feasible to take full advantage of the size of the generating capacity of a rectenna.

\section{INTERACTION WITH FEDERAL NATIONAL POWER GRID PROGRAM}

In 1977, Senator Metcalf proposed the National Electrical Energy Reliability and Conservation Act (S.1991). The Department of Energy was asked to perform a study on the apparent viability of the national network of high capacity, extra high voltage lines, more fully coordinated planning, and potential bulk supply power corporation proposed in this bill. The Secretary of Energy 
committed to perform such a study and assigned it to the Office of Utility Systems. The inhouse study began in November 1977 and an extensive request for proposal (RFP) effort was initiated in April 1978.

Presently the "National Power Grid Study," represented by the proposed major contracting effort resulting from these studies, is at a state of analysis that is somewhat analogous to the state of the evaluation effort for the SPS. Many of the issues that are directly relevant to the institutional framework within which the SPS might operate are also critical to the national power grid study; these issues include (1) the need for better coordination, (2) increasingly regionalized supply, and (3) the uncertainty associated with long time frame.

In this context, it is useful to review the major objectives of the current study effort in the National Power Grid Project Plan. The "National Power Grid Study Project Plan"(86) indicates that the actual contracts for the various parts of the study are to be let in August of 1978, the individual component contracts are to be completed by early 1979, and the final report is to be completed by the second quarter of 1979.

Thirteen major objectives cited in the study are as follows:

Group 1: Develop National Power Grid Concepts and Issues

1. National power grid concepts.

2. National power grid issues.

3. Public, private, and cooperative systems.

\section{Group 2: Bulk Power Supply Improvement Potential}

4. Generation cost and fuel conservation.

5. Diversity utilization.

6. Coal by wire.

7. Bulk power grid capability.

8. Emergency transfers.

\section{Group 3: Technical and Institutional Impediments}

9. Federal and state statutes and regulatory practices.

10. Industry planning and operating processes.

11. Financial decision processes.

Group 4: Impact of Proposed Legislation

12. Economic and structural implications of S.1991.

13. Competition.

The "Technical and Institutional Impediments," described as Group 3, above, are directly relevant to the SPS. To a large extent, they overlap the content of the present study (although they specifically include federal regulation). 
Close monitoring, and possible expansion, of the results of this effort may illuminate specific interactions with the SPS evaluation effort.

While SPS is not explicitly a "bulk power" source at this time, it is likely that the institutional and ownership arrangements required to fund and operate it will create an entity whose primary function is to sell bulk power. Further, the critical question of reliability is directly dependent on the size and extent of the grid into which SPS power is fed: the larger the grid, presumably the lower the extra reserve margins required tor the SPS. This latter point is more relevantly considered under the issue of "utility integration."

In summary, even in the narrow context of state and local regulation, the ongoing national power grid evaluation effort may contribute significant insights into the problems of regional control, jurisdictional interface, and the need for new institutions. All of these issues have emerged as key regulatory problems in the power grid study. 
VII. "SUB-NATIONAL" POWER PLANT REgULATION IN OTHER COUNTRIES

SCOPE AND DEFINITION OF ANALYSIS

In the United States (and a few other countries in the world), there are three definately separate levels of regulation: federal, state (provincial) and local (municipal). A limited literature search as well as a general knowledge of international political structures indicates that this explicity federal form of government is the exception rather than the rule in the governments of the world. Selected European countries, Canada, and Australia are somewhat unique in representing truly effective federal structures -- these are among the few nations in which the sub-national governmental agencies, specifically the state or province, have a degree of sovereignty adequate to override or obstruct decisions of national policy.

This distinction seems particularly significant in the case where other countries will have a dearee of regulation over the SPS. Although there exists a real possibility that the SPS program may become an international rather than a domestic program, this issue is still being explored and there is no joint commitment to such a program, even in the evaluation stages, at this time. The subject of international participation requiring changes in international organization is being dealt. with in a separate White Paper. In the context of this research, the regulation question has been narrowed to whether or not analogs exist in other countries for the state and local regulation of power plant siting and operation as it exists in the United States.

\section{PRELIMINARY GENERAL FINDINGS}

A brief literature search and limited discussion with informed sources froduced the following highly general observations, many of which may be more in the nature of initial surmise rather than of formal conclusions:

1. Effectively federal forms of national governments in which state or provincial entities have significant powers to obstruct or override Federal decisions are fairly unusual.

2. The degree and extent of power plant siting and environmental regulation seems much more highly evolved in the United States than virtualiy anywhere else in the world.

3. What evidence there is of detailed regulation of power plants siting at any level seem to be either concentrated in the more highly industrialized countries, or largely oriented to restrictions and safety provisions in the location of nuclear power plants

4. Notwithstanding the absence of state or provincial regulation, there is a pattern in the more industrialized nations of limited local participation in power plant siting decisions.

This latter point is of particular significance since it would seem to correspond much more appropriately to city or county levels of regulation than to 
the pattern of state regulation in the United States. Such things as building permits, fire inspections, conformance with local zoning or land use codes do appear to exist in other countries.

What limited specific data could be obtained on this issue is derived largely from countries belonging to the Organization for Economic Cooperation and Development (OECD).

\section{REGULATORY PATTERNS IN OECD COUNTRIES}

A preliminary literature research indicated that most power plant regulation in the OECD countries is oriented toward regulation of nuclear power plants. Apparently, except for the nuclear power plants, no specialized process has evolved for coordinating local or state approvals for power plant sitings.

In general, the pattern seems to be one of notification and solicitation of comments from local, i.e. municipal authorities. Sometimes the transmission of this data does go through a provincial, departmental or prefect official.

In general, even in the federalized countries of Europe, the veto powers or jurisdictions of the state or provincial governments are quite limited. For example, in West Germany, one of the most highly evolved federal governments in Europe, the law states that regional and municipal authorities "may be involved in the licensing procedure to the extent that their proper jurisdiction is concerned." Similarly, in Switzerland the only specific reference to the Canton (province) is that the Federal Office of Energy Economy must "obtain the opinion of the Canton in which the installation is to be constructed." (65) Cantonal authorities are also responsible for authorizing the facility under building, fire and water regulations. In Belgium, France, and the United Kingdom, the responsibility for approving a site rests with the national authorities. There are, however, provisions -- mandatory in some cases and optional in others -- for public notification, public hearings, and the solicitation of opinions from local government.

In summary, it would appear that even in the very sensitive area of nuclear regulation, power siting control is not nearly as highly evolved elsewhere as it is in the United States. Futher, participation on the part of either state provincial or purely local authorities seems to be largely informational in nature with few if any indications of pure veto power of the type that is characteristic of the United States.

While the particular data source did not discuss Canada in depth, the provincial governments have, if anything, greater autonomy in matters relating to resources and, by extension, energy than the states in the U.S. Some of this authority has been preempted with respect to nuclear development - an explicit federal function in Canada. It is not clear, without extensive further research, what the precise boundaries of jurisdictional control in the matter of siting non-nuclear projects in Canada. A similar, but even more generalized, 
observation may be made with respect to Australia; there, the various component states have fairly highly developed autonomy in many jurisdictional areas.

\section{THIRD WORLD AND DEVELOPING NATIONS}

For the most part, third world countries are dominated by centrally planned economies. Local opposition to governmentally-approved rectenna facilities is therefore unlikely to cause significant changes in the plans for siting. Assuming future conditions similar to those existing today, local opposition is likely to be sporadic or feeble.

Local opposition to govermentally approved facilities is particularly unlikely to be a major consideration in developing countries if present trends continue to apply. Power plant siting is likely to be accomplished as part of an overall development plan in the locality of the rectenna site. Futhermore, concern for the environment is generally weaker in these countries, and western environmental considerations are often regarded as an attempt to inhibit growth in the less developed countries. Income and employment are clearly the overriding goals in these countries. 


\section{RECOMMENDATIONS FOR FURTHER STUDY}

\section{LIMITED VALUE OF FURTHER INDEPENDENT PROCEDURAL RESEARCH}

Any attempt to deal meaningfully with state and local regulation of power plant siting and operation, or directly with state agencies, necessarily involves wading through a morass of detail about procedures, jurisdictions, and case law. Because of the limited applicability of the present framework of regulation to the SPS, additional research in this area seems unwarranted. However, such detailed analysis is often a pre-requisite for identifying significant issues or vectors in regulation which may, in fact, be meaningful to the evaluation of the SPS.

The rewards of further independent, detailed procedural research will probably be fairly minor, although some reinforcment of the research from similar studies to synthesize patterns and generic issues from detailed research would be valuable. Some of the issues or vectors which have been identified in this report are suited to a more limited and focused study of regulatory issues.

\section{REINFORCEMENT OF ONGOING STUDIES}

The study of critical issues in power plant regulation by the Berkeley Energy Facility Siting Study (BEFS Study) have al ready been noted as a key data source. Further, the study, funded by the Department of Energy, is staffed by individuals who are quite knowledgeable and have been very helpful in the conduct of this research. Although technically their charter is to consider only coalfired power plants, the substance of their research covers much if not all of the ground of the "detailed procedural research" required for the analysis of SPS regulatory issues.

The BEFS Study has not explicitly considered the SPS, and its staff was generally uninformed and skeptical. They are, however, well qualified to draw useful and relevant conclusions about patterns and trends in regulation. At the very least, their completed study should be reviewed in detail for its implications for the SPS.

Consideration also should be given to possibly expanding the scope of their effort to deal specifically with the SPS, possibly in cooperation with DOE staff or current consultants, who are already familiar with the SPS issue.

The Southern Interstate Nuclear Board (SINB) has been interested in the question of regional planning and regional regulation for some time. There is currently a study effort or the subject of regional control of power plant siting which apparently does address the prospects and problems in coordinating state regulation. This study should be investigated and certainly evaluated in light of its implications for the SPS.

Historically, some parallel efforts in identifying key issues and prospects for state regulation of utilities have been undertaken by both the National Association of Public Administrators and the Western Interstate Energy Board (formerly Western Interstate Nuclear Board). 
In general, the options available to DOE for future study in coordination with these studies include:

1. Careful review of findings and interpretations for the SPS by other consultants directly retained by DOE and familiar with the SPS.

2. Limited "add-ons" to their present scope of work in conjunction with consultants already familiar with the SPS

3. Authorization of additional studies to address the SPS issues.

NEED FOR ADDITIONAL ISSUES OR "VECTORS" RESEARCH

The issue of Centralization, probably warrants further investigation, This need not take the form of extended detailed research, but rather should be an overview and a projection of increasing centralization. It is important that centralization be considered not only in terms of the total generating capacities of individual plants, but also the capacity of individual units within these plants.

Such research into centralization need not be restricted simply to the regulatory framework but might also consider reliability and reserve.

Clearly regionalization is an issue that needs further examination. Once again, there is no need for an extensive catalogue of detailed procedures. Instead, a systematic examination, including extensive personal interviews of existing regional organizations and their observations and the implications of their operations for regional control and regulation, is probably worthwhile.

\section{INTERFACE WITH LAND USE AND SITING STUDIES}

One problem with any attempt to study state and local regulation is that it does not easily lend itself to abstraction. Meaningful response as to the character and rigor could only be obtained in the context of a specific problem. This is clear evidence that in a large society many types of regulations can be classified as "location-dependent". A possibly still premature way of dealing with this process would be to coordinate the regulatory efforts with the siting and land use efforts. It should be possible, and in fact would parallel some efforts being made by Arthur D. Little Inc. for Marshall Space Center, to take one or a small subset of potential sites and actually do a paper-processing exercises to identify what limitations would be encountered. This would be analagous or identical to the recent study by the Institute for Telecommunications on radio frequency interference (RFI) effect on two tentative sites in the Mojave Desert.

In any case, regulatory considerations should certainly be integrated in with the next iteration of the siting and land use aspect of the SPS evaluation. 


\section{REFERENCES}

1. Andersen, Stephen, et al., Cal ifornia Energy, The Economic Factors, Federal Reserve Bank of San Francisco, 1976.

2. Association of Bay Area Governments and State of California, Governor's office of Planning and Research, Bay Area Permit Directory for Industrial Development, November 1977.

3. Baroff, J.H., and D.H. Hovey, State-of-the-Art Review of Socioeconomic and Institutional Aspects of Energy Facility Siting, (report for The Center for the Study of Environmental Policy, Pennsylvania State University, \#RF-TPSU-JB-76049-83 (Phase One)), The Energy Center, Washington, D.C., February 7, 1977.

4. Batinovich, Robert, California Public Utilities Commission, "The 'In All Events Tariff'--It Means What It Says," undated.

5. Bos, Piet B., Director, New Energy Resources Department, Electric Power Research Institute, "Advanced Technologies: An Overview," speech, (Palo Alto, California), undated.

6. Brooker, T. Kimball, Managing Director of Morgan Stanley \& Co., Inc., address before the Western Conference of Public Service Commissions, Energy Seminar, (program by the Pacific Coast Gas Association), February 5, 1976.

7. $\quad$ prepared direct testimony on behalf of Pacific Indonesia LNG Company and Western LNG Terminal Company, In the Matter of Pacific Indonesia LNG Company, et a1., before the Federal Power Commission, Docket No. CP74-160, et aT.

8. Brookhaven National Laboratory, Energy Policy Analysis Group, et al., Prel iminary Assessment of a Hypothetical Nuclear Energy Center in New Jersey, BNL 50465, (Upton, New York), November 1975.

9. Burchell, Robert W. and David Listokin, The Environmental Impact Handbook, Center for Urban Policy Research, Rutgers-The State University, New Brunswick, New Jersey, 1975. (Updated draft of chapter entitled "EIS Progeny at the State, County, and Local Levels" provided by Burchell, August 1978.)

10. California Energy Commission, Energy Resources Conservation and Development Commission, Staff Report on Data Adequacy, Pacific Gas \& Electric Company, Stanislaus Nuclear Project, Notice of Intention (NOI), Docket No. 77-NOI-3, November 1977.

11. Staff Report on Data Adequacy, Southern California Edison Company, Combined Cycle Generating Station, Notice of Intention (NOI), Docket No. 77-NOI-1, December 1977. 
12. , Warren-Alquist Act, June 1978.

13. California Energy Resources Conservation and Development Commission*, California Energy Trends and Choices, Volume 7, Power Plant Siting, 1977 Biennial Report of the State Energy Commission, 1977.

14. - Final Report on the San Diego Gas and Electric Company's Notice of Intention to Seek Certification for the Sundesert Nuclear Project, November 1977.

15. Geothermal Policy Option Paper for the Development of Notice of Intention Regulations for Geothermal Power Plants, January 18, 1978.

16. , Siting Manual - Thermal Power Plant Site Screening and Site Evaluation, (EDAW, Inc.), September 1976.

17. Energy Facility Siting Division, Underground Siting of Nuclear Power Plants - A Discussion of Relevant Issues, September 3, 1976.

18. California Public Utilities Commission, In the Matter of the Application of Southern California Edison Company for a Certificate That Present and Future Public Convenience and Necessity Require or Will Require the Construction and Operation by Applicant of Combined Cycle Electric Generating Unit Nos. 1, 2 and 3 at a Site Known as Lucerne Valley Generating Station..., Application No. 54148, July 2, 1973.

19. $\quad$ Rules Relating to the Planning and Construction of Facilities for the Generation of Electricity and Certain Electric Transmission Facilities, General Order 131-A, effective February 20, 1976.

20. , Rules of Practice and Procedure.

21. California, State of, Public Utilities Code, and Related Constitutional Provisions, (Division 1 . Regulation of Public Utilities, and Division 2. Regulation of Related Businesses by the Public Utilities Comission), 1977.

22. , Roster, 1977-78.

* "California Energy Resources Conservation and Development Commission" is the formal legal name of the agency. In several recent publications, the shortened name "Cal ifornia Energy Commission" (CEC) has been used. The two names apply to the same agency. Citations here are in conformance with the primary title page reference. 
REFERENCES

(Continued)

23. California State Water Resources Control Board, The Porter-Cologne Water Quality Control Act, and Related Code Sections (Including 1977 Amendments), January 1978.

24. "Regulations Concerning Waste Discharge Requirements, National Pollutant Discharge Elimination System," California Administrative Code, Title 23, Chapter 3, March 1977.

25. The Center for Policy Process, The Trend Report, A Forecast and Evaluation of Developments in the United States, Volume 1, 1978.

26. Colorado Air Pollution Control Commission, Department of Health, Colorado Air Quality Control Regulations and Ambient Air Quality Standards, undated.

27. Colorado Division of Planning, Department of Local Affairs, Winter Resource Management Plan: Manual for Use of the Colorado Review Process and Impact Analysis Guidelines, August 1976.

28. Colorado Public Utilities Commission, decisions regarding application of Public Service Company of Colorado, 550 15th Street, Denver, Colorado, for a Certificate of Public Convenience and Necessity for the construction, operation and maintenance of a steam electric generating plant to be known as the Pawnee Steam Electric Generating Station, near Brush, Colorado, Application No. 28815 (December 1, 1975), Decision No. 88670 (Apri1 30, 1976), and Decision No. 90066 (January 25, 1977).

29. In the Matter of Proposed Increased Rates and Charges Contained in Tariff Revisions Filed by Public Service Company of Colorado Under Advice Letter No. 715-Electric, Advice Letter No. 716-Electric, Advice Letter No. 249-Gas, and Advice Letter No. 250-Gas, Investigation and Suspension, Docket No. 1200, Decision and Order of the Commission, Decision No. C78-1018, August 1, 1978.

30. Rules of Practice and Procedure, effective November 1970 with amendments to November 15, 1974.

31. Colorado, State of, Colorado Water Quality Control Act, Title 25, Article 8, reproduced by the Colorado Department of Health, July 1975.

32. Environmental Permit Directory, 1977.

33. Governor's Energy Policy Council, The Colorado Energy Conservation Plan, (submitted to the Federal Energy Administration), March 28, 1977.

34. Colorado Water Quality Control, Department of Health, Water Quality Standards for Colorado, adopted May 2, 1978, effective July 20, 1978. 
35. Cone, B.W., et al., An Analysis of Federal Incentives Used to Stimulate Energy Production, An Executive Summary, (for the Division of Conservation and Solar Applications, Department of Energy), PNL-2410, Battelle Pacific Northwest Laboratories, Richland, Washington, March 1978.

36. Connecticut Law Journal, "Administrative Regulations, Power Facility Evaluation Council," July 18, 1972.

37. Connecticut Office of Policy and Management, Conservation and Development Policies Plan, Proposed Revision of 1979, Summary Report, (Hartford, Connecticut).

38. Connecticut Power Facility Evaluation Council, Community Antenna Television Tower Rules of Practice.

39. Connecticut Public Utilities Commission, Administrative Regulations, December 21, 1971.

40. Connecticut, State of, Public Utility Environmental Standards Act, Chapter 227a, (includes amendments through 1978 Session of General Assembly).

41. Council of State Governments, The States and Electric Utility Regulation, 1977.

42. Council on Environmental Quality, Environmental Quality - 1977, December 1977.

43. ECON, Inc., Political and Legal Implications of Developing and Operating a Satellite Power System, 77-195-1, August 1977.

44. Electric Power Research Institute, State and Federal Regulatory Commissions Rate Design Activities, July 12, 1977.

45. Electrical Week, "FERC Sets Cash Need - At Issue in CWIP Test Case," June 5,1978 .

46. "White House Consumer Office Intervenes at FERC to Oppose CWIP in Rates," August 7, 1978.

47. * The Energy Center, Issues in Power Plant Siting, The 94th Congress and The States, (report for the Federal Energy Administration, Office of Siting), P-05-77-4428-0, (Washington, D.C.), January 15, 1977.

48. Environment, "Electric Power: Who Pays for Expansion?" June-July 1977.

49. Field Research Corporation, Awareness of Peak Load Demand as Related to Electricity, (conducted for California State Energy Commission), May 1977.

* A brief description of this document is provided in Appendix $A$. 
REFERENCES

(Cont inued)

50. Finder, Alan E., The States and Electric Utility Regulation, The Council of of State Governments, Iron Works Pike, Lexington, Kentucky, February 1977.

51. Florida Department of Environmental Regulation, "Application for Certification of Proposed Electrical Power Generating Plant Site," DER Form PERM 19-1, August 7, 1978.

52. Florida Division of State Planning, Department of Administration, Annual Progress Report on State and Regional Planning, 1976-77.

53. The Florida State Comprehensive Plan, Utilities Element, (Draft), August 15, 1977.

54. $\quad$ Forms and Instructions for Preparation of Ten-Year Site Plans for Electrical Generating Facilities and Associated Transmission Lines, January 1, 1977 .

55. $\quad$ Rules of Practice and Procedure Pertaining to Developments of Regional Impact, Chapter 22F-1, Part II.

56. Florida Public Service Commission, Evaluation of 1977 Ten-Year Site Plans, March 22, 1978.

57. , Engineering Department, Electrical Engineering Section, Latest Preliminary Report of the Florida Public Service Commission, (concerning Application for Site Certification, Coal Fired 235 Megawatt, Deerhaven Unit No. 2, Gainesville Alachua County Regional Electric, Water, \& Sewer Utilities Board), February 10, 1978.

58. $\quad$ "Presentation of Joseph D. Jenkins, Electrical Engineering Supervisor," before the Federal Environmental Protection Agency," (concerning the Application of Florida Power Corporation for IIPEDES Permit Nos. FL0002992 and FL0036081, Clearwater, Florida, June 28, 1978.

59. Florida, State of, Committee Substitute for House Bill No. 1543, Chapter 74-196.

60 . - 1976 Revised Florida Plant Site Act, Chapter 403, Part II.

61. Fortune, "For the Utilities, It's a Fight for Survival," March 1975.

62. Four Corners Regional Commission, 1976 Annual Report.

63.

64. General Electric Company, Center for Energy Systems, Assessment of Energy Parks Vs. Dispersed Electric Power General Facilities, Final Report, NSF Grant OEP74-22625 A01, (Washington, D.C.), May 30, 1975.

${ }^{\star}$ A brief description of this document is provided in Appendix $A$. 
65. International Atomic Energy Agency, Siting of Nuclear Facilities, Proceedings of a Symposium Jointly Organized by The International Atomic Energy Agency and the OECD Nuclear Energy Agency, Vienna, December 9-13, 1974, (Vienna, 1975).

66. National Academy of Publ ic Administration, The Institutional Aspects of the Energy Centers Concept, (Washington, D.C.), March 1977.

67. National Association of Regulatory Utility Commissioners, 1976 Annual Report on Utility and Carrier Regulation of the National Association of Regulatory Utility Commissioners.

68. National Economic Research Associates, Inc. An Overview of Regulated Ratemaking in the United States: Topic 1.1, (prepared for Electric Utility Rate Design Study: A nationwide effort by the Electric Power Research Institute, the Edison Electric Institute, the American Public Power Association, and the National Rural Electric Cooperative Association for the National Association of Regulatory Utility Commissioners), February 2, 1977.

69. National Electric Reliability Council, 7th Annual Review of Overall Reliability and Adequacy of the North American Bulk Power Systems, (Princeton, New Jersey), July 1977.

70. , 1977 Annual Report, (Princeton, New Jersey).

71. Fossil and Nuclear Fuel for Electric Utility Generation Requirements and Constraints, 1977-1986, (Princeton, New Jersey), August 1977.

72. National Research Council, Commission on Natural Resources, Committee on Energy and the Environment, Implications of Environmental Regulations for Energy Production and Consumption, National Academy of Sciences, Washington, D.C., 1977.

73. Organisation for Economic Co-operation and Development, Nuclear Energy Agency, Nuclear Legislation, Analytical Study, Regulations Governing Nuclear Installations and Radiation Protection, 1972.

74. Perl, Dr. Lewis J., Vice President, National Economic Research Associates, Inc., "The Impact of Environmental Standards on the Financial Viability of the Electric Utility Industry," speech presented at The Edison Electric Institute, Financial Division, Annual Meeting, New York, New York, May $19,1978$.

75. Porte, Joan E., Solar Legislation of the Fifty States, Consumer Action Now, Inc., Washington, D.C., Apri1 19, 1978.

* A brief description of this document is provided in Appendix $A$. 
76. Reuy1, John S., Energy Futures for California: A Conference to Explore the Alternatives, (prepared for Energy Systems Integration Office, California Energy Resources Conservation and Development Commission), JSR Associates, Palo Alto, California, September 1977.

77. Rossi, Lyna Wiggins, and Dan Wormhoudt, Trends in the Siting of Conventional Coal-Fired Power Plants, (a report of the Berkeley Energy Facility Study to the Office of Environmental Policy Analysis, U.S. Energy Research and Development Administration, Department of Energy), October 1977 Progress Report of the Land Use Component, Institute of Urban and Regional Development. (Draft, subject to revision)

78. Rowe, Peter G. et al., Principles for Local Environmental Management, Ballinger Publishing Company, Cambridge, Massachusetts, 1978.

79. Schroeder, Chris, and John Wiley, Earl Warren Legal Institute, University of California, State Facility Siting Legislation and Its Impact on the Siting of Coal-Fired Power Plants, (Draft - Subject to Revision), (prepared for the Office of Environmental Policy Analys is of the Energy Research and Development Administration, Department of Energy), Lawrence Berkeley Laboratory and the University of California, Berkeley, October 1977.

80. Smith, Don S, and A. Angela Lancaster, "Nuclear Power's Effects on Electric Rate Making," Public Utilities Fortnightly, February 2, 1978.

81. Southern Interstate Nuclear Board, Power Plant Siting in the United States, June 1976.

82. TRW, Energy Systems Management Division, California Electricity Generation Methods Assessment Project, Final Report, (prepared for California Energy Resources Conservation and Development Commission), 1459.77.009-EJ, January $30,1977$.

83. University of California, Los Angeles, Environmental Science and Engineering Program, An Assessment of Electric Power Generating Options for the State of California, (Summary), Contract No. 4-0125, August 1977.

84 . - Power Plant Siting Assessment Methodology: A Case Study Utilizing Coal Gasification Combined Cycle Along the Southern Coast of California, Report No. 77-25, November 1977.

85. U.S. Army Corps of Engineers, Florida Department of Environmental Regulation, and Florida Department of Natural Resources, Application for Construction, Dredging and Filling in the Waters of Florida, September 1, 1977.

86. U.S. Federal Energy Regulatory Commission, National Power Grid Study, Project Plan, May 12, 1978. 
87. U.S. News \& World Report, "Reasons U.S. May Not be Number One in Nuclear Energy Much Longer," JuTy 11, 1977.

88. U.S. Nuclear Regulatory Commission, Office of State Programs, Improving Regulatory Effectiveness, (Draft), March 28, 1977.

89. The Western Interstate Nuclear Board, Regional Factors in Planning and Siting Electrical Energy Facilities in the Western States, (prepared for the U.S. Nuclear Regulatory Commission, Office of Standards Development, (49-24)-0249, (Lakewood, Colorado), Apri1 5, 1977.

90. Western Systems Coordinating Counci7, Ten-Year Coordinated Plan Summary, 1978-1987, May 1978.

A brief description of this document is provided in Appendix A. 
CALIFORNIA, STATE OF

101. Energy Commission, John Burton, Information Officer, July 1978.

102. __ Engineering and Environmental Division, Dave Maul, July 1978.

103. _ Projects Administration, Steve Williams, Chief, July 1978.

104. Office of Planning and Research, Laurie K. Wright, July 1978.

105. Public Utilities Commission, Division of Policy and Planning, Barbara Barkovich, August 1978.

106. , Andy Tokmakoff, JuTy 1978.

107. , Lesley S. Witt, Advisor and Counsel to the President, JuTy 1978.

COLORADO, STATE OF

108. Department of Natural Resources, Bob Seik, July 1978.

109. Division of Planning, Department of Local Affairs, Charlie Jordan, July 1978.

110. Public Utilities Commission, Ray Garrison, July 1978.

CONNECTICUT, STATE OF

111. Department of Environmental Protection, Coastal Area Management, Arthur Rocque, Acting Director, August 1978.

112. , Planning Section, Joe Laforte, July 1978.

113. , Planning Section, George Seel, July 1978.

114. Office of Policy and Management, Comprehensive Planning Division, Terry Schnure, Assistant Director, July 1978.

115. , Energy Division, Joe Bellanger, August 1978.

116. , Energy Division, Sister Claire Markham, July 1978.

117. Public Utilities Control Authority, Rate Structure Department, Larry Pederson, July 1978.

118. Electric Power Research Institute, New Energy Resources, Piet B. Bos, Department Director, July 1978. 
REFERENCES: PERSONAL COMMUNICATIONS

(Continued)

119. , Solar Program, John Cummings, Manager, July 1978.

120. Environmental Law Institute, Warren Brown, Planner, July 1978.

$121 . \ldots$ G Gayle Hayes, July 1978.

122. Federal Regional Council, Mike Hammer, July 1978.

FLORIDA, STATE OF

123. Bureau of Coastal Zone Management, Jim Quinn, Coastal Zone Planner, July 1978 .

124. Department of Environmental Regulation, Buck Oven, July 1978.

125. Division of State Planning, Bill Durant, July 1978.

126. Public Service Commission, Engineering Department, Joseph D. Jenkins, P.E., Electrical Engineering Supervisor, July 1978.

127. , Wayne Mákin, July 1978.

128. Little, Arthur D., Inc., Betty We iner, July 1978.

129. Northeast Utilities, Nicholas Derewianka, July 1978.

130. Rutgers University, Center for Urban Policy Research, Robert Burche1l, July 1978.

131. Solar Energy Research Institute, Bruce Douglas Green, July 1978.

132. Armour, Schroeder, St. John, Wilcox and Goodin, San Francisco, Robert A. Enholm, Senior Analyst, July-August, 1978 (Mr. Enholm is a student at Boalt Hall School of Law, University of California, Berkeley.)

133. , Christopher T. Schroeder, Partner, August 1978.

134. University of California, Berkeley, Institute of Urban and Regional Development, Daniel T. Wormhoudt, Project Director, August 1978.

135. University of California, Los Angeles, Environmental Science and Engineering Program, Bart Sokolow, Ph.D., July-August 1978.

136. U.S. Department of Energy, Los Angeles, Ken Brunot, July 1978.

137. U.S. Department of Energy, Los Angeles, Harry Dotson, July 1978.

138. U.S. Department of Energy, San Francisco, Intergovernmental Affairs, Office, Judy Plotka, JuTy-August, 1978. 
139. , Washington, D.C., Economic Regulatory Administration, Division of Power Supply and Reliability, Charles Falcon, Director, July 1978.

140. Washington, D.C., Economic Regulatory Administration, Systems Analysis Branch, Alan Starr, Chief of Power Supply \& Reliability, July 1978.

141. U.S. Environmental Protection Agency, Office of Energy Activity, Dan Kimbal, July 1978.

142. Western Interstate Energy Board/WINB, Doug Larson, July 1978.

143. , John L. Watson, Executive Director, August 1978. 
47. The Energy Center, Issues in Power Plant Siting, The 94th Congress and The States, Washington, D.C., January 15, 1977.

Description:

This report was prepared for the Federal Energy Administration, Office of Siting for submittal to the Siting and Licensing Working Group of the Energy Resources Council (Subcommittee on Electricity). The report was prepared by the Energy Center and represents primarily a review of legislative and administrative activity in power plant siting in both the States and the Federal Government during the period of the 94th Congress (1975-1976). Included is a review of previous activity which would affect the thinking of anyone drafting Federal legislation for the future. After describing factual information, ten general power plant siting issues were identified and analyzed. Recommendations for action are also provided.

Of use to the SPS study: Some of the ten generic power plant siting issues were quite relevant to the construction of a rectenna facility. The observations of the Energy Center both as to issues and recommendations were valuable inputs to the discussion of regulatory issues that may affect the SPS.

Availability: FEA Purchase Order \#P-05-77-4428-0.

64. General Electric Company, Center for Energy Systems, Assessment of Energy Parks Vs. Dispersed Electric Power Generating Facilities, Final Report, May 30, 1975.

Description:

Under a grant from the Office of Energy Research and Development Policy of the National Science Foundation, the General Electric Company carried out a generalized assessment of the energy parks, or energy centers, concept in comparison with the conventional practice of dispersed, distributed siting of electric generating plants. The study was accomplished during the period July 1, 1974 through May 30, 1975.

The overall objective of the study was to examine and compare the technical, economic, environmental and institutional issues related to the energy park concept and to identify the obstacles, benefits and penalties that would result if the concept were adopted.

Concommittant objectives were (1) to identify major research and development needs, both technological and institutional, and (2) to identify possible approaches to resolution of significant policy issues associated with the energy park concept. The time frame of the study assumes initial generating unit start-up in 1985 and completion of construction about 20 years later. 
The energy parks described in this study consist of either 20 nuclear (light water) reactor units, each generating 1,300 megawatts for a total of 26,000 MW or 24 fossil fuel (coal) units, eight each at $885 \mathrm{MW}, 1,075 \mathrm{MW}$ and $1,320 \mathrm{MW}$ for a total of $26,250 \mathrm{MW}$.

Of use to the SPS study: The report thoroughly addresses the problems of developing a large, centralized power generating facility. It also provides a framework for looking at the changes needed in regulation at the regional and federal level in order to respond to a proposal of generating capacity of this magnitude.

Availability: U.S. Government Printing Office Stock No. 038-000-0023-9 (in two volumes); UCLA Library call number: TK, 1191 , G286a, 1975.

66. National Academy of Publ ic Administration, The Institutional Aspects of the Energy Centers Concept, Washington, D.C., March 1977.

\section{Description:}

The study consists of papers written by a number of consultants engaged to investigate the institutional problems associated with the implementation of the energy center concept. A panel of these consultants (some of whom had participated in an earlier study of energy centers for General Electric, see above) was formed and given the mandate to examine the experience in two states where the energy center concept had been actively considered. The states of Pennsylvania and Washington were selected by the panel for this analysis. The panel met for four, two-day meetings over the course of the twelve month period of the study.

The papers included in this report are:

"Nuclear Energy Centers: Equity Considerations Relating to Taxation and Revenue Distribution", Terry A. Ferrar, Ph.D., Frank Clemente, Ph.D., and Alan B. Brownstein, M.A.

"Report on the Jurisdictional Authorities of State and Local Government Related to Centralized and Decentralized Alternative Energy Systems" Prepared by the Environmental Policy Institute as part of its Powerplant Siting Project, Marc Messing, Matthew O'Meara and Richard M. Hall.

"Federal-State Conflict and Cooperation in the Siting of Nuclear Energy Facilities", Orval Hansen.

"The Energy Park Experience In Pennsylvania", Dr. Frank Clemente and Dr. Terry A. Ferrar.

Of use to the SPS study: The jurisdictional conflict issues were clearly applicable to the SPS rectenna facility if built by an interstate group.

Availability: Contact the National Academy of Public Administration (202) 659-9165. 
77. Rossi, Lyna Wiggins, and Dan Wormhoudt, Trends in the Siting of Conventional Coal-Fired Power Plants, October 1977 Progress Report of the Land Use Component, Institute of Urban and Regional Development.

79. Schroeder, Chris, and John Wiley, Earl Warren Legal Institute, University of California, State Facility Siting Legislation and Its Impact on the Siting of Coal-Fired Power Plants, Lawrence Berkeley Laboratory and the University of California, Berkeley, October 1977.

\section{Description:}

These two reports represent initial draft output from the Berkeley Energy Facility Siting (BEFS) Study. This study is being funded by the Division of Policy Analysis in the Office of Technology Impacts of the Assistant Secretary for Environment, United States Department of Energy. The investigators are: Christopher H. Schroeder, Daniel T. Wormhoudt, Robert $A$. Enholm, Lyna Wiggins and John Wiley. The current institutional affiliations for those members of this team who provided input to this report can be found in the preceding section: Personal Communication.

The "Trends in the Siting of Conventional Coal-Fired Power Plants" draft report is the land use portion of the BEFS Study. It is the documentation of existing and prevailing siting patterns for coal-fired power plants only. It reviews the actual physical facilities and locations of over 400 plants. It outlines the existing land use planning methodologies employed by utilities, states and other governmental units as aids in decisionmaking. Trends in lead time between planning, construction and operations were also studied.

Of use to the SPS study: Conclusions as to centralization and other locational aspects of current trends.

The "State Facility Siting Legislation and Its Impact on the Siting of Coal-Fired Power Plants" study attempts to assess the success of recent efforts to improve the energy facility siting process. It focuses on the processes employed by the states to plan and approve the location and construction of coal-fired power plants. The emphas is on coal, however, is not evident in the report because many of the administrative issues raised in the context of coal also apply to other, large-scale technologies as well.

Of use to the SPS study: This effort took data from other sources (notably References 47,64,66,81 and 89) and categorized the siting legislation, analyzed the issues, evaluated the success of various methods of legislating siting, indicated apparent shortcomings in the various states' systems, and presented the results in a clear, organized manner. It also provided a review and evaluation of current literature on the subject.

Availability: The DOE contact for these studies is Susan Wellborn (202) $376-4449$. 
81. Southern Interstate Nuclear Board, Power Plant Siting in the United States, June 1976.

Description:

This report is the fifth update of a review of siting legislation. The review was begun in 1972 by the Southern Interstate Nuclear Board (SINB). It summarizes the existing body of state power plant siting legislation for all fifty states. Included is a copy of the existing law, or any pertinent pending law, governing energy facility siting and an analysis of that legislation. A section of the report is devoted to the activities at the federal level, including pending legislation which could affect the states.

Of use to the SPS study: Descriptions of legislation and the actual process in Florida and Connecticut.

Availability: For sale from the Southern Interstate Nuclear Board (404) 455-8841.

34. University of California, Los Angeles, Environmental Science and Engineering Program, Power Plant Siting Assessment Methodology: A Case Study Utilizing Coal Gasification Combined Cycle Along the Southern Coast of California, November 1977.

\section{Description:}

This study was performed under contract from the Electric Power Institute (EPRI) by a team of graduate students and faculty from the Environmental Science and Engineering Program at the University of California, Los Angeles. The central focus is in the application of the Power Plant Siting Assessment System (PPSAS) to the siting of a hypothetical combined cycle coal gasification energy facility.

The intent of the study was to identify limiting factors before preparation of the environmental impact report. The second objective was to demonstrate an application of the PPSAS using, as a test case, a location at ormond Beach, California. Practical experience in power plant siting was incorporated in the report from two sources: one of the team of researchers worked for the Department of Water and Power in its application for approval of the San Joaquin Nuclear Power Plant; secondly, much of the environmental data used in the application of PPSAS was obtained from the Final Environmental Impact Statement on the Liquefied Natural Gas Facilities' application at Ormond Beach, near Oxnard, California.

Of use in the SPS study: A step-by-step enumeration of the process of obtaining permits, reviews, etc. within the state of California. The information provided included names of agencies, legal mandates, authority 
APPENDIX A

vested in various agencies, time limitations and to the degree possible, threshholds of acceptability. The bibliographic information was also very useful.

Availability: For sale at the Office of the Environmental Science and Engineering Program, UCLA, (213) 825-3178.

89. The Western Interstate Nuclear Board, Regional Factors in Planning and Siting Electrical Energy Facilities in the Western United States, Lakewood, Colorado, Apri1 5, 1977.

\section{Description:}

This report was performed by the Western Interstate Nuclear Board (WINB, now called Western Interstate Energy Board, or WIEB). for the Office of Standards Development of the Nuclear Regulatory Commission (NRC). The study was directed at identifying some of the existing and emerging issues, problems and conflicts arising in the planning and siting of electrical energy facilities in the WIEB region (Arizona, California, Colorado, Idaho, Montana, Nevada, New Mexico, Oregon, Utah, Washington and Wyoming.)

The second objective was to prepare recommendations and alternative courses of action by state, federal and regional agencies for streamlining the regulatory and decision-making processes involved in the siting of nuclear and other electric eneray facilities.

Of use to the SPS study: Excellent description of the siting process in Colorado (which does not have siting legislation); valuable insights as to regional issues.

Availability: For sale by the Western Interstate Energy Board (303) 837-5851. 
Nine types of state and local regulation are identified as involving a universal processing requirement for the SPS. Of these nine, seven lend themselves to meaningful description at the state level.

The major elements of each of these types of regulation are surmarized in a standard format which covers the four states selected for detailed analysis: California, Colorado, Connecticut and Florida. The seven summaries included in this Appendix are:

1. Generating Facilities (Construction Approva1)

2. Energy Policies (Need for Facilities)

3. Electric Utility Regulation (Rate Case Approval)

4. Land Use and Zoning (All Levels)

5. Protection of Natural Aereal Resources (Coasta) Commission)

6. Air Quality

7. Water Quality

Page $B-2$

Page $B-3$

Page $B-4$

Page B-5

Page $B-6$

Page $B-7$

Page $B-8$ 

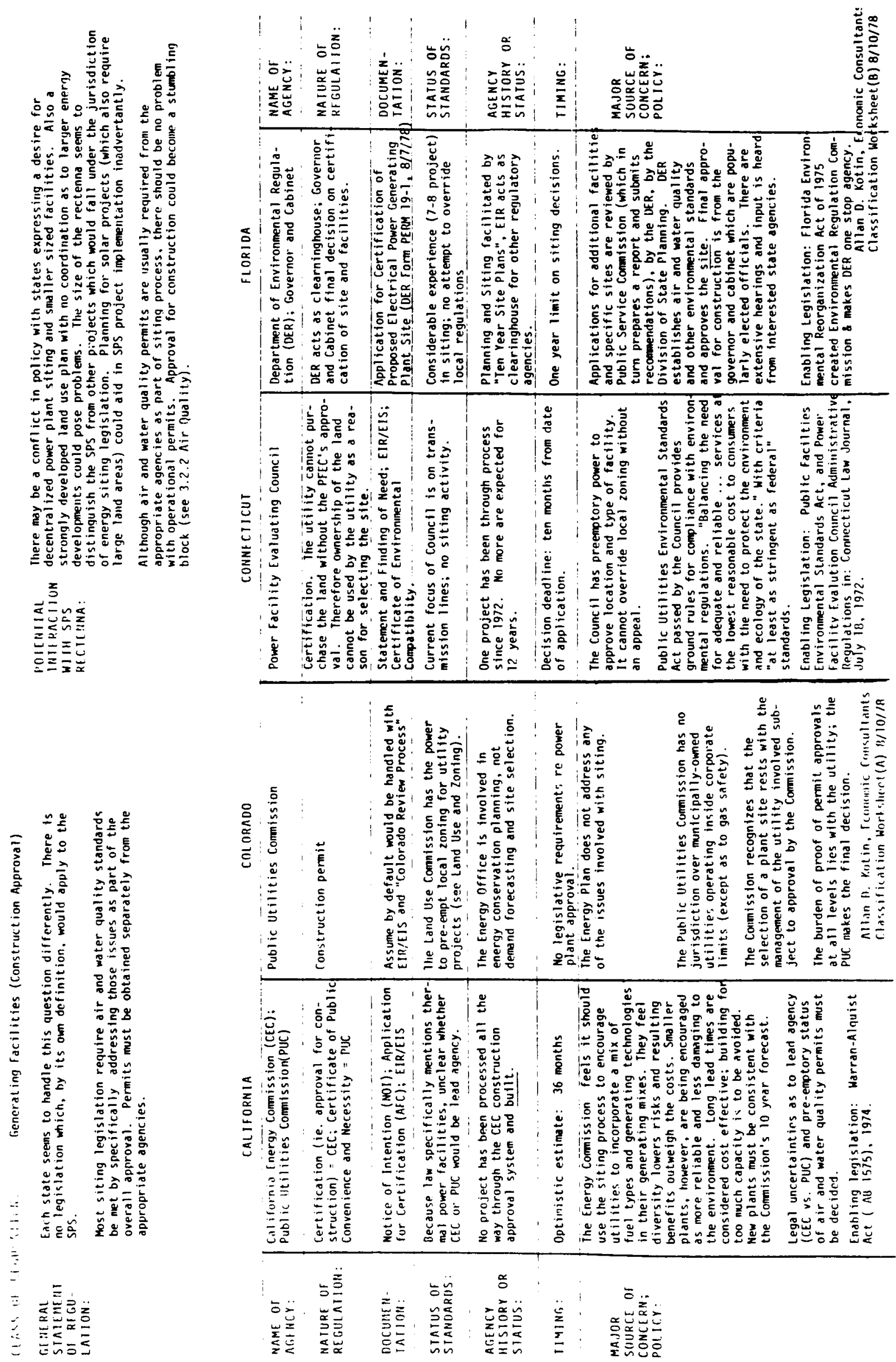


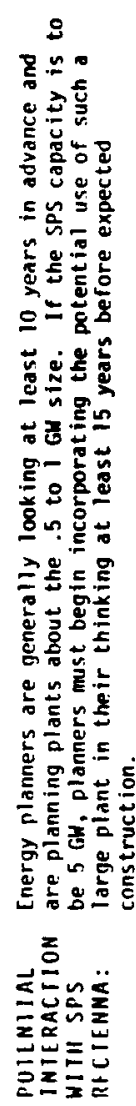

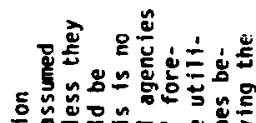

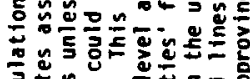

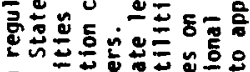
5 势

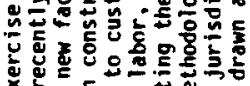

言

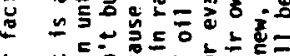

s.

蛋

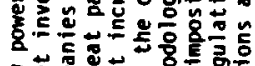

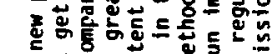
- 5 s. เอ

管

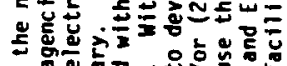

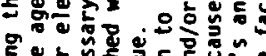

$\because \frac{1}{3}$

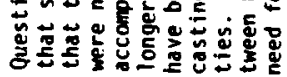

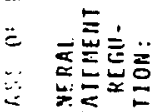

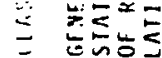

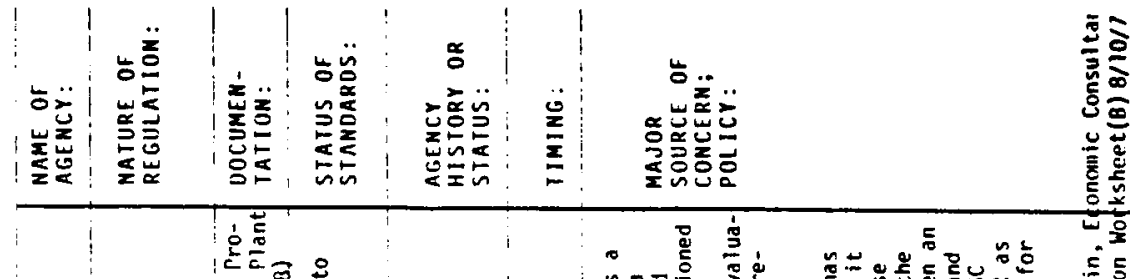

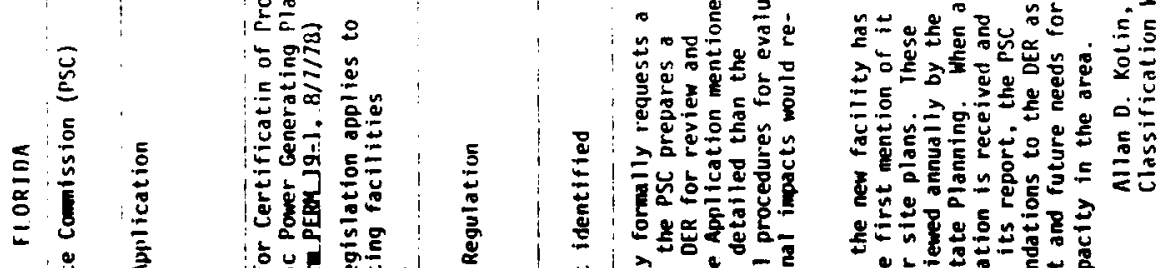

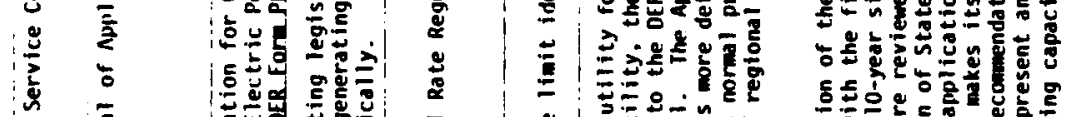

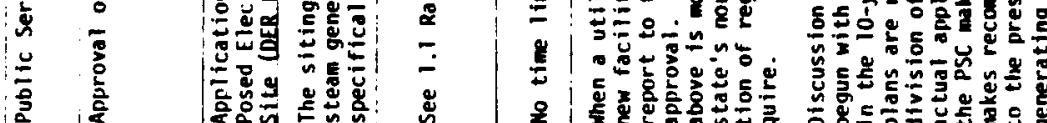

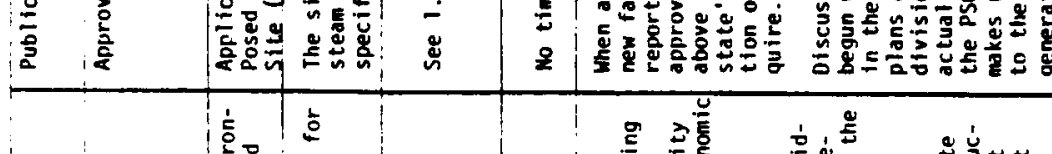
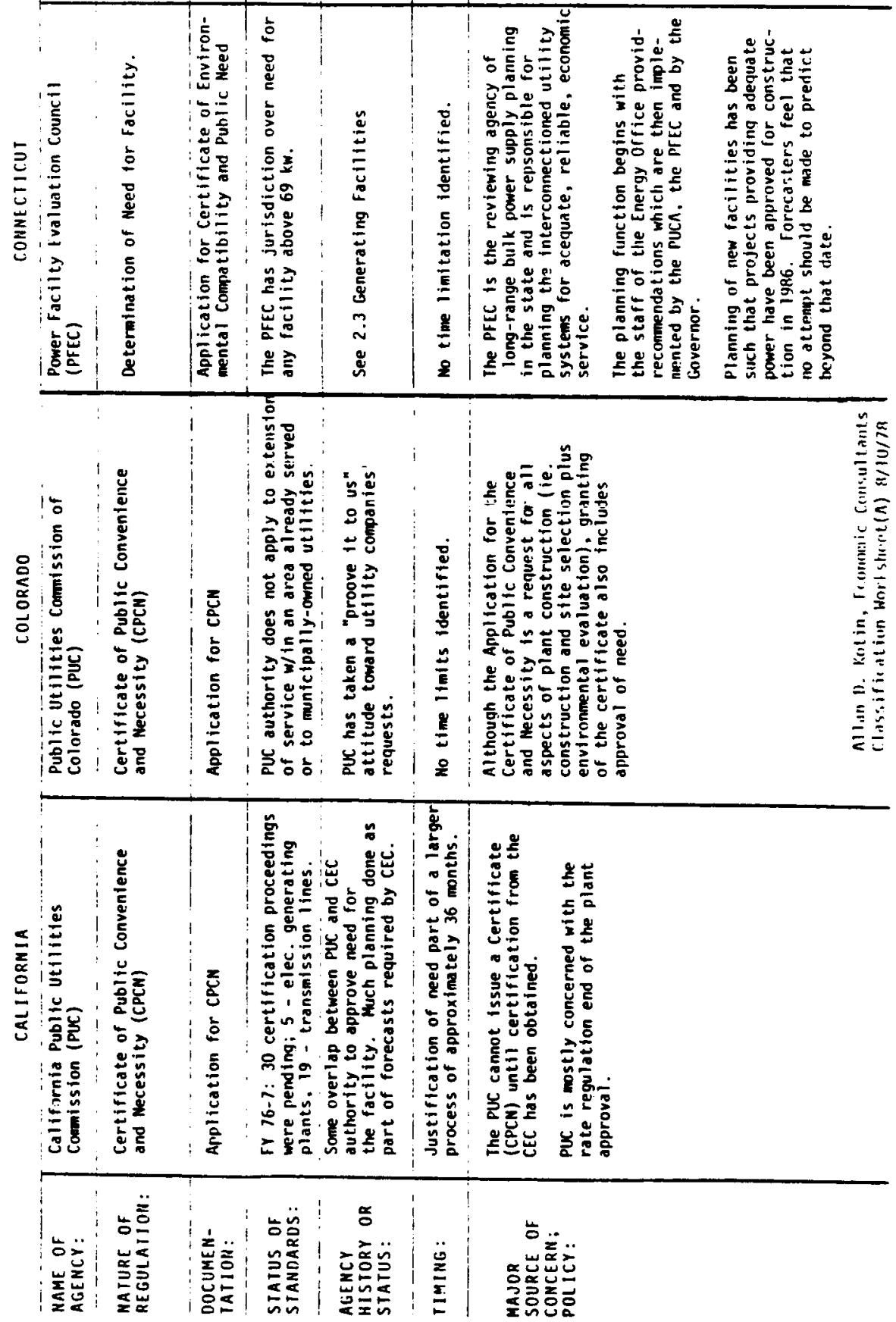

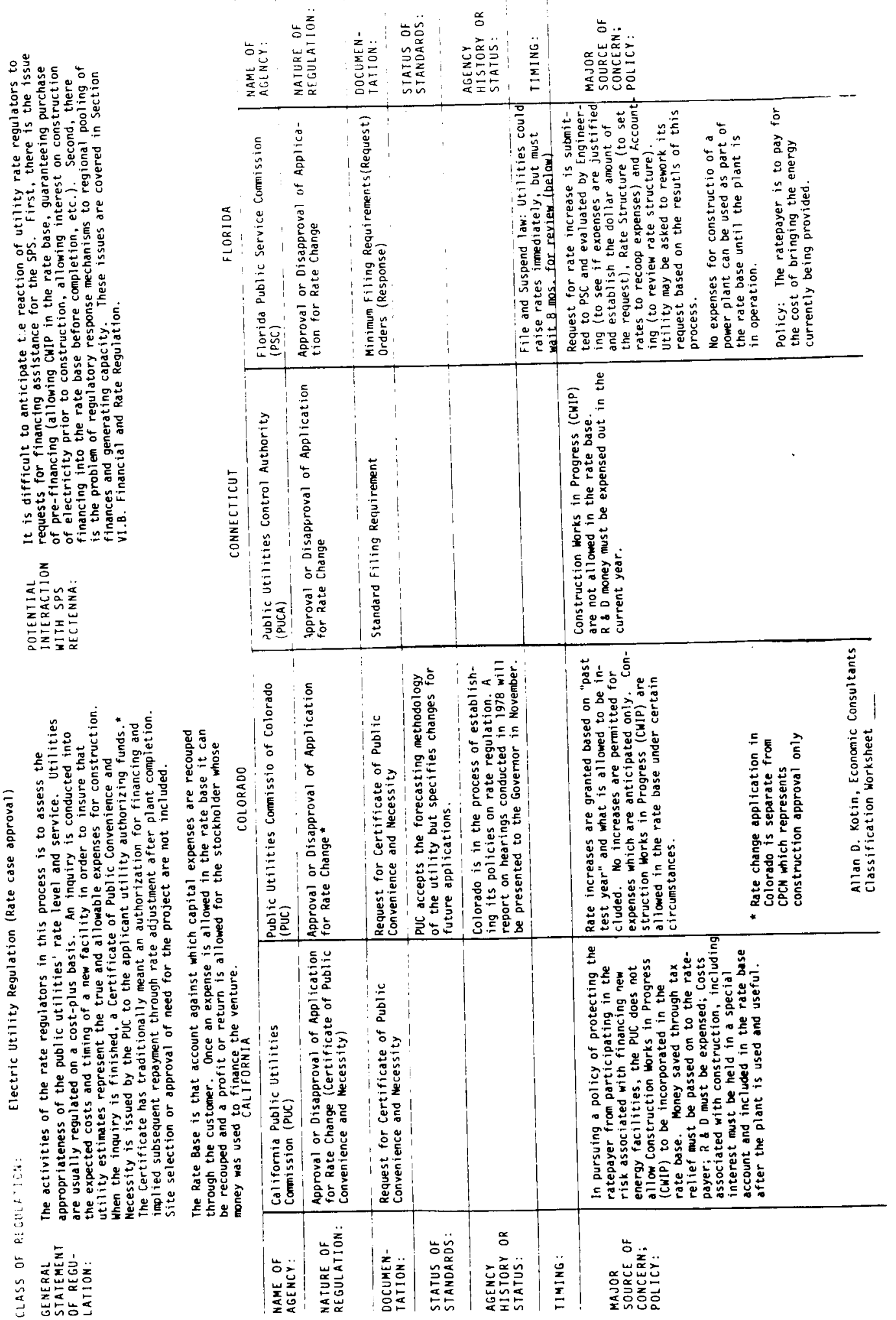

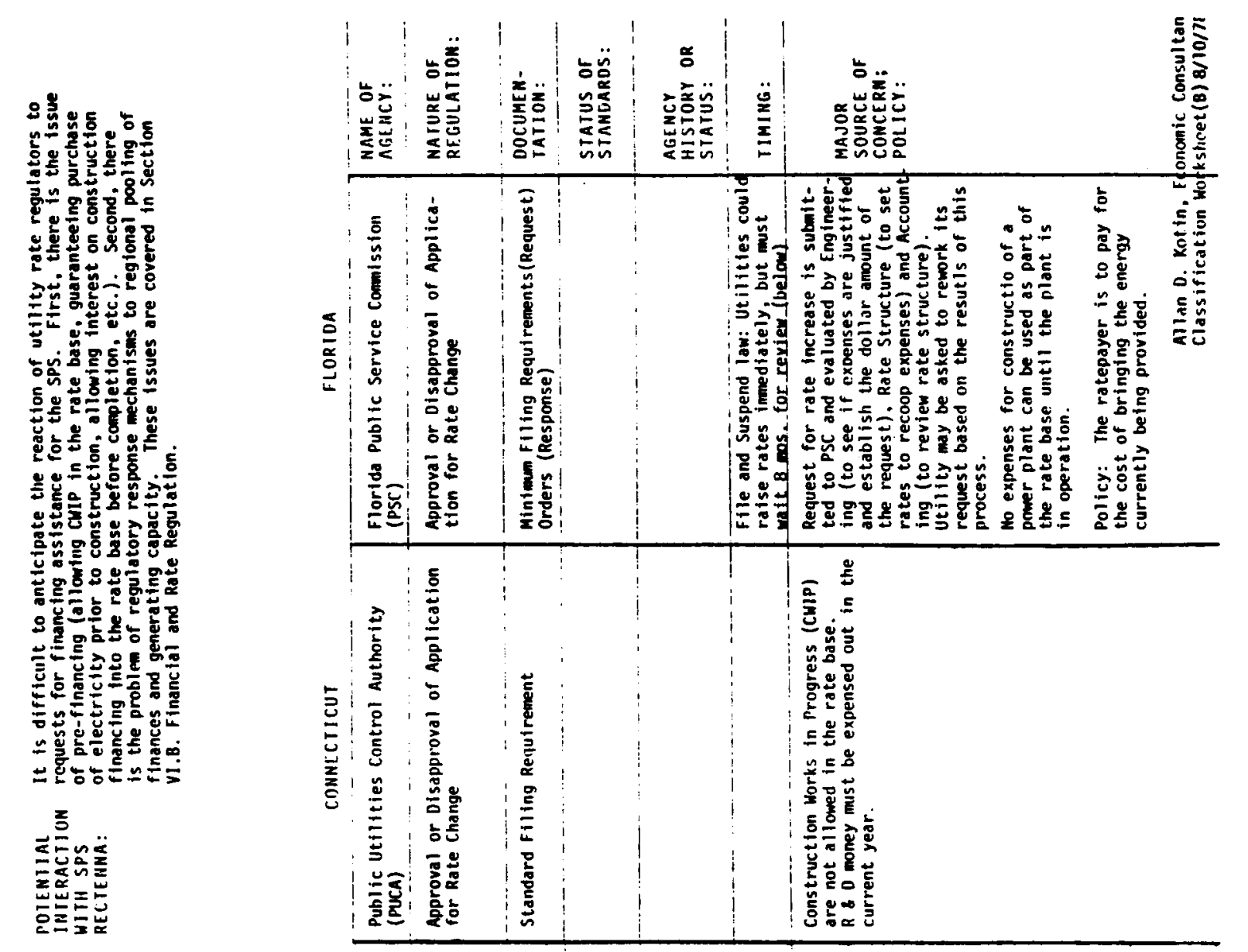

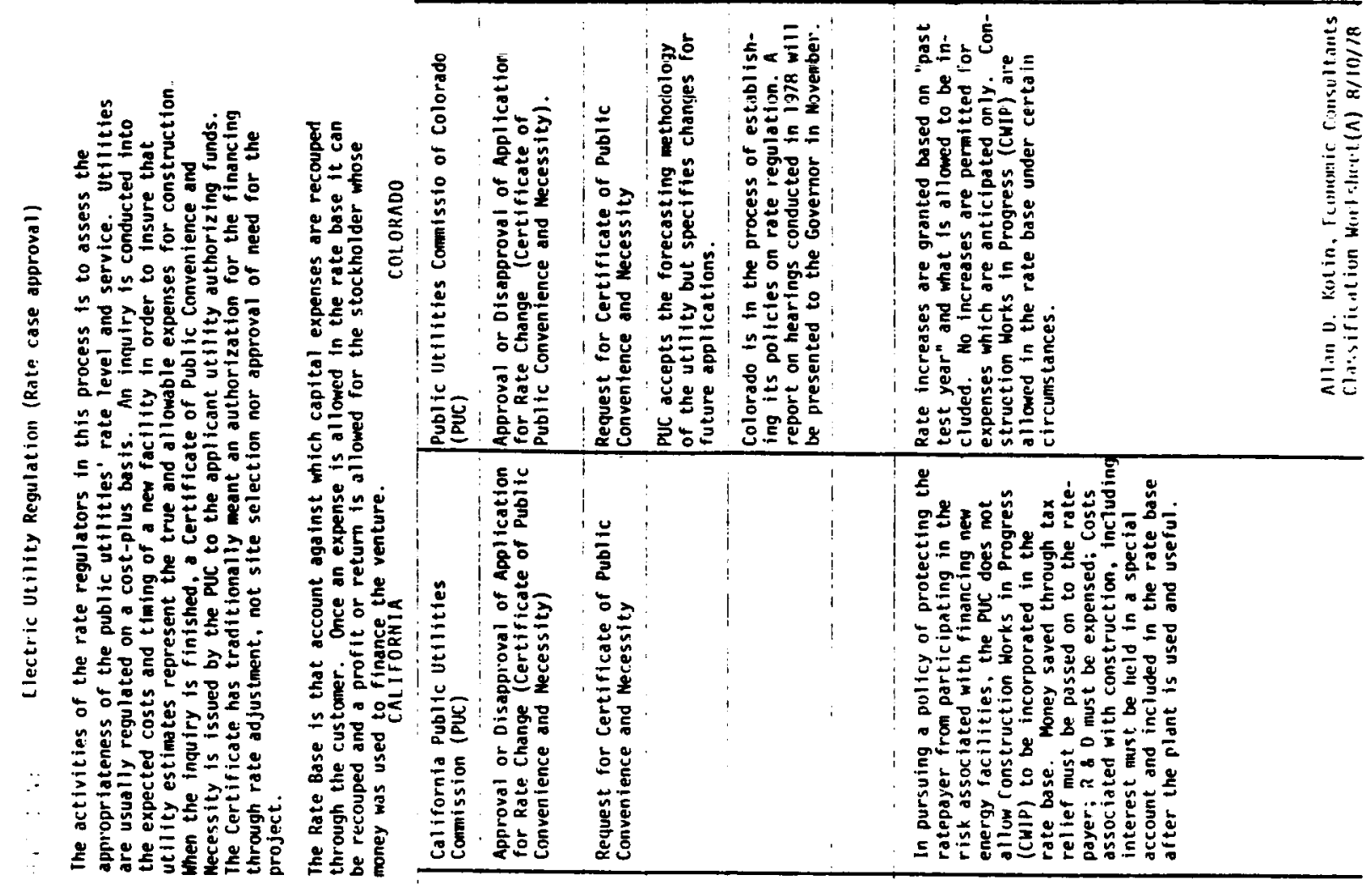

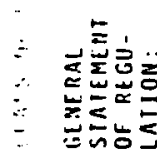

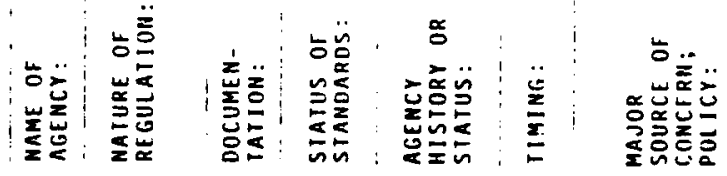




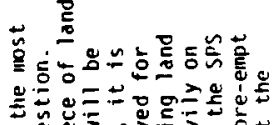

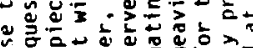

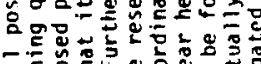

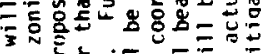

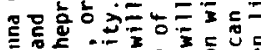

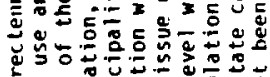

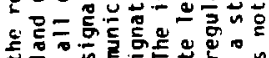

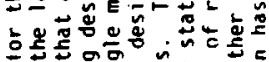

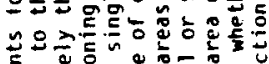

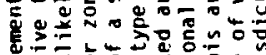

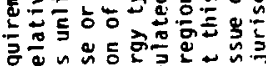

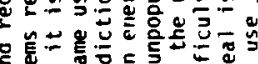

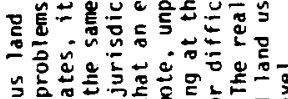

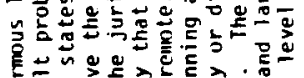

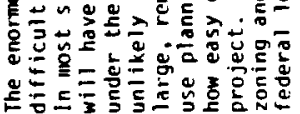

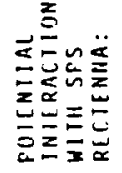

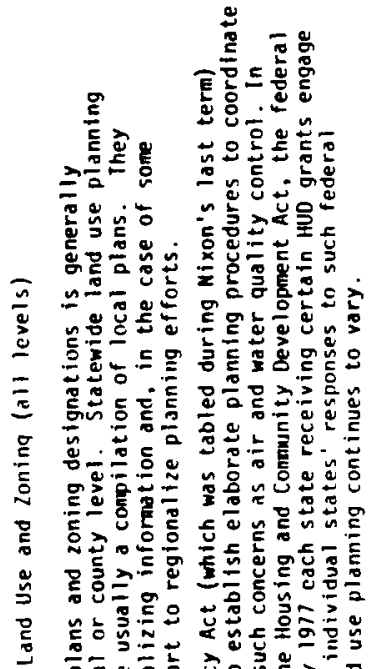
วัต

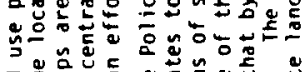

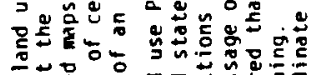

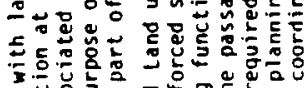

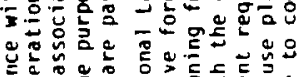

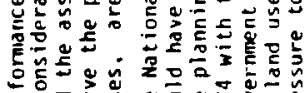

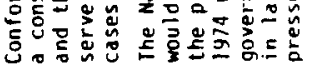

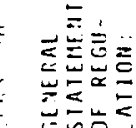

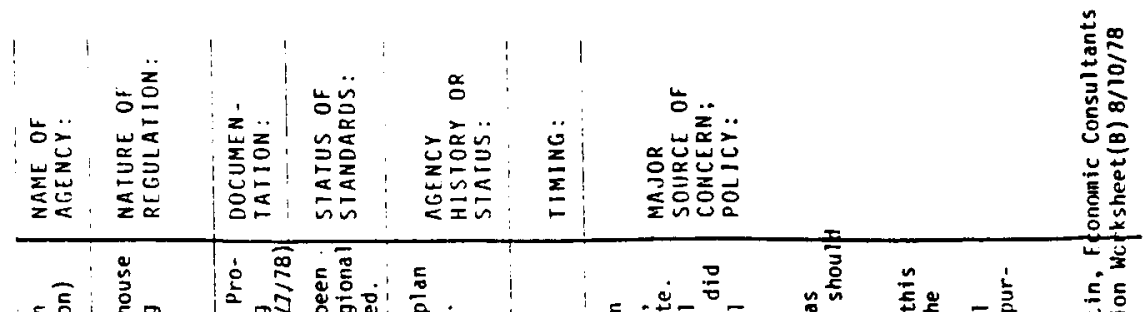

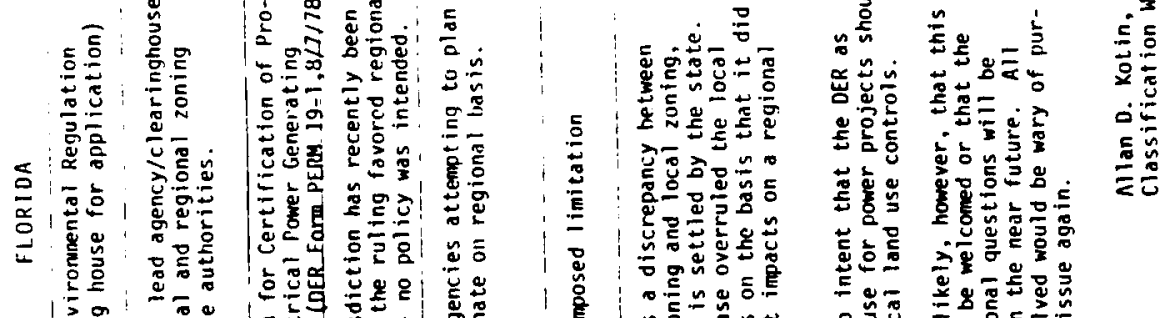

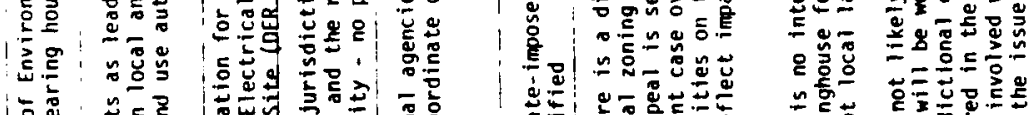

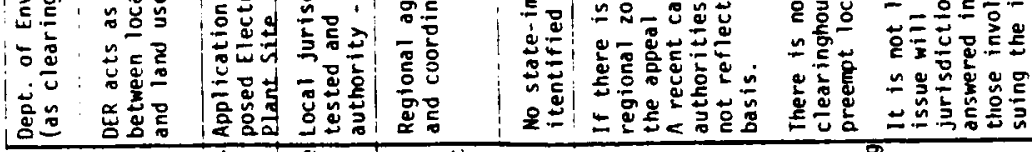

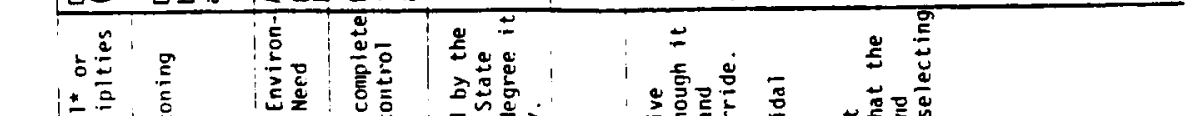

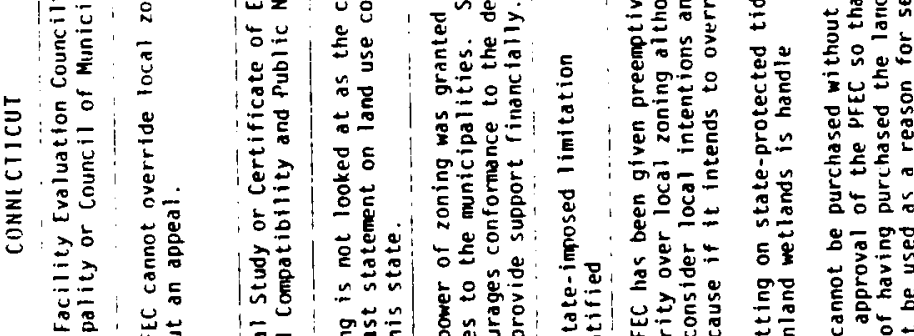

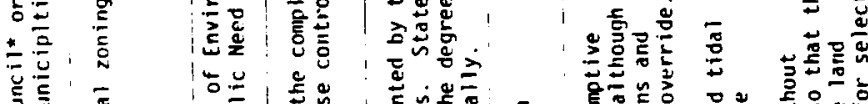

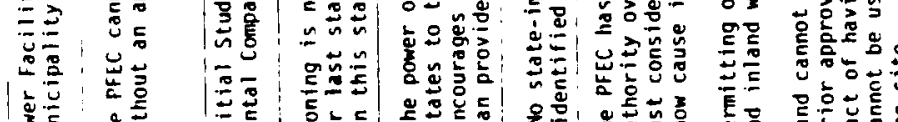

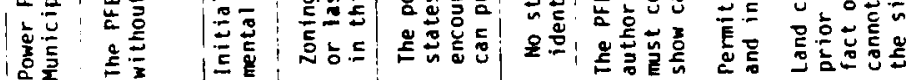

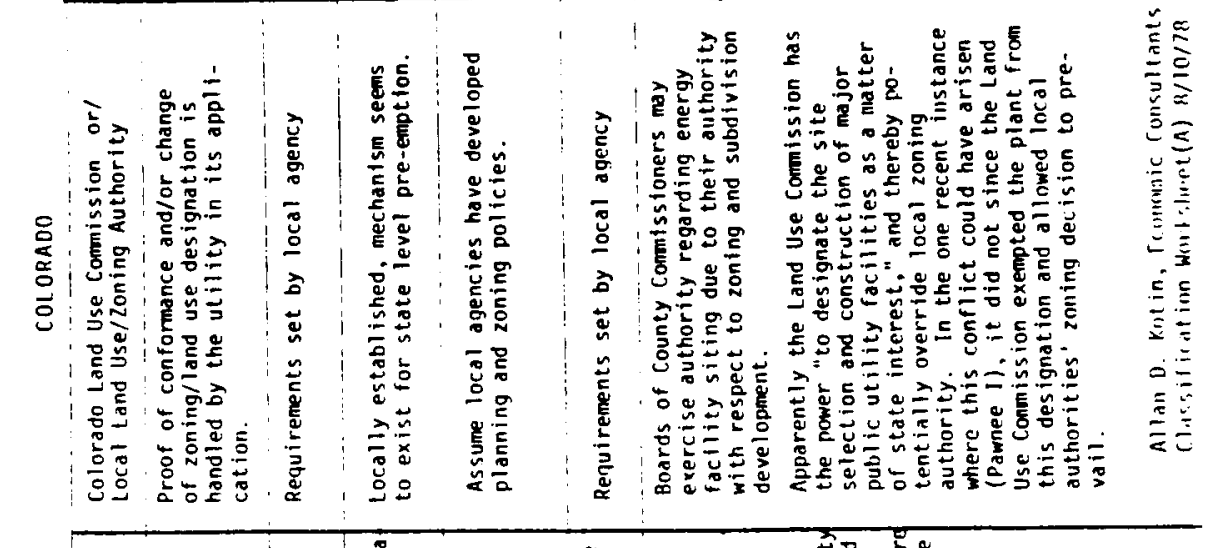

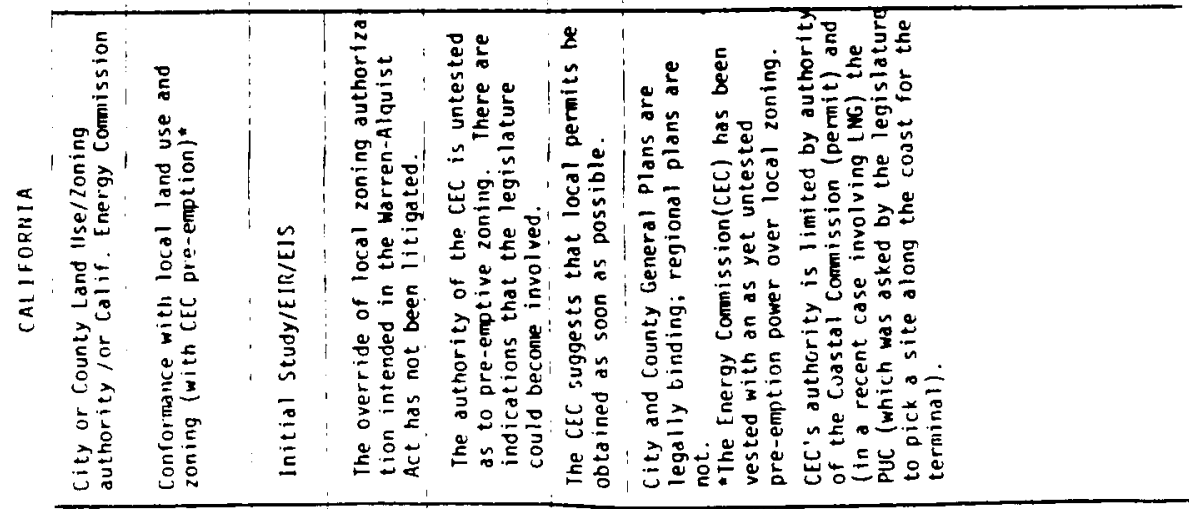

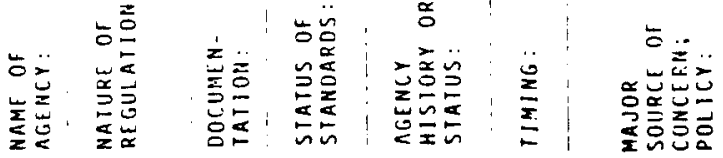




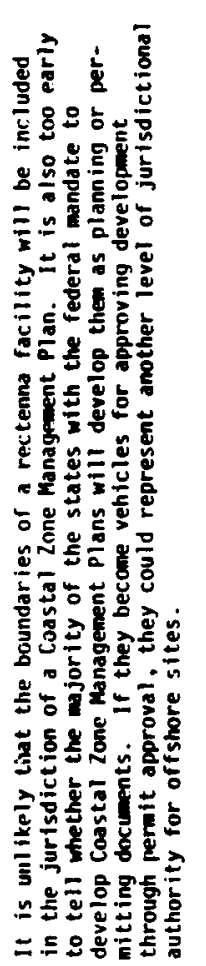

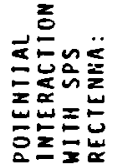

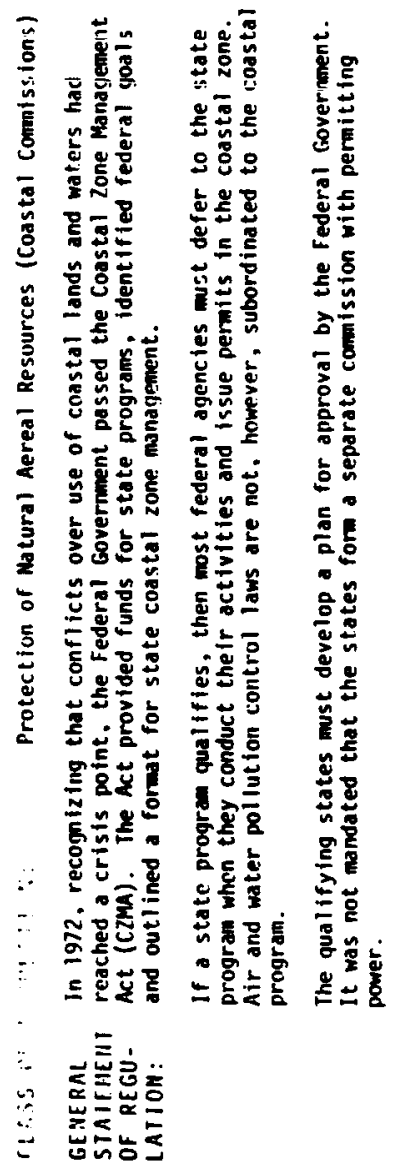

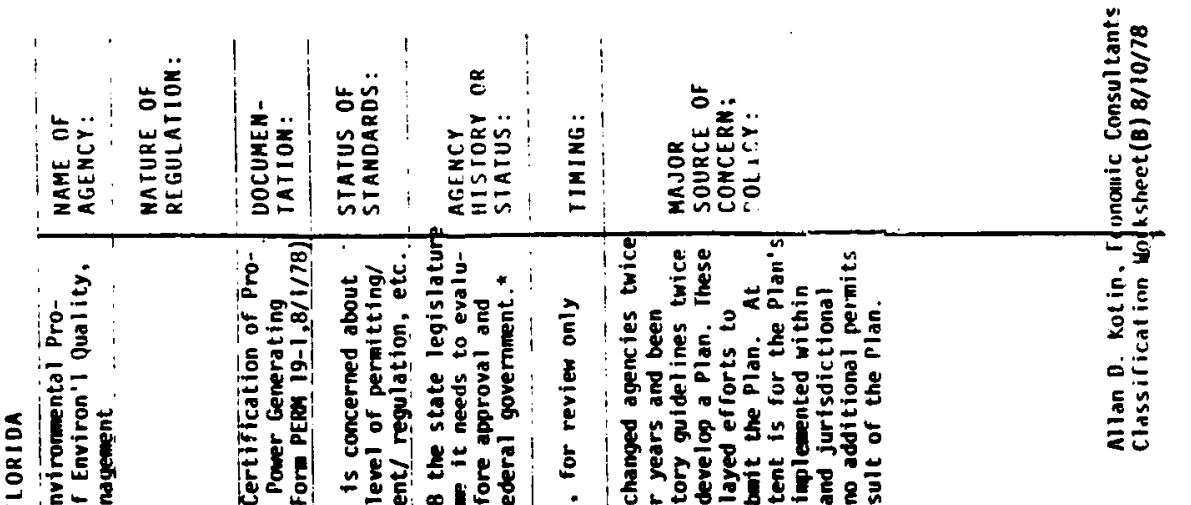

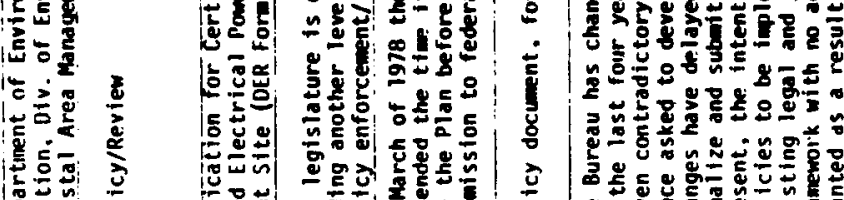

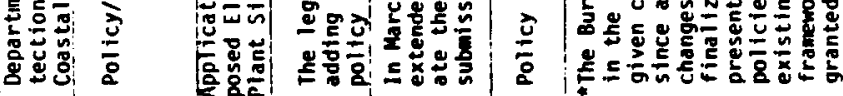

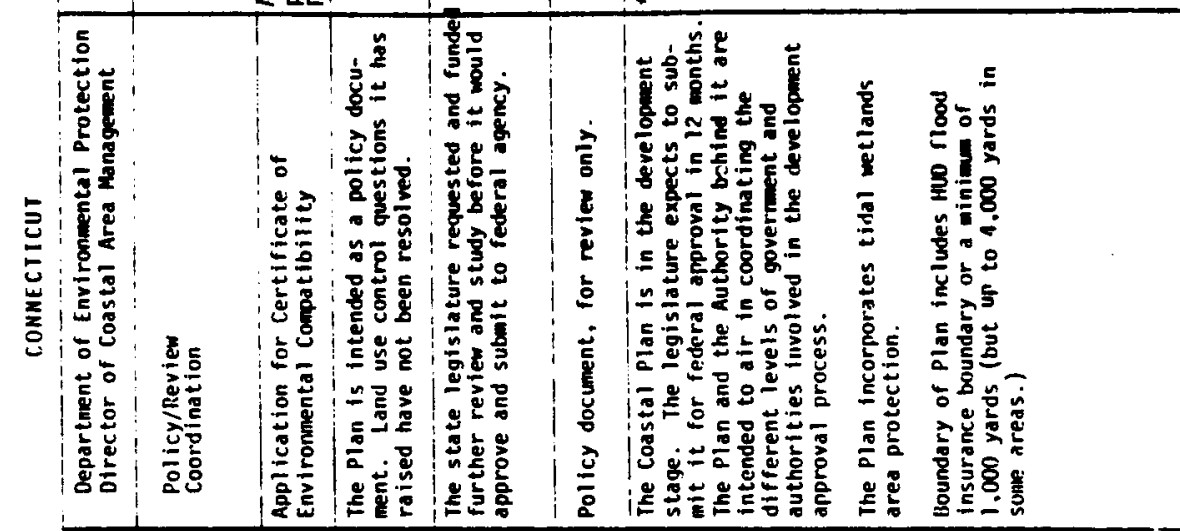

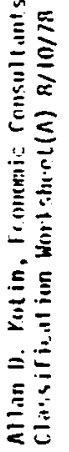

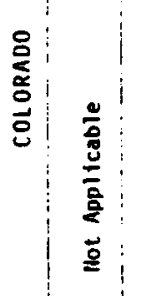



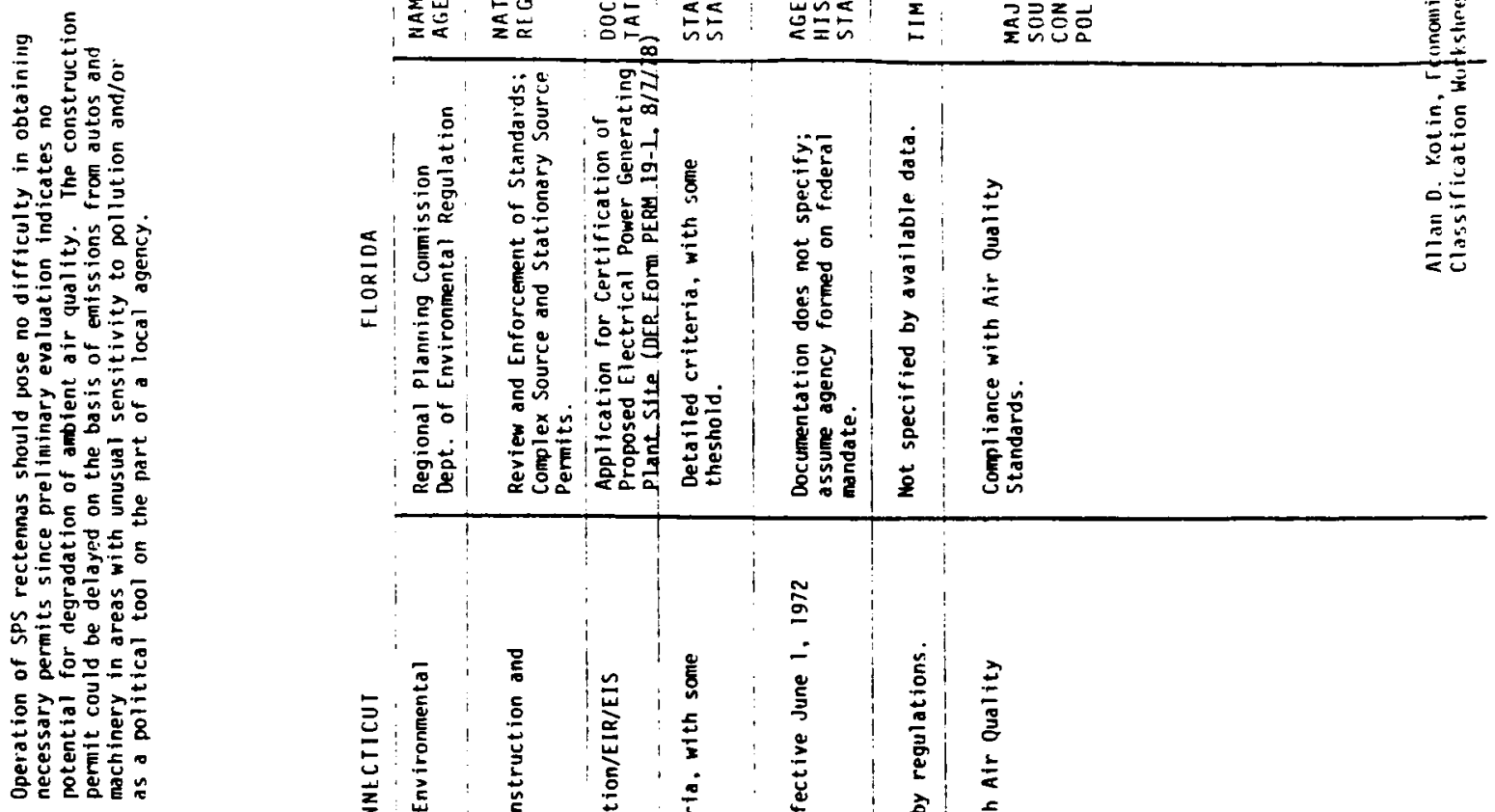

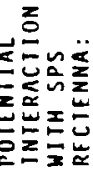
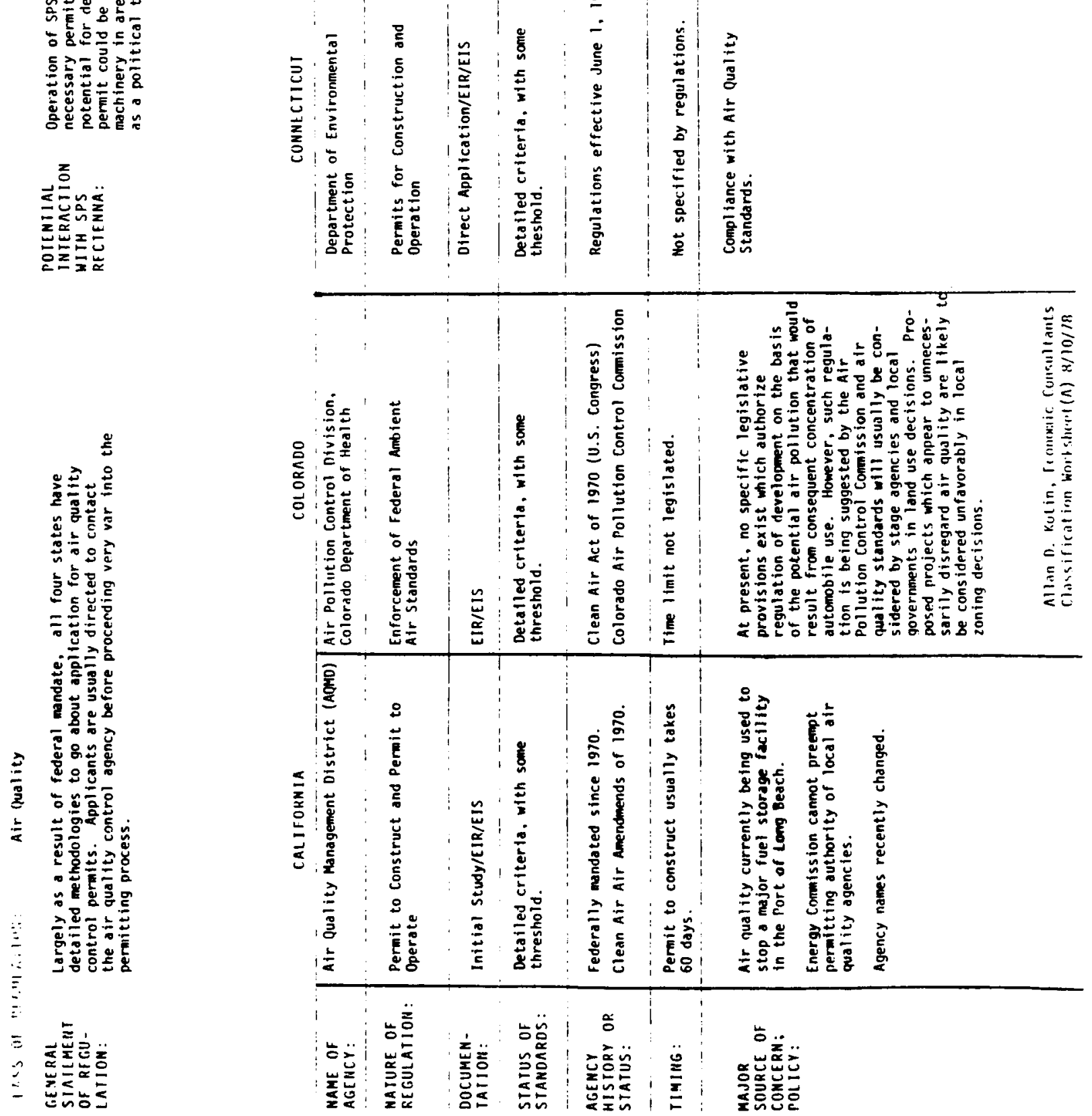


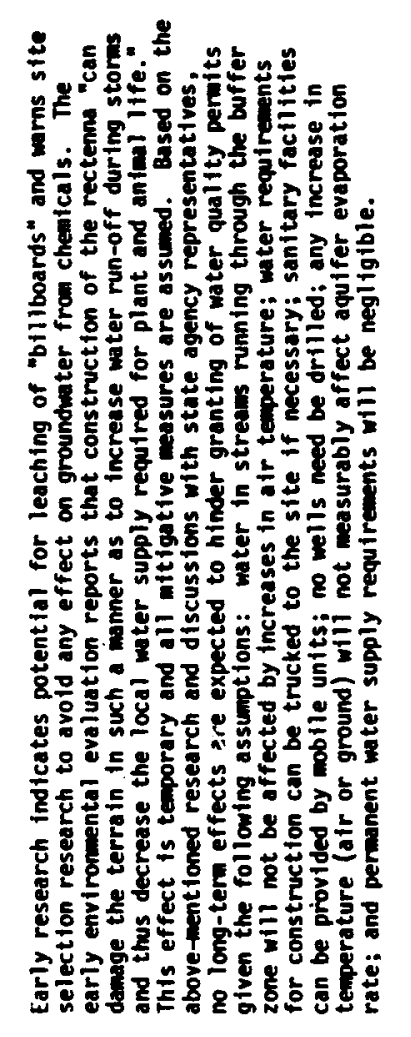

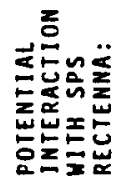

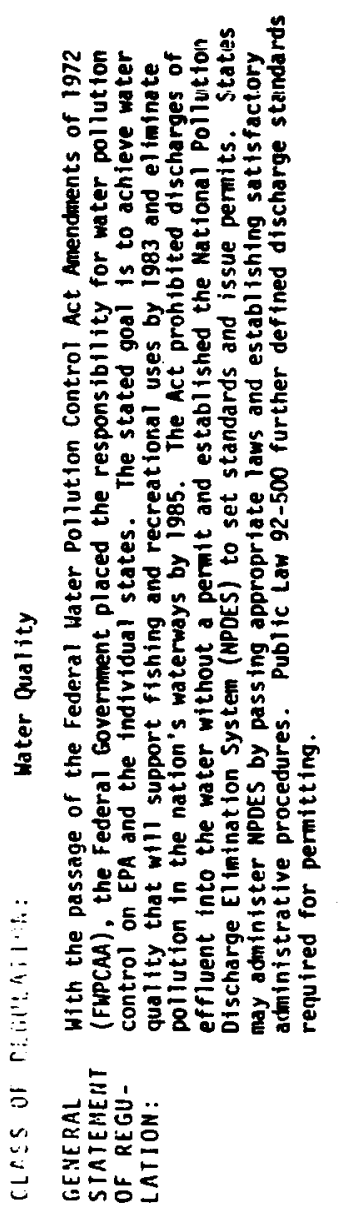

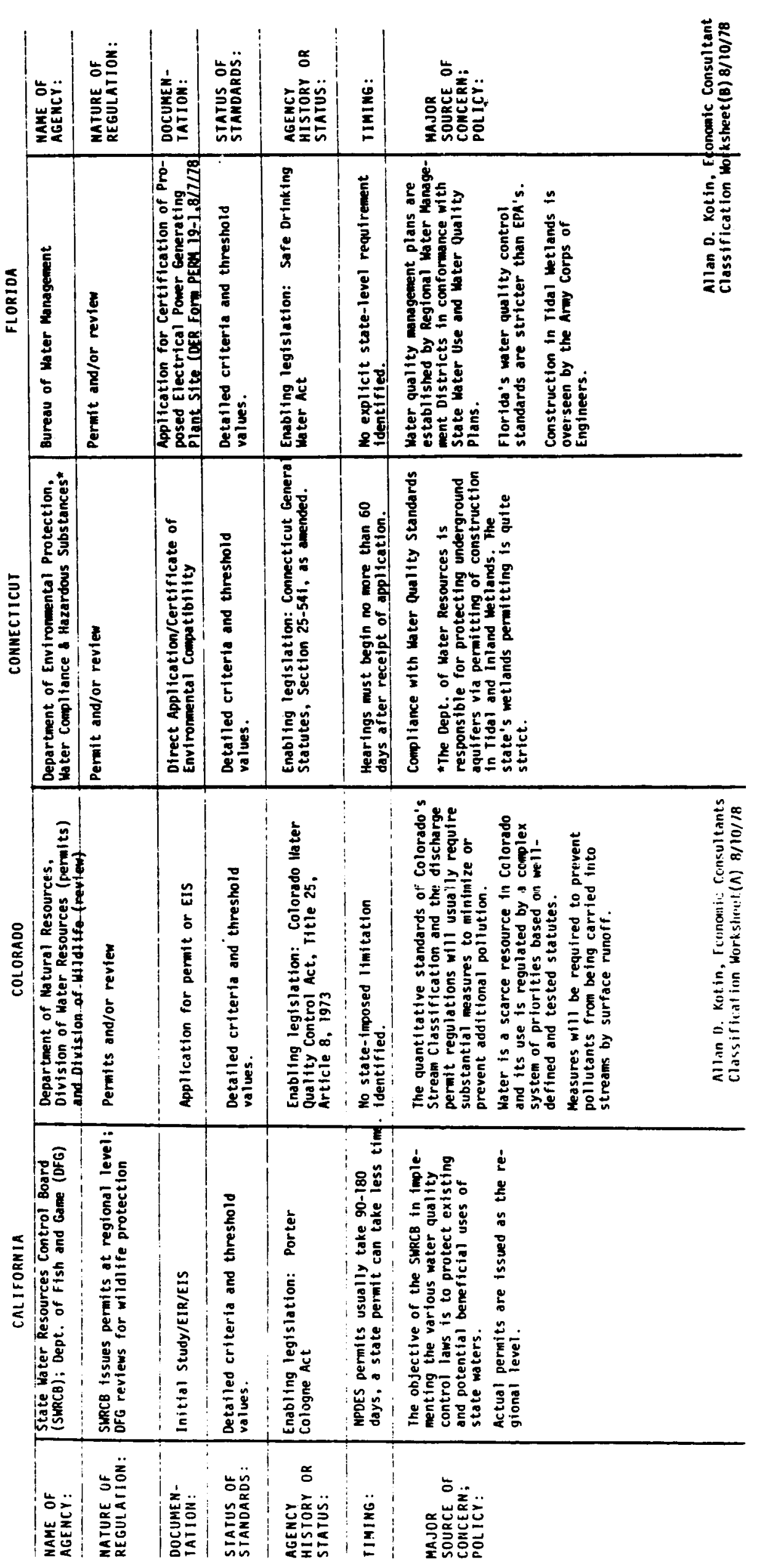


S1. Boeing Aerospace Company, Solar Power Satellite, System Definition Study, Parts I and II, Vols. II-VI, December 1977, $\left(\overline{I-256)^{\star}}\right.$.

S2. Boeing Aerospace Company and NASA/JSC, SPS Concept Evaluation Program, January 25, 1978, (I-28.3).

S3. Boeing/G.E., SPS System Definition Study (Part III); Preferred Concept Definition, March 1978, (1-28).

S4. SPS System Definition Study (Part III); Final Briefing, March 7, 1978, (I-28.3).

S5. Clark, Wilson, Energy for Survival, The Alternative to Extinction, Anchor Books, Garden City, New York, 1974.

S6. DOE/ET, SPS Concept Development and Evaluation Program Plan (July 1977August 1980), DOE/ET-0034, February 1978.

S7. DOE/NASA, SPS Concept Evaluation Program Plan (July 1977-August 1980), MSFC-76-PA-4000-491, January 1978.

S8. FASST News, "The Issues Behind Solar Power Satellites," Vol. 7, Nos. 1 \& 2 , Winter-Spring 1978.

S9. Giaser, Peter, Arthur D. Little Inc., personal communications, July 1978.

510. International Technica! Services. Inc., An Overview of Prospective urganizational Structures in the Solar Power Satellite Field, Draft reports for Task I, Subtask 3, and Task II, Subtask 3, (prepared for Argonne National Laboratory, Argonne, I1linois, Contract No. 31-109-38-4387), Arlington, Virginia, June 30 and July $3,1978$.

S11. Jet Propulsion Laboratory, Satellite Power System. (SPS) Microwave Subsystem Impacts and Benefits, (prepared by Richard M. Dickinson, Radio Frequency and Microwave Subsystems Section, Telecommunications Science and Engineering Division), California Institute of Technology, Pasadena, California, September 28, 1977.

S12. Library of Congress, Congressional Research Service, Solar Energy From Space: Satellite Power Stations, (prepared by Marcia S. Smith, Science Policy Research Division), Issue Brief Number IB78012, Update 06/23/78, Originated $02 / 14 / 78$.

S13. NASA/JPL, Satellite Power System Environmental Impacts -- Preliminary Assessment, (prepared by Floyd R. Livingston), May 12, 1978, (I-24).

* Reference codes used in PRC/ANL bibliography distributed June 1978. 
S14. NASA/MSFC, Preliminary Basel ine SPS Concept Recommendations to DOE/NASA, January 24, 1978, (I-43).

S15. NASA, MSFC-JSC, Solar Power Satellite Baseline Review (Preliminary), July 13, 1978.

S16. Planning Research Corporation, Charles E. Bloomquist, A Survey of Satellite Power Stations, DSE/2071-1, September 1976, (I-161).

S17. PRC Energy Analysis Company, Interim Environmental Guidelines for Satellite Power System (SPS) Concept Development and Evaluation - Iteration 2, (prepared for the Department of Energy, Office of Energy Research, Associate Director for Research Policy, SPS Project Office), June 1978, (I-4I).

S18. Rockwell International, Satellite Power Systems (SPS) Concept Definition Study, SPS System Requirements, Final Report, Vols. II-VII, April 1978.

S19. Smith, Marcia S., Research Analyst, Library of Congress, Congressional Research Service, personal communications, July 1978.

S20. U.S. House of Representatives, Solar Satellite Power System Concepts, Hearings before the Subcommittee on Space Science and Application and the Subcommittee on Energy Research, Development and Demonstration of the Committee on Science and Technology, 94th Congress, Second Session No. 67, February 20, 1976.

S21. Universities Space Research Association, Report of the Solar-Power Satellite Task Group, (Houston, Texas), March 1978. 